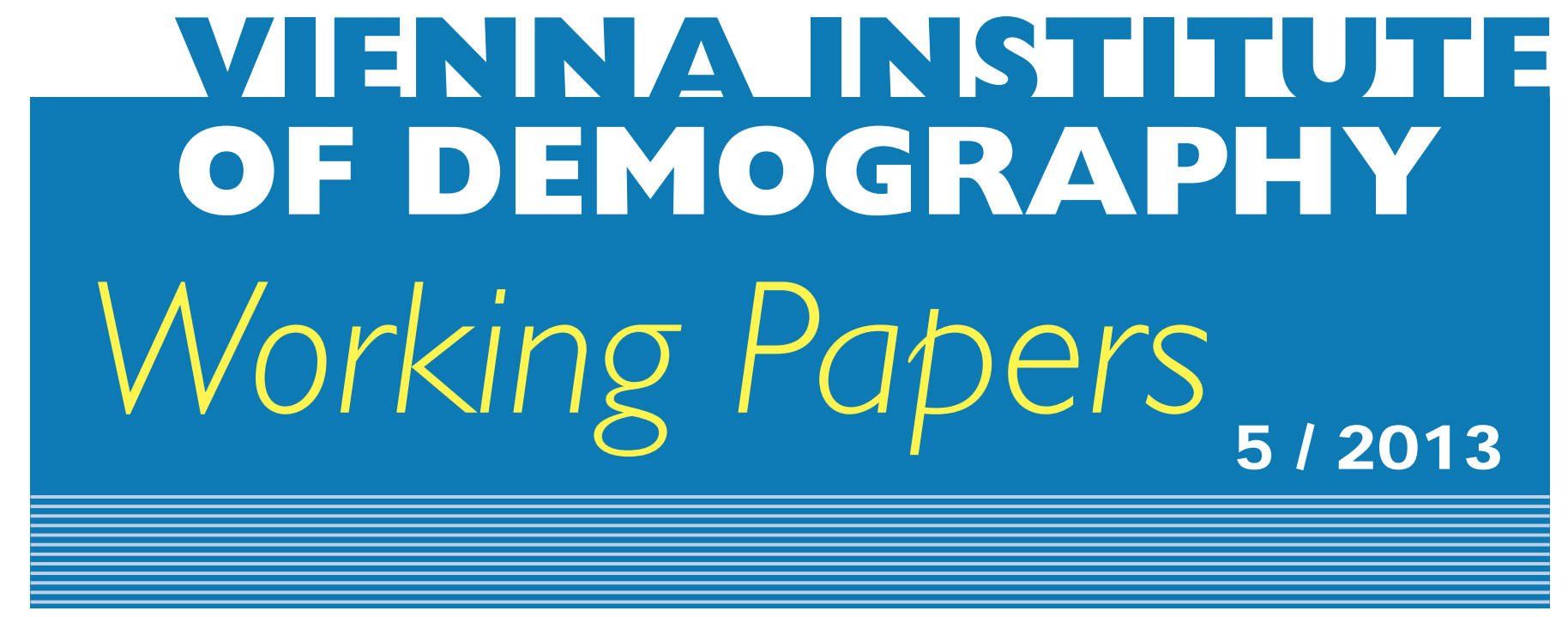

Stuart Basten, Tomáš Sobotka and Kryštof Zeman

Contributing Authors: M. Jalal Abbasi-Shavazi, Alicia Adsera, Jan Van Bavel, Caroline Berghammer, Minja Kim Choe, Tomas Frejka, Henri Leridon, M elinda M ills, S. Philip M organ, Ronald R. Rindfuss, Louis Rosero-Bixby, Anna Rotkirch, W arren Sanderson, Maria Rita Testa, Olivier Thévenon, Zhongwei Zhao

\title{
Future Fertility in Low Fertility Countries
}

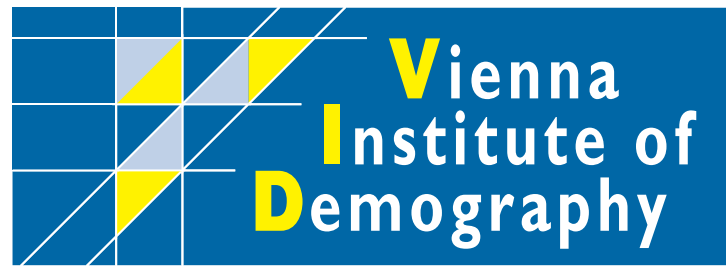

Vienna Institute of Demography Austrian Academy of Sciences

Wohllebengasse 12-14

A-I040Vienna $\cdot$ Austria

E-Mail:vid@oeaw.ac.at

Website: www.oeaw.ac.at/vid 


\begin{abstract}
This paper discusses results of the global survey of experts on the future of low fertility in low-fertility countries. The survey was coordinated by the Wittgenstein Centre for Demography and Global Human Capital as a part of an effort to produce global argumentbased population projections by age, sex and level of education. First we give an overview of fertility changes in major low-fertility regions. Next we outline main theoretical arguments and review a wide range of factors contributing to fertility change and variation in contemporary low-fertility settings. Subsequently, we present survey results based on 184 assessments of over 170 experts analysing 41 countries with currently low or aroundreplacement fertility and Israel. These experts provided forecasts of period total fertility rate (TFR) in 2030 and 2050, estimated $80 \%$ confidence interval of their forecast and assessed the validity and potential impact on fertility of 46 factors. We also compare expert-derived projections of the TFR trends with the forecasts formulated by the UN World Population Prospects in 2010. The survey results in combination with the feedback provided by the invited experts then serve as a basis for formulating a set of projection scenarios for all low fertility countries up until 2050, which are additionally expanded (in a simpler form) through 2200 . We present these scenarios and discuss past changes in fertility differences by level of education and their potential future trends in main regions. Presented analyses and projections indicate that a global convergence of fertility to around replacement level, envisioned in the UN projections, appears unlikely. Continuing differentiation combined with partial convergence in fertility towards lower levels is suggested as a more plausible scenario, with East Asia (including China) as well as Russia expected to have sustained very low fertility below 1.5 through 2050 .
\end{abstract}

\title{
Keywords
}

Fertility, low fertility, fertility determinants, projections, uncertainty, education, highly developed countries, Europe, East Asia

\section{Authors}

Stuart Basten, University of Oxford, Department of Social Policy and Intervention.

Tomáš Sobotka (corresponding author), Wittgenstein Centre for Demography and Global Human Capital (IIASA, VID/ÖAW, WU), Vienna Institute of Demography/Austrian Academy of Sciences. Email: tomas.sobotka@oeaw.ac.at

Kryštof Zeman, Wittgenstein Centre for Demography and Global Human Capital (IIASA, VID/ÖAW, WU), Vienna Institute of Demography/Austrian Academy of Sciences.

\section{Contributing Authors}

M. Jalal Abbasi-Shavazi, Alicia Adsera, Jan Van Bavel, Caroline Berghammer, Minja Kim Choe, Tomas Frejka, Henri Leridon, Melinda Mills, S. Philip Morgan, Ronald R. Rindfuss, Louis Rosero-Bixby, Anna Rotkirch, Warren Sanderson, Maria Rita Testa, Olivier Thévenon, Zhongwei Zhao 
The contributing authors have drafted considerable parts of Sections 1.4 and 2. They were selected as lead experts in respective topics and regions. Specifically, they have provided texts to the following sections: M. Jalal Abbasi-Shavazi to Section 1.4.8 ("Middle East"), Alicia Adsera to Sections 1.4.7 ("Southern Europe") and 2.4 ("Employment, economic uncertainty and fertility"), Jan Van Bavel and Ronald R. Rindfuss to Section 2.8 ("Education"), Caroline Berghammer to Section 2.3.2 ("Religion"), Minja Kim Choe to Section 1.4.9 ("East Asian countries and territories") and Box 2 ("Living arrangements, gender roles, and their relationship to fertility in East Asia"), Melinda Mills to Section 2.3.3 ("Gender equality"), S. Philip Morgan to Section 1.4.1 ("The United States, Australia, Canada, and New Zealand"), Anna Rotkirch to Section 1.4.6 ("Nordic countries"), Warren Sanderson to Section 5.2 ("Long-term futures: preparing fertility scenarios beyond 2050"), Louis Rosero-Bixby to Section 1.4.2 ("Latin America"), Maria Rita Testa to Section 2.3.1 ("Fertility intentions"), Olivier Thévenon to Section 2.5 ("Family policies"), and Zhongwei Zhao to Sections 1.4.10 ("China") and Box 1 ("Finding China's Fertility Rate"). Henri Leridon has reviewed Section 2.7 ("Biomedical factors"). Tomas Frejka has provided detailed comments on the first draft of the paper and produced regional cohort fertility estimates. The lead authors have modified these texts in order to achieve higher uniformity and reduce overlaps and consulted these modifications with the contributing authors and book editors. In addition, the first complete version of the paper has been distributed to selected experts for additional comments and revisions.

\section{Acknowledgements}

The completion of this research would not be possible without the committed involvement of different contributors-researchers, contributing authors, experts participating in the online survey and those participating in the meeting in Vienna-who have organised the survey of experts or contributed to it, were involved in the debates on fertility scenarios presented here, and who have directly contributed to this working paper or helped checking and reviewing it. Special thanks are due to Bilal Barakat, who helped designing the survey of experts and provided first analyses of survey results, Michaela Potančoková who helped us collect data on education-fertility differentials analysed in Sections 5.3.1-5.3.4, Nikola Sander who operationalised Circos plots used in Figures 7 and 8, Bill Butz, Josh Goldstein and Tomas Frejka who provided detailed comments on the first draft of the chapter on which this paper was based, and Jim Dawson who has provided copy editing. Sobotka and Zeman's contribution was funded by the European Research Council under the European Union's Seventh Framework Programme (FP7/2007-2013) / ERC Grant agreement

284238. Basten's contribution was funded by the European Research Council (ERC) Advanced Investigator Grant entitled 'Forecasting Societies' Adaptive Capacities to Climate Change" (ERC-2008-AdG 230195-FutureSoc); and the UK Economic and Social Research Council's 'Future Research Leader' Grant, number ES/K001434/1. 


\section{Contents}

1 Introduction and Summary of Past Trends: Beyond the Fertility Transition ................................. 5

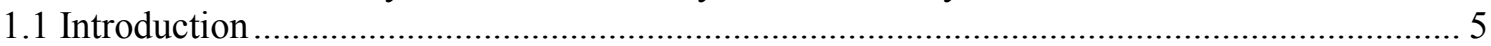

1.1.1 The Future of the Low Fertility World ……................................................................. 5

1.1.2 Outline of this Working Paper .................................................................................. 5

1.2 The ongoing Fertility Transition in East Asia, Middle East and Latin America....................... 7

1.3 Europe, United States, Japan and Other Highly Developed Countries ................................... 9

1.4 Summary of Past Trends and Key Factors in Major Low-Fertility Regions........................... 12

1.4.1 The United States, Australia, Canada, and New Zealand........................................ 12

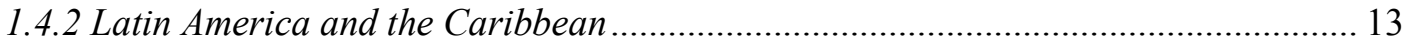

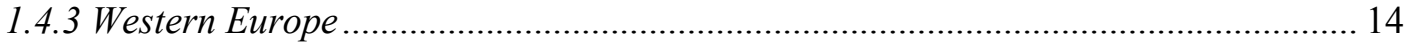

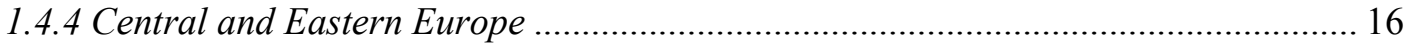

1.4.5 Germany, Austria, and Switzerland ("German-Speaking” Countries)....................... 17

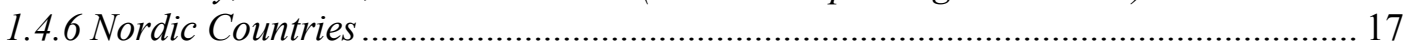

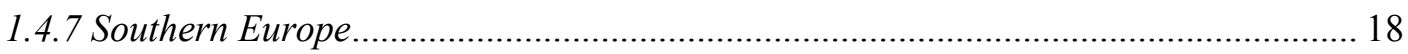

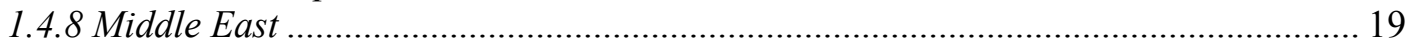

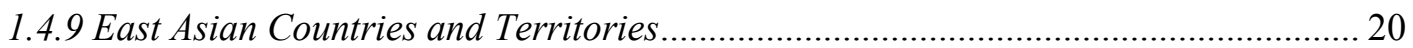

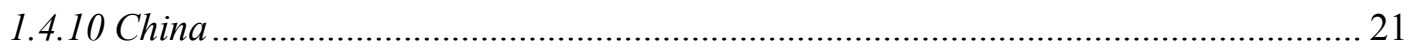

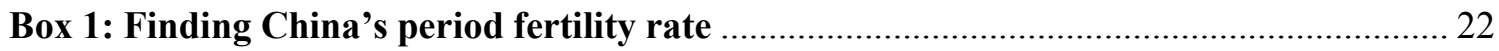

1.5 Regional Trends: Common Issues and Key Factors ......................................................... 23

2 Explaining Past and Future Fertility Trends: Theories and Empirical Evidence ........................... 24

2.1 'Meta-theories' of Low Fertility and Family Changes......................................................... 24

2.2 Fertility Postponement and its Impact on Period Fertility ..................................................... 26

2.3 Cultural and Social Forces in Fertility Ideals, Intentions and Reality .................................... 28

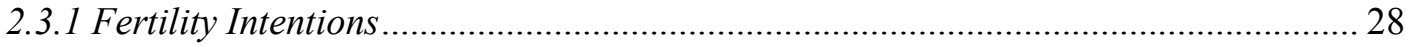

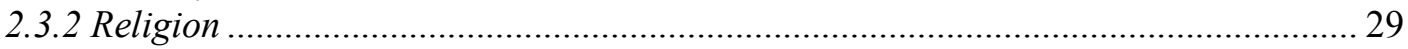

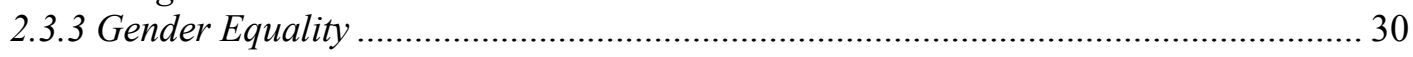

Box 2: Living arrangements, gender roles, and their relationship to fertility in East Asia. 31

2.4 Employment, Economic Uncertainty and Fertility............................................................ 32

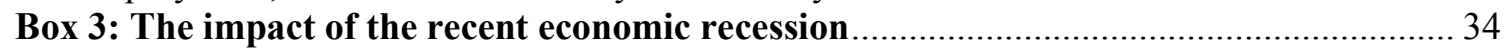

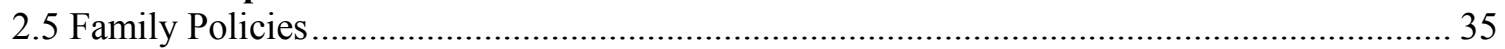

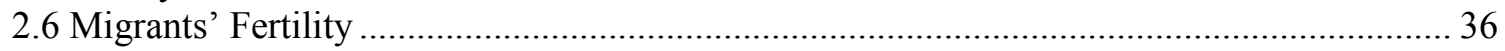

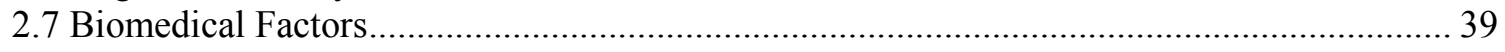

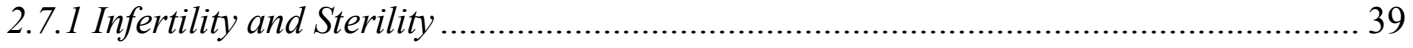

2.7.2 Deteriorating Male Reproductive Health? ............................................................ 41

2.7.3 Fertility Postponement and Assisted Reproduction ................................................... 41

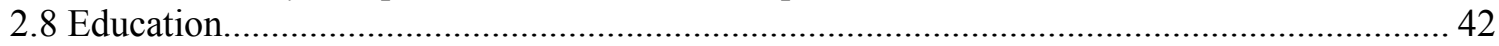

3 Expert Survey and Results of Expert Meeting: Summary of Findings ........................................ 45

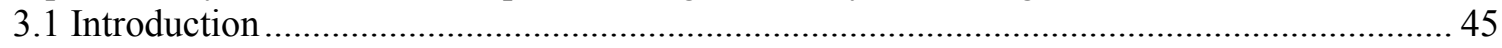

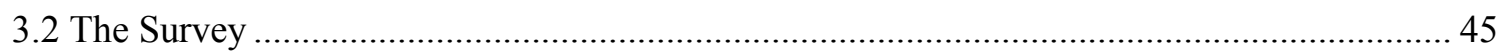

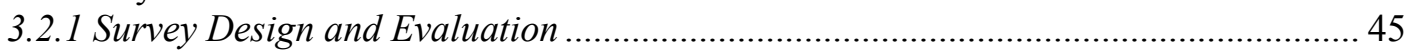

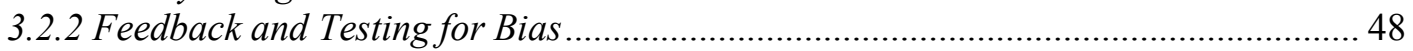

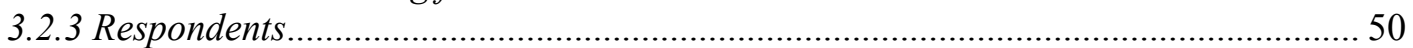

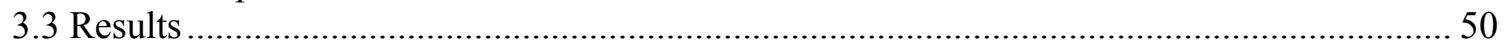

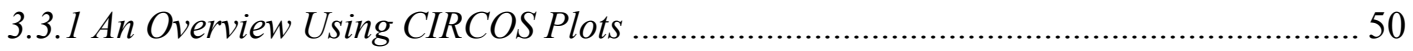

3.3.2. The Relative Importance of Different Forces (Width of Sections) ............................ 52

3.3.3. Mean Net Impact (Outer Circle) ............................................................................ 52

3.3.4 Validity of Arguments and the Index of Disagreement (Inner Circle) .......................5 53

3.3.5 Regional Differences in Net Impact of Arguments ..................................................... 54

Box 4: Expert views on current economic uncertainty by country ....................................... 59

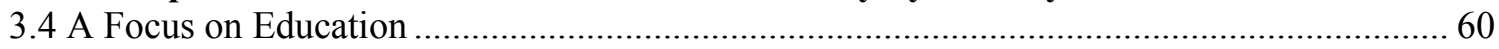




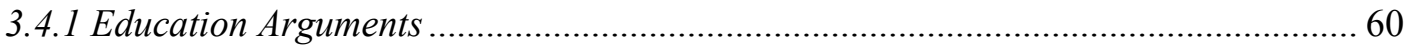

4 Quantitative Forecasts of Future Fertility Levels: Experts' Views ................................................. 62

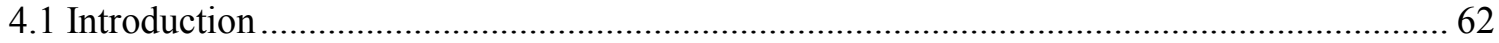

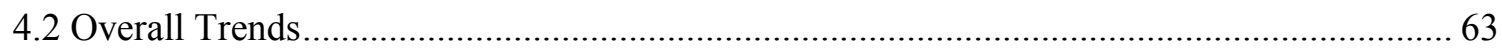

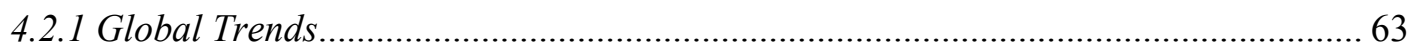

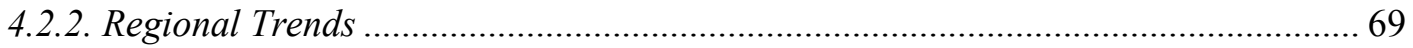

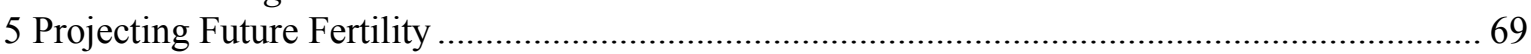

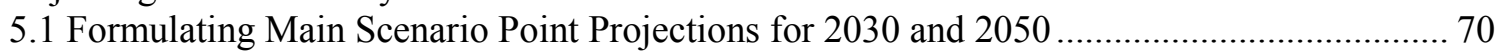

5.2 Long-Term Futures: Preparing Fertility Scenarios Beyond 2050 …................................ 72

5.3 Defining TFR Assumptions by Level of Education ........................................................... 75

5.3.1 Education-Fertility Differentials in Low-Fertility Settings: Empirical Evidence ...... 75

5.3.2 Do Fertility Differentials by Level of Education Vary by Region? ............................. 76

5.3.3 Is There a Distinct Trend in Education-Fertility Differentials once the Overall Fertility Declines Below a Threshold of 2.2? ................................................................. 77

5.3.4 Is There a Distinct Trend in Education-Fertility Differentials Across Cohorts?....... 78

5.3.5Expected and Projected Future Trends in Education-Fertility Differentials

Conclusion

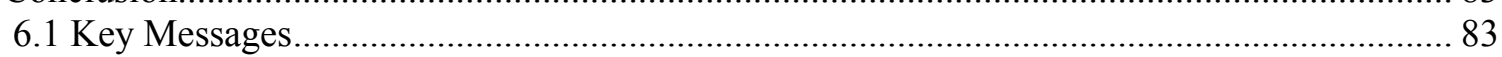

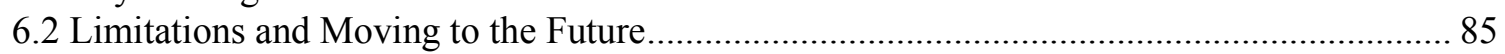

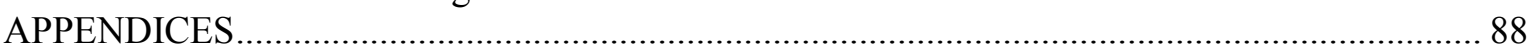

Appendix 1: Defining the initial TFR values in 2010 and formulating main scenario point

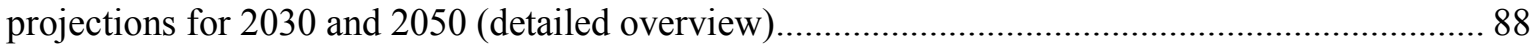

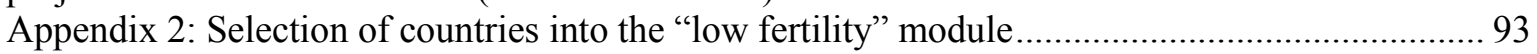

Appendix 3: Profile of respondents and country responses. ....................................................... 96

Appendix 4: Complete list of arguments and their groupings by major factors in the low fertility

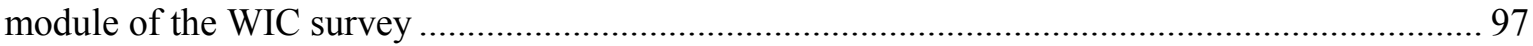

Appendix 5: Regional graphs of expected TFR trends up to 2050: A comparison of the global survey of experts and the 2010 UN projection (probabilistic fertility scenarios) ........................... 100

Appendix 6: Specifying source data on education-fertility differentials....................................... 102

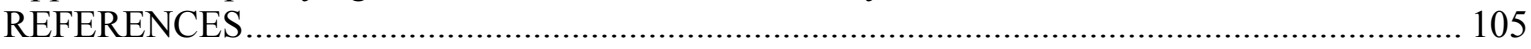




\title{
Future Fertility in Low Fertility Countries
}

\author{
Stuart Basten, Tomáš Sobotka and Kryštof Zeman
}

Contributing authors:

M. Jalal Abbasi-Shavazi, Alicia Adsera, Jan Van Bavel, Caroline Berghammer, Minja Kim Choe, Tomas Frejka, Henri Leridon, Melinda Mills, S. Philip Morgan, Ronald R. Rindfuss, Louis Rosero-Bixby, Anna Rotkirch, Warren Sanderson, Maria Rita Testa, Olivier Thévenon, Zhongwei Zhao

\section{Introduction and Summary of Past Trends: Beyond the Fertility Transition}

\subsection{Introduction}

\subsubsection{The Future of the Low Fertility World}

The ongoing transition to low fertility is, alongside the long-term expansion of life expectancy, the key force reshaping populations around the world. It has sweeping economic and social repercussions as it affects labour markets, intergenerational ties, gender relations, and public policies. Many middle income countries including China, Brazil, Iran, and Turkey have joined the expanding list of low fertility countries. Consequently, low fertility is no longer an exclusive feature of rich Western societies. As close to half of the global population now live in regions with below replacement fertility (Wilson and Pison 2004), low fertility has become a truly global phenomenon.

What are the key ingredients of this "revolutionary" change? Expanding education, rising income, the rise of gender equality, female labour force participation, ideational changes, consumerism, urbanisation, family disintegration, economic uncertainty, globalisation, modern contraception and many other complementary or contrasting forces are often highlighted. But how will these drivers shape the long-term future of fertility? Will fertility in most countries stabilise at around the replacement level threshold, as implied by the demographic transition theory, or will it decline below this level? Is very low fertility merely a 'passing phenomenon', a sign of a temporary imbalance between rapid social and economic changes and opportunities on the one hand and family, gender relations and reproduction on the other hand?

\subsubsection{Outline of this Working Paper}

This working paper aims to present a systematic overview of the forces shaping contemporary reproductive behaviour in low fertility countries and explore possible future scenarios based upon a new survey of international experts. The paper is an expanded version of Chapter 3 in Lutz et al. (forthcoming) and contains, in particular, extended literature review and reference list as well as more detailed documentation of the selection criteria for the countries covered, fertility projection scenarios and data used, including the survey of experts. The research covered here is part of a new attempt to produce expert- 
derived population projections of age, sex and education for all the world's countries (see Lutz et al. (forthcoming) for a full discussion). We begin with a presentation of recent trends in fertility in low fertility settings followed by a review of the particular recent histories of fertility change in North America, Europe and the emerging low fertility settings in East Asia, Latin America and the Middle East. We then explore the theoretical and empirical evidence which has been cited in the literature as underpinning these past trends and possible future scenarios. Alongside "meta-theories" such as the Second Demographic Transition, Section Two considers the roles played by cultural, biomedical and economic factors as well family policies, economic uncertainty, education and the contribution of migrants' fertility.

The concise summaries of underlying drivers of recent fertility trends presented in Section 2 therefore pave the way to the overview of main results of the expert survey in Section 3. While most demographers as well as the global projection scenarios by the United Nations expect that fertility will continue declining in countries with currently higher fertility rates (Chapter 4 of Lutz et al. forthcoming), there are many uncertainties about the future of fertility in the low fertility world. Some of these uncertainties have been addressed in the Wittgenstein Centre for Demography and Human Capital (WIC) global survey of population experts, which included a module on the future of fertility in low fertility countries and the main factors likely to drive these future trends. In Section 3, therefore, we outline the raison d'être for the Expert Survey, its design and evaluation, and present the results of the qualitative element of the survey - namely the subjective appraisal of a series of forces shaping future trends of fertility in low fertility settings.

In Section 4 we present the results of the quantitative component of the Survey. Here, experts were invited to provide point-and-range estimates of period total fertility rates in 2030 and 2050. We summarise these figures and compare them to the assumptions used by the United Nations in their global population projections. Section 5 takes all of the information gathered throughout the exercise, and the arguments of the experts participating in the Vienna meeting. It demonstrates how we then produce a series of fertility projections scenarios-medium-term until 2050, and very long-term until 2200to be integrated into the WIC global population projections. In particular, we attempt to integrate education-specific futures into our projection scenarios.

Compared to many existing studies on low fertility, this working paper is innovative in several respects. Firstly, in line with the evidence that low fertility has become a global phenomenon, it covers both the "traditional" low fertility world (Europe, Japan, North America, Australia, and New Zealand) and the more recent and emerging low-fertility regions. Thus, it also bridges the increasingly artificial distinction that is still often made between "developing" and "developed" countries. Secondly, the discussion about likely future developments is shaped by the views of experts who represented in their responses as many as 42 countries. This is an important step forward in overcoming the limitations of traditional population projections, where a few carefully selected experts formulate national and global fertility scenarios, and it also allows incorporating nonconformist voices that would otherwise be disregarded (Lutz et al. 1999a). One way to find out that our approach does make a difference from the more traditional projection-making exercise was to compare the projected future fertility trends with those of the 2010 World Population Prospects by the United Nations (see Section 4.2). Thirdly, many contributing authors and collaborators have been involved in drafting selected sections of the paper and 
also in reviewing its early drafts. Finally, the special focus on education brings to the fore a dimension that can be quantified, has been neglected in the past population analyses and projections and, at the same time has been suggested as "a key factor, if not the single most important determinant in development" (Lutz et al. 1999b: 45; see also Chapter 2 of Lutz et al., forthcoming). Specifically, we argue that rising education level, especially among women, is the most important factor contributing to the observed global fertility trends in the last decades, especially the decline of fertility in higher-fertility countries, and the postponement of parenthood to higher childbearing ages in affluent countries with low fertility. In addition, the inclusion of education is also adding a "quality" dimension to the otherwise quantitative study of population changes (Lutz and KC 2011).

\subsection{The ongoing Fertility Transition in East Asia, Middle East and Latin America}

Half a century ago, the global fertility map was polarised, reflecting the traditional division between "developed" and "developing" countries. The group of the "more developed countries" (MDC, defined by the United Nations for statistical purposes as Europe, Northern America, Japan, Australia, and New Zealand) had experienced relatively low fertility by the early 1950s and saw gradual but continuing fertility reduction from the late 1960 s through the 1990s, when the period total fertility rate (TFR) ${ }^{1}$ in the region fell below 1.6 (UN 2011, Figure 1a). In contrast, the group of the "less developed countries" (LDC) i.e. all other regions not listed above - had high and stable fertility rates at about six births per woman throughout the 1950s and 1960s; more than double the level of the MDC group . However, in the early 1970s, sustained fertility declines across much of the LDC group had begun, with the whole set of countries reaching a TFR level of 2.6 by 2010 (PRB 2012) - a level reached by European countries in the 1950s and early 1960s. The continuous and strong fertility declines in the LDC group led to the gradual reduction in fertility differences between major world regions that began in the early 1970s, with only sub-Saharan Africa and parts of Asia recording fertility rates above four births per woman in 2010 (PRB 2012).

Three regions covered in this working paper-Latin America, East Asia, and parts of the Middle East-have undergone dramatic fertility transformation since the 1960s. The breathtaking pace of fertility decline in the largest countries in these regions is illustrated in Figure 1b. In 1960-65, fertility in these countries ranged from a TFR of 5.6 in China and South Korea to 6.8 in Mexico and 6.9 in Iran. Rapid fertility declines then ensued, with fertility rates typically falling by a half in the course of two to three decades. This surprising pace of fertility transitions is partly attributed to government action concerning family planning, whether through explicit restrictions in China (see section 1.4.10), effective campaigns in Korea and elsewhere in East Asia (Choe and Park 2006), or the sanctioning of family planning by religious authorities in Iran (Abbasi-Shavazi et al.

\footnotetext{
${ }^{1}$ The period TFR is a widely available but also problematic indicator that is affected by changes in the timing of births as well as parity composition of the female population of reproductive ages (Bongaarts and Feeney 1998, Sobotka and Lutz 2011; see also Section 2.1). In conformity with its dominance in the literature and data sources we employ it frequently in this chapter, but also complement it with cohort fertility indicators as well as alternative measures of period fertility.
} 
2009a). However, the remarkable similarity of fertility transitions, with all of the compared countries experiencing fertility rates in 2005-2010 ranging from 1.45 in China to 2.4 in Mexico, indicates that while targeted government action might have facilitated or accelerated observed changes, fertility change was driven by a host of other factors related to socio-economic development, modern contraception, and new values and norms favouring small family sizes (e.g. Cai 2010 for China). Caldwell (2001: 109) sees this transformation as a manifestation of a "globalisation of fertility attitudes and behaviour."

As the boundaries between MDC and many LDC countries are becoming increasingly blurred with regard to demographic and socio-economic characteristics, so it is with fertility behaviour. Many "less developed" countries, including China, Cuba, and Iran have lower fertility today than some of the countries traditionally belonging to the club of the "most developed" countries with low fertility, such as Sweden, France, and the United States. Indeed, more than 45 percent of the global population lives in countries with belowreplacement fertility levels, and when regions of India are taken into account, more than half of humanity lives in below-replacement fertility settings (Wilson and Pison 2004). Low fertility is no longer an issue confined to the most affluent societies, but has become an important topic for public discussion and a motivation for development of government policies. A few countries have even reversed their policies and become explicitly pronatalist either through limiting family-planning programs (as in Turkey and Iran) or through extensive, explicitly pro-natalistic family policy interventions (e.g. Singapore, Taiwan, South Korea) (Section 1.4.8). On the other hand, the Chinese government has been slow to respond to demographers' arguments calling for dismantling China's fertility restrictions that limit the authorised number of births per couple (Wang et al. 2013).

With this transformation in fertility regimes, many new questions arise. Where will fertility decline stop? Will East Asia retain the position of the lowest-fertility region globally? Will the Middle East and Latin America follow and experience decades of very low fertility? Can previous experience of post-transitional fertility trends in Europe, United States, Japan, and other rich societies serve as a guide to what might happen elsewhere? Will many non-European countries experience protracted postponement of family formation to ever-later ages, depressing period fertility levels for many decades to come? (Bongaarts 1999). 
FIGURES 1A AND 1B: PERIOD TFR IN MAJOR WORLD REGIONS AND IN LARGEST COUNTRIES COVERED IN THIS WORKING PAPER, 1950-55 TO 2005-10
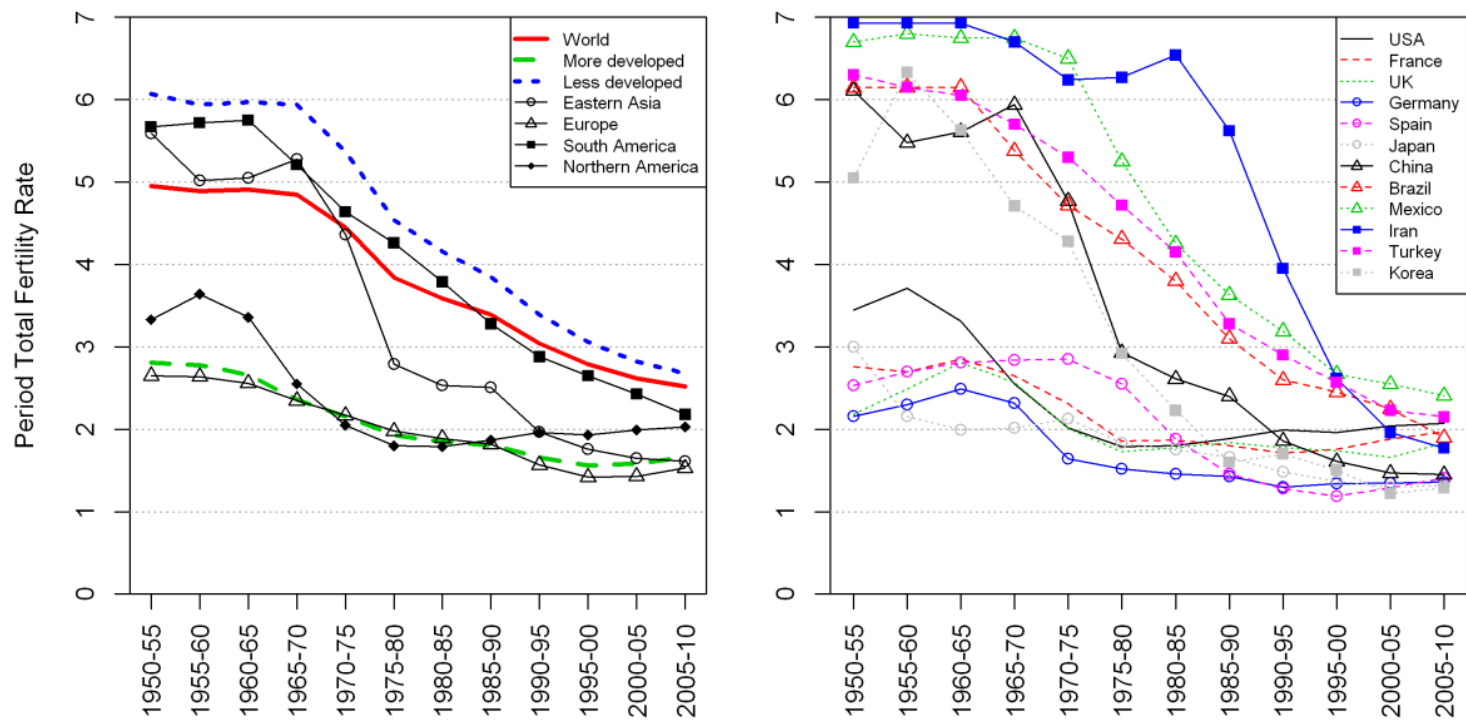

Data source: UN 2011, Table A.22.

Note: Period TFR in China in 1990-2010 is likely to be overestimated in the official statistics and the UN data (see Box 1); data shown are based on Zhao and Zhang (2010, p.490, Table 6).

\subsection{Europe, United States, Japan and Other Highly Developed Countries}

The United States, Canada, Japan, and most European countries have a long history of low fertility rates. In the $1930 \mathrm{~s}$, in the context of economic crisis and shifts in values and attitudes towards family, many Western countries including Austria, Germany, Sweden and Great Britain temporarily experienced TFRs falling below two births per woman (Kirk 1946; Festy 1979; Van Bavel 2010b). In the 1970s and 1980s ever more developed countries experienced what were thought to be irreversible falls of fertility to subreplacement levels. In the 1990s, a phenomenon of "lowest-low fertility" with a TFR declining below 1.3 temporarily affected countries with more than half of Europe's population (Kohler et al. 2002; Sobotka 2004a; Billari and Kohler 2004). Beginning in around 2000, however, declines in period fertility halted and an upturn took place across most low-fertility regions, with the notable exception of East Asia (Goldstein et al. 2009; OECD 2011; Hoorens et al. 2011). The upturn lasted until the onset of the global economic recession in about 2008 (see Box 3 below). This fertility recuperation was largely an expected consequence of the slowing-down in the pace of fertility postponement and the associated tempo effect (Bongaarts and Sobotka 2012; see also Section 2.2). It marked the first concerted rise in fertility across the developed world, with many countries registering an absolute TFR increase of 0.3-0.6, or around 20-40 percent in absolute terms (Goldstein et al. 2009). Moreover, this fertility increase demonstrated that there is nothing inevitable about extreme low fertility rates, as many former state-socialist countries that were 
seemingly "stuck" at very low fertility levels suddenly experienced remarkable increases in their period TFRs'.

While period fertility rates are notoriously unstable, estimates and projections of cohort fertility suggest a broad stabilisation or even a small increase among the women born in the 1970s in most European countries as well as the US, Australia, Canada, Japan, and New Zealand (Myrskylä et al. 2013; Mazuy et al. 2011: 459, Table A.7). Figure 2 presents observed and projected completed cohort fertility (CFR) for larger regions in Europe and East Asia among women born in 1960-1979, based on Myrskylä et al.'s (2013) computations. ${ }^{3}$ Although the data for the most recent cohort, 1979, are still subject to possible downward revisions due to the recent recession-induced period fertility declines (Section 2.4, Box 3), the contrasts in regional fertility trends are sizeable and robust. Among women born in 1960, five out of seven analysed regions had fertility rates very close to two children per woman; only Southern Europe (CFR at 1.77) and the three predominantly German-speaking countries in Central Europe (Austria, Germany, Switzerland, CFR at 1.66) showed an early spread of fertility well below replacement. Subsequently, regional cohort fertility trajectories diverge. The English-speaking countries outside Europe show a modest increase to cohort fertility slightly above replacement in the 1979 cohort (CFR at 2.18), chiefly because of the projected fertility increase in the United States (CFR at 2.23). Nordic countries have a flat fertility at around the CFR of 2.01. Western Europe shows a slight U-shaped trend, with a projected CFR in the 1979 cohort identical to that in 1960 (2.03). In contrast, former state-socialist countries of Central and Eastern Europe display sizeable falls in cohort fertility in the 1960s cohorts, with the projected CFR down to 1.66 in the 1979 cohort; even stronger and continuous declines are projected for East Asia (Japan, Korea, Singapore, and Taiwan), where the projected CFR falls to a lowest level in all regions analysed, 1.44. Finally, cohort fertility in the two regions with earlier spread of sub-replacement fertility is expected to decline as well, moderately in the three German-speaking countries (with a slight recovery in the 1970s cohorts) and more in Southern Europe, eventually falling below the 1.5 threshold (CFR of 1.47 in the 1979 cohort).

\footnotetext{
${ }^{2}$ The most remarkable TFR upturn took place in Eastern Germany (former German Democratic Republic) where period TFR plummeted below 0.8 after German unification in the early 1990s and then almost doubled, reaching 1.46 in 2010 (Goldstein and Kreyenfeld 2011, see also Section 1.4.5).

${ }^{3}$ Regional data weighted by 2012 population size of all the countries in each region.
} 
FIGURE 2: OBSERVED AND PROJECTED COMPLETED FERTILITY RATE IN MAJOR REGIONS OF EUROPE, SELECTED COUNTRIES OF EAST ASIA AND ENGLISH-SPEAKING COUNTRIES OUTSIDE EUROPE; WOMEN BORN IN 1960, 1970, AND 1979

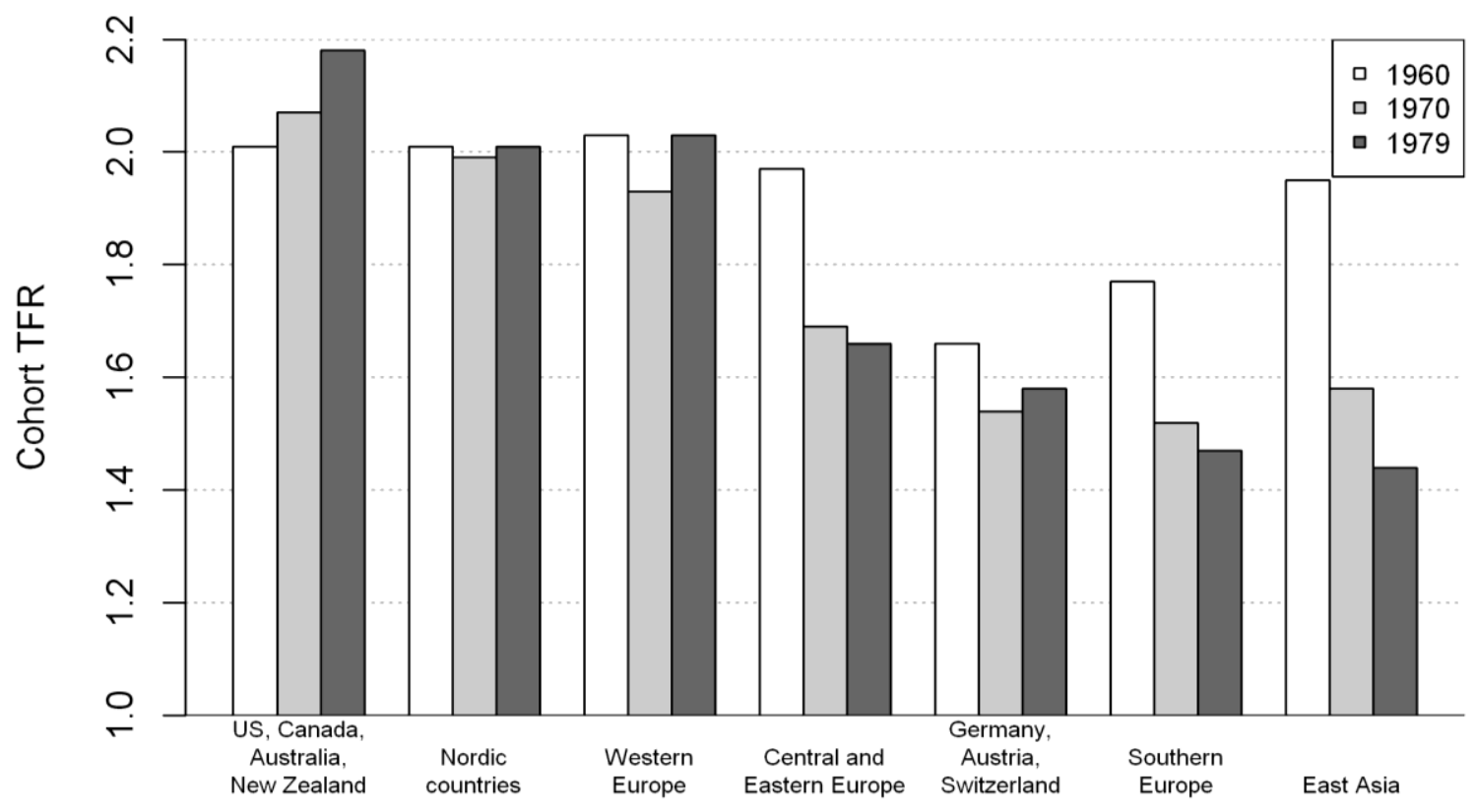

Notes: Completed fertility is partly projected in the cohorts born in 1970 and 1979. Regional data are weighted by population size in 2012 of all countries in a given region. The region "Central and Eastern Europe" includes all former "state-socialist" countries of Europe including former Soviet Union (except Latvia), but excluding most of the former Yugoslavia, where only Slovenia was included (data not available for other countries). "East Asia" includes Japan, South Korea, Singapore and Taiwan.

Sources: Computations based on cohort fertility data and projections presented by Myrskylä et al. (2013, Table 2)

Prior to the fertility upturns of the early $21^{\text {st }}$ century, a notable reversal in an aggregate correlation between socio-economic and cultural indicators and fertility rates occurred (Castles 2003). Factors traditionally associated with low fertility rates became associated with higher fertility when most developed countries were compared with each other (see also Section 2.1 below). While these findings were often not replicated at the individual level, they nevertheless signal an important change. The aggregate reversal was most frequently discussed in the relationship between women's labour force participation and fertility (Brewster and Rindfuss 2000; Engelhardt and Prskawetz 2004). More recently, it has been suggested that at advanced levels of development, further increases in development no longer translate into lower fertility, but could instead lead to rising fertility rates (Myrskylä et al. 2009, 2011; OECD 2011; Section 2.1). 


\subsection{Summary of Past Trends and Key Factors in Major Low-Fertility Regions}

In this section we outline recent trends in fertility by region. ${ }^{4}$ We use regions that are distinct geographically, economically, culturally, and demographically. In Europe we distinguish smaller regions that mirror particular histories of low fertility and family patterns.

\subsubsection{The United States, Australia, Canada, and New Zealand}

The United States, Australia, Canada, and New Zealand have shared similar fertility patterns for much of the post-World War II period, including a relatively a pronounced baby boom in the 1950s and the early 1960s. Between 1960 and 1980, these countries experienced fertility declines from around 3.5 (higher in New Zealand) to sub-replacement TFRs ranging from 1.8 in Canada to 2.0 in New Zealand (Preston 1986). In the US, fertility decline bottomed out in 1976 when the TFR reached 1.75, the lowest level recorded to date.

Since 1980 , fertility has remained relatively stable. While the US experienced gradual increases, Canada's fertility decline continued through 2000 when it briefly dropped below 1.5. By then, the fertility contrast between Canada and the United States surpassed half a birth (TFR 1.49 and 2.05 respectively). Most recently, the US fertility declined most following the onset of the recession, while Canada's TFR showed continued slow recovery. The period TFR in 2011 ranged from below 1.6 in Canada through 1.9 in Australia and the US up to a 'high' value of 2.1 in New Zealand. The lower fertility in Canada is illustrated in differences in cohort fertility among women born in 1970, which declined below 1.8 in Canada, but remained above 2.0 in the other three countries, reaching 2.02 in Australia, 2.11 in the U.S., and 2.17 in New Zealand (Myrskylä et al. 2013: Table 2).

The US has relatively high fertility compared to most other developed countries, which, combined with its population size of 314 million, warrants special attention. Different explanations have been proposed to explain the US "exceptionalism" in fertility, including higher fertility rates among specific migrant and minority groups, especially Hispanics; a slower trend toward delayed childbearing; stronger importance of religion; and highly flexible labour markets combined with ample availability of cheap private childcare (Morgan 2003; Adsera 2004; Frejka and Westoff 2008; Frejka 2004; Hayford and Morgan 2008; McDonald and Moyle 2010). But, arguably, the key factor in the higher fertility in the US is the closeness of intended and realised family size, with the level of intended fertility being only slightly higher than observed period TFRs despite considerable inconsistency in the number of children individual women intend and actually bear (Quesnel-Valléee and Morgan 2003; Morgan and Rackin 2010; see also Section 2.3.1). In other words, a large number of women "miss their target," but approximately equal numbers miss low and high. The primary reason many women exceed intended parity is a

\footnotetext{
${ }^{4}$ For details regarding the selection of countries for the low and high fertility modules respectively, see Appendix 1. To keep text conscise and informative, we focus especially on main countries in each region and pay only marginal attention to small countries and territories, especially those with a population below 1 million.
} 
high frequency of unplanned pregnancies - especially among teenagers and low educated and economically disadvantaged social groups (resulting in unintended and unwanted births (Finer and Henshaw 2006; Finer and Zolna 2011; Musick et al. 2009). A nonnegligible share of women who do did not plan to get pregnant and were sexually active (7\%) did not use any contraceptive method in 2006-2008 (Mosher and Jones 2010: Table 6). Almost a half of all pregnancies (49\% in 2006) in the US are unintended, with very high shares among never-married young women. This level increases to 73 percent of unwanted pregnancies in predominantly Latino communities (Rocca et al. 2010). Fewer than half of these pregnancies (43\%) were terminated by abortion (Finer and Zolna 2011).

In contrast, Canadian completed fertility is more than 0.3 births per woman lower despite evidence of a "remarkable stability of fertility intentions reported by Canadian women" averaging 2.1 births (Edmonston et.al. 2010: 320). While high teenage childbearing has been a general characteristic of English-speaking countries, this is less true for Canada where the mean age of childbearing has increased to nearly 30 years, similar to Western Europe. Thus, Canadian women, as in much of Europe, have low fertility because, in the language above, many more "miss low than high". The Canadian and US difference may also represent different effects of immigrant fertility (see also Section 2.6). The flow of Hispanics (especially Mexicans) into the US increases fertility (Frank and Heuveline 2005). The immigrants to Canada (primarily from Asia) often exhibit higher fertility initially (with a notable exception of Chinese immigrants who display low fertility early on), but their fertility quickly falls to the levels of natives (Woldemicael and Beaujot 2012). Indeed, among the second generation, fertility among migrants is, in fact, lower (Adsera and Ferrer 2010).

If one compares 2010 non-Hispanic whites' TFR in the United States with overall Australian TFR, the rates are very similar (1.8 and 1.9 respectively). Australia's selective immigration policy reduces the impact of immigrant fertility. In contrast, the higher TFR seen in New Zealand - in 2010 the second highest after Iceland (2.2) among developed countries - partly reflects the higher fertility rates of Māori and Pacific women (New Zealand Government 2010).

\subsubsection{Latin America and the Caribbean}

The most recent UN estimates show a TFR in the Latin America and Caribbean (LAC) region of 2.3 births per woman in 2005-10, with a falling trend of about 0.2 every five years (UN 2011). ${ }^{5}$ As such, by the time of publication it is highly likely that period TFR in this region has fallen to replacement rate.

Brazil and Mexico are key to understanding the trends in LAC given that their populations make up about 50 percent of the region's population. Brazil has recently reached subreplacement fertility with an estimated 2009 TFR of 1.94 (IBGE 2010). In Mexico, meanwhile, the TFR is estimated at 2.4 births per woman in 2005-10 (UN 2011). In both countries this represents a fall of over four births per woman since the onset of the fertility

\footnotetext{
${ }^{5}$ Although the lack of reliable vital statistics in most LAC countries limits monitoring demographic trends in a timely way, data from population censuses of 2010 and 2011 make estimates for 2005-10 robust in most countries. The 2012 World Population Datasheet estimates region's TFR level at 2.2 (PRB 2012).
} 
transition in the 1960s. Fertility decline in Brazil has accelerated in the 2000s (Rodriguez Wong 2009, Potter et al. 2010), concurrent with rapid economic growth and broadening of the middle class (Souza 2012). Brazilian fertility is clearly heading to levels substantially lower than replacement, especially if Brazil experiences an intensive postponement of childbearing similar to that experienced in European and East Asian countries in recent decades. By contrast, fertility decline in Mexico has slowed down: its TFR estimate for 2005-10 was corrected upward by 0.2 in the light of the 2010 census results. The anticipation of the Mexican government of reaching the replacement level by 2005 (Tuiran et al. 2002) will only be fulfilled at least a decade later.

The highest fertility in LAC occurs in the two countries with the largest indigenous ethnic groups (CELADE 2012): Guatemala (41\% indigenous) and Bolivia (62\%) with a TFR of 4.1 and 3.5 respectively, as well as in Haiti, the poorest country in the region with a TFR of 3.5. The onset of the fertility transition arrived in these countries later-in the 1970s and 1980 s - but their fertility decline has been faster in the first decade of the 21 st century, by about one birth per woman compared to the LAC average of 0.4 (UN 2011). There is no reason to believe that the fertility decline in these "laggard" countries will stop before reaching the replacement level.

Cuba has the lowest TFR in LAC, estimated at 1.8 in 2011 (ONE 2012), following an upturn from a low of 1.4 in 2006. But even in Cuba, adolescent fertility remains relatively high at 57 births per thousand women aged 15-19 in 2011. This high adolescent fertility is a characteristic of the whole region with an average rate of 73 per thousand (Rodríguez 2011). Closely related are the statistics revealing that women in Latin America also report very high shares of unwanted pregnancies and births, ranging from 21 percent in Paraguay to 60 percent in Bolivia in the early 2000s (Casterline and Mendoza 2009: Figure 1). However, recent census and survey data suggest both teenage fertility rates and unwanted fertility rates have declined in the region, fuelling to a large extent the observed fertility decline (Casterline and Mendoza 2009). The social imperative of early motherhood and motherhood in general, which have long prevailed in the region, is weakening in young cohorts (Rosero-Bixby et al. 2009). An increase in voluntary childlessness coupled with further reductions in unwanted fertility and the trend towards childbearing postponement would facilitate the occurrence of lowest-low fertility levels, similar to those in Southern Europe, in many LAC countries.

\subsubsection{Western Europe}

Western European countries (Belgium, France, Ireland, Luxembourg, the Netherlands, and the United Kingdom) - alongside the Nordic countries - generally exhibit higher fertility than other parts of Europe. They share family and fertility patterns typical of an advanced stage of the Second Demographic Transition, marked by a late timing of childbearing (except in the United Kingdom, where teenage fertility rates remain considerably higher), high rates of extramarital childbearing, and a high labour force participation of women (see Section 2.1). In Western Europe, the trend toward late childbearing began already in the early 1970s but slowed after 2000. This led to a pronounced cycle of fertility decline after 1970s and a gradual fertility recovery in more recent years, especially between the late 1990s and 2008 when period and cohort fertility levels converged to similar values. Once changes in fertility timing are taken into account, period and cohort fertility levels in 
Western Europe have been remarkably stable during recent decades despite the on-going trend to later childbearing, rapid family transformations, rising tertiary education, female labour participation, and more competitive labour markets (Caldwell and Schindlmayr 2003; Section 1.3).

Fertility outside marriage has been increasingly accepted since the 1970 s, so that by 2011 between 34 percent (Ireland) and 55 percent (France) of births took place outside marriage, mostly in cohabiting unions. This broad acceptance of cohabiting unions and childbearing outside marriage may arguably have a positive impact on fertility (Section 2.1).

France and the United Kingdom have similar fertility levels, with the period TFR close to 2.0 in 2010 and cohort fertility of women born in 1970 at the same level for France and a slightly lower level of 1.9 in the UK (VID 2012). But this similarity masks contrasts with respect to birth timing, order-specific fertility, and social status differences in fertility, which partly reflect different institutional conditions including family policies, norms, and contraceptive use. The French fertility pattern, similarly to the Nordic countries, can be characterised as 'egalitarian', with low childlessness and relatively low differentials between social status (Toulemon and Mazuy 2001; Ekert-Jaffé et al. 2002; Rendall et al. 2009). This can be explained, in part, by an active family policy introduced in France in the 1940s and adapted in the 1980s to accommodate women's entry into the labour force. Pro-natalist in nature, this active set of policies seems to have created especially positive attitudes towards two- or three-child families in France (Toulemon et al. 2008).

The fertility pattern in the United Kingdom can be seen as "polarised", marked by high childlessness around 20 percent (especially among women with university education), a higher share of women with four or more children (Shkolnikov et al. 2007), high social status differentials (Ekert-Jaffé et al. 2002) and, similar to the US, relatively high rates of both teenage and unintended pregnancies (Sigle-Rushton 2009). Since reaching a low point of 1.6 in 2001, period TFR in the UK has increased as a consequence of diminishing importance of the tempo effect, higher fertility among immigrants and, arguably, the introduction of a raft of more "family-friendly" policies (Jefferies 2008; RAND Corporation 2012; Sigle-Rushton 2008).

Ireland, until recently a rather conservative Catholic country, has been an outlier in Western Europe in maintaining a high TFR above 3.0 until the mid-1970s and barely falling below 2.0 in the period 1994-2006. In contemporary Ireland a strong preference for larger families seems to be in evidence (Testa 2012a). In fact, Ireland now has the highest TFR level in Europe of 2.11 in 2011, followed by Iceland (2.04 in 2012) and France (2.00 in 2012).

The Benelux countries (Belgium, the Netherlands, and Luxembourg) also experienced sharp declines in fertility in the 1970s and 1980 s, followed by a gradual recovery. In the Netherlands TFR briefly fell below 1.5 in the early 1980s, but a subsequent recovery brought it back to about 1.7 by the turn of the millennium, a rate similar to Belgium and to the completed fertility in both countries. In the Netherlands, a combination of work and family life is facilitated by a wide adherence to part-time work, which is very common among women with children, and also of some significance among men (Yerkes 2009; Fokkema et al. 2008). In Belgium, relatively high and stable cohort fertility (just above 1.8 for the 1950s-1970s cohorts) went hand-in-hand with reversals in the educational gradient 
in fertility, with tertiary educated women having above-average fertility levels since the 1950s cohorts (Neels and De Wachter 2010).

\subsubsection{Central and Eastern Europe}

Central and Eastern Europe (CEE) is an economically, culturally, and demographically heterogeneous region composed of countries that had belonged to a state-socialist political system that collapsed between 1989 and 1991. Fertility rates in the region fell to relatively low levels in the late 1950s following legalisation of abortion and a push to dramatically expand women's labour force participation. Unlike many other parts of Europe, CEE did not experience a distinct baby boom in the 1950s and 1960s, instead recording some of the lowest fertility rates globally, with some countries, including Croatia, Hungary, Romania, Russia, and Ukraine experiencing sub-replacement TFR levels (Sobotka 2011). In response, governments started stimulating fertility in the form of social, housing and family policies as well as more restrictive measures, especially limiting access to abortion (David 1999).

By the late 1990s the CEE countries stood out as a result of their almost universal and relatively early marriage and childbearing, a strong adherence to the two-child family norm and high abortion and divorce rates, especially in parts of the former Soviet Union (Sobotka 2003). Political regime change in 1990 resulted in a long and painful period of economic and social transformation toward a market economy, parliamentary democracy, and, in the case of central and parts of South-eastern Europe (Bulgaria and Romania), eventual entry to the European Union (Heyns 2005). Fertility and family have changed profoundly, with marriage and fertility trends best characterized by later, fewer, less universal, and with respect to social status differential, more heterogeneous. A rapid shift toward later timing of births generated a sizeable tempo effect, which exacerbated the fertility decline in the 1990s, leading to extreme low levels of period fertility rates across the whole region at the end of the decade (Sobotka 2003, Goldstein et al. 2009). The multifaceted nature of fertility changes fuelled discussion of both positive and negative aspects of the impacts, including falling living standards, expanding tertiary education, new opportunities, spread of modern contraception, and new attitudes typical of the Second Demographic Transition. Because these changes proceeded simultaneously, it is impossible to single out the effects of individual factors that drove fertility decline and postponement (Philipov and Dorbritz 2003; Frejka and Westoff 2008; Sobotka 2011).

After recovering somewhat in the decade since 2000, fertility rates in CEE still remain relatively low, with a period TFR ranging between 1.1 in Latvia and 1.5-1.6 in Estonia, Belarus, Lithuania, Russia, and Slovenia in 2010. The lowest levels of completed fertility rates among women born in 1970 were recorded in Russia (1.60) and Ukraine (1.55; VID 2012). Fertility and family patterns grew much more differentiated, with Central European countries, especially the Czech Republic, Estonia, Hungary, former GDR (East Germany), and Slovenia experiencing particularly rapid postponement of first births and also the shift away from marriage to cohabitation and single living, including single motherhood, especially among socially disadvantaged women (Sobotka and Toulemon 2008; Bilingsley 2010; Perelli-Harris et al. 2012). The prolonged experience of very low fertility rates led to renewed concerns about low fertility and population decline, and to the resurgence of explicit top-down pronatalism in parts of Eastern Europe, especially in Belarus and Russia, 
where achieving higher birth rates is seen as a matter of national interest and a key for achieving 'demographic security' (e.g., PDR 2006; Ministry of Labour 2010; Heino 2012).

\subsubsection{Germany, Austria, and Switzerland ("German-Speaking” Countries)}

A number of distinct fertility developments in Austria, Switzerland, and Germany can be pointed out. First, fertility has been lower in these three countries than in most of Europe since the 1920s, and the fall in fertility rates after 1964 took place with greater intensity than in neighbouring regions. The Federal Republic of Germany (Western Germany) was the first European country experiencing a TFR fall below 1.5 in 1975 and a brief decline below 1.3 a decade later. Second, fertility has remained at similar low levels since the mid1970s, little affected by the shifts typical for many other parts of Europe (Dorbritz 2008, Prskawetz et al. 2008). In 2011 the period TFR ranged from 1.36 in Germany to 1.52 in Switzerland, slightly above the lows reached between 1994 and 2001; the adjusted TFR that aims to eliminate influences of the changes in the timing of births (Section 2.2) has remained around 0.2 higher. Third, low fertility in Austria, Switzerland, and western Germany is largely attributable to high childlessness, especially among tertiary educated women. Finally, low fertility appears to be linked to low family size intentions and ideals, in contrast to North America (Goldstein et al. 2003; Sobotka 2009).

In Germany, low fertility has resulted in a negative balance between births and deaths since 1972. The data for Germany hide persistent contrasts in fertility patterns and their underlying institutional conditions between eastern and western part of the country (Dorbritz 2008; Cassens et al. 2009; Kreyenfeld 2010; Basten et al. 2011; Goldstein and Kreyenfeld 2011; Sobotka 2012). However, differences in fertility levels diminished after the post-unification "demographic shocks" in eastern Germany (Conrad et al. 1996) when a record low TFR level of 0.77 was reached in 1993-94 (Goldstein and Kreyenfeld 2011).

As the three countries were relatively little affected by the recent economic recession, fertility rates remained stable after 2008. Projections suggest a stabilisation in completed fertility rates among Austrian women born after 1970 at a level of 1.6 and a slight rise among (West) German women, who reached the lowest cohort fertility in Europe of 1.5 in the 1968 cohort (Myrskylä et al. 2013; Prioux et al. 2010).

\subsubsection{Nordic Countries}

The five Nordic countries (Denmark, Sweden, Norway, Finland and Iceland) are characterised by stable and relatively high fertility, with completed cohort fertility of postwar generations consistently around two children per woman (Andersson et al. 2009). In Finland, for example, two surviving children per mother has been the dominant pattern for well over a century (Liu et al. 2012). Women born in the 1960s had their first child two to three years later than those born in the 1950s and mean age at first birth is now around 29 years. There has also been a steady increase in childlessness, reaching around 15 percent for women born in the 1960s (Andersson et al. 2009). The great majority of Nordic women wish to have two or three children and voluntary childlessness stands at less than 5 percent (Thomson and Hoem 1998; Miettinen 2010). 
The period TFR increased modestly after the early 1980s, peaking in 2008-2010, and then began declining, arguably as a result of the recent economic recession. Apart from Iceland which retained TFR around replacement level (reaching 2.23 in 2009, but declining thereafter), Norway has the highest completed fertility (Andersson et al. 2009) as well as lowest ages at first birth and lowest proportion of childless women (around 12 percent for women born in the late 1960s). Denmark had the lowest fertility in the 1980s with TFR falling briefly below 1.4, but is now close to Finland with a TFR of 1.73 in 2012. Finland exhibits higher childlessness, around 19 percent for the youngest cohorts now completing their fertility (Miettinen 2010). Projections by national statistical offices published in 20122013 assume fertility rates just below replacement levels by mid-century, reaching in 2050 1.89 in Norway, 1.91 in Sweden and 2.00 in Iceland, according to the medium variant (online databanks of Statistics Sweden, Statistics Norway and Statistics Iceland accessed 20 June 2013).

Higher fertility in Nordic countries is often explained by generous family policies and high levels of gender equality (Rønsen and Skrede 2010, see also Section 2.5). Availability of local childcare has been shown to increase fertility at all parities (Rindfuss et al. 2010), while family policy in the form of childcare allowance buffered Finnish fertility at higher parities during the severe economic recession in the early 1990s (Vikat 2004). Gender equality also appears to promote family formation in the region, but not necessarily progression to third or later births (Duvander et al. 2010). The relationship between socioeconomic status and number of children is positive among men and neutral or positive among mothers (Kravdal and Rindfuss 2008; Lappegård et al. 2011).

\subsubsection{Southern Europe}

Fertility in Southern Europe has undergone many major changes during recent decades. Fertility rates remained among the highest in developed countries well into the late 1970s. In 1975 the TFR ranged from 2.80 in Spain and 2.75 in Portugal to 2.32 in Greece and 2.21 in Italy. Since the mid-1980s, however, all these countries experienced a dramatic fertility decline. After 1992, Italy and Spain became the first countries in Europe to experience "lowest-low fertility"-a TFR below 1.3 (Kohler et al. 2002) —with Greece joining them in the late 1990s. The decrease was initially more moderate in Portugal. Tempo effects associated with the rapid expansion in educational attainment and subsequent entry of women into the labor market are estimated to have depressed TFR by about 0.3 during the late 1990s, although this influence decreased thereafter (see VID 2012 for Spain).

Furthermore, high unemployment rates during the late 1980s and early 1990s contributed to fertility postponement (Adsera 2011): indeed, the mean age at first birth in Spain and Italy, about 30, is now among the highest in Europe. Childlessness has been rising rapidly but still remains at less than 20 percent. Surveys on fertility intentions indicate only a low proportion of women desiring no children (Goldstein et al. 2003; Testa 2012a). Since the 1990s almost all Southern European countries have experienced a rapid increase in the share of out-of-wedlock children, an uncommon occurrence until very recently (Surkyn, and Lesthaeghe 2004; Delgado et al. 2008). However, this trend is very unevenly distributed - in 2011 non-marital births comprised 43 percent of all births in Portugal, 37 percent in Spain, 23 percent in Italy, but only 7 percent in Greece. 
The consequences of the dramatic decline in fertility are evident in the age composition of the population (OECD 2012). The current imbalance between births and deaths was compensated by large immigration flows between the mid-1990s and late 2000s, particularly to Spain and Italy, reversing the migration outflows of the 1960s and 1970s. Though migrants display on average higher fertility than natives, this difference diminishes over time and gives only a minor boost, if any, to the TFR (Roig Vila and Castro-Martín 2008, see also Section 2.6). The recent economic crisis has had a strong impact in Southern Europe-particularly among recent migrants. Fertility is down from 2008 levels (see also Box 3), accompanied by a decrease of immigration flows or even net outflows in Spain.

\subsubsection{Middle East}

In 1950, the total fertility rate in the Middle East stood at 7.0, higher than in other world regions including Sub-Saharan Africa. The lowest TFR was recorded in Lebanon (5.7) while the highest was in Yemen, which had fertility above eight children per woman. The figures for such countries as Iran, Turkey, Kuwait, United Arab Emirates, and Qatar were also remarkably high at around 7.0 (UN 2011; Dyer 2008). High fertility rates prevailed in the region throughout the 1950s and 1960s and were noted by Kirk (1966) who argued that Muslim countries as a group were experiencing only the early stages of demographic transition.

Fertility decline in the Middle East commenced in the mid-1960s, and by 1980 the period TFR had slightly declined to around 6.3 in the region as a whole. However, many countries experienced an accelerated decline during the 1980s, so that by 2010 the TFR in the region was below 3.0. But the regional average masks wide cross-country differences. Iran's sharp fertility decline since the mid-1980s is, for example, unique: the TFR declined from around 6.5 in 1985 to around 2.0 in 2000, and further decreased to around 1.8 in 2006 (Abbasi-Shavazi et al. 2009b). Recent studies have shown that fertility in Iran has been stabilized and cohort fertility rate has been estimated to around 2.0 (Hosseini-Chavoshi et al. 2013). The recent fertility levels in several other countries in the region have also been much lower than those recorded in the 1980s. For example, during 2005-2010 the TFR in Qatar (2.2) and Turkey (2.2) was slightly higher than the figure in United Arab Emirates (2.0) and Lebanon (1.6); all of these countries have reached fertility around or below replacement. In contrast, Yemen (4.9) and Iraq (4.4) still retained very high TFR levels (UN 2013). Indeed, many of these countries are included in Chapter 4 of Lutz et al. (forthcoming) which deals with 'higher' fertility settings.

The high Muslim fertility observed in the past led some scholars to believe that religion and fertility were more closely correlated for Muslims than for any other religious groups (Lucas and Meyer 1994: 65; Jones and Karim 2005). However, the sharp and accelerated fertility decline of recent decades does not support this hypothesis (Chamie 1981: 79; Abbasi-Shavazi and Jones 2005: 35-36; Karim 1997; Rashad 2000; Eberstadt, and Shah 2012). ${ }^{6}$ The decline of fertility in recent decades appears to be much more clearly linked to

\footnotetext{
${ }^{6}$ Courbage (1999) argued that high fertility in some of the Middle East countries has been linked to their oildriven economy that allowed governments to establish subsidies leading to the reduction of the costs associated with children and reinforcing preferences for large families. The fall of the oil price in the 1980s followed by cut-backs in subsidies, also coincided with the fall of fertility in these countries.
} 
urbanisation, advancement of women's education (Abbasi-Shavazi and Torabi 2012; Lutz, et al. 2010), and rising aspiration for women who seek employment (Jones 2012), as well as an accentuation of children's education and opportunities, access to media, changing family ideals, decline of infant mortality, and the introduction of effective contraception. Finally, there are indications that universality of marriage is also being questioned (Rashad et al. 2005; Torabi et al. 2012), with divorce rising in most countries (Singerman 2007).

Fertility trends in Israel warrant special attention - it is a society more developed and more affluent than many countries in Europe and East Asia, yet it shows a persistence of high fertility and fertility intentions, with the period TFR stabilizing around 3.0 since the mid1980s (CBS 2011). This is achieved through a unique combination of pronatalism (policies supporting large families), cultural, ethnic and religious diversity, competition and polarisation. Some population subgroups, especially the "ultra-religious" Jews, maintain traditional values in tandem with very high fertility (Bystrov 2012, DellaPergola 2007, Fargues 2000). Such unique conditions will not be repeated elsewhere, but the same elements may contribute to higher fertility and possibly also a return of more traditional values in some post-transitional settings in the future.

The social, cultural, economic, and ethnic diversity of the region implies that Middle East countries will retain different fertility patterns, although recent trends and the experience of other countries suggest that further declines in fertility may be likely. Despite this, some countries in the region, especially Iran and Turkey have reverted to actively pro-natalist rhetoric and policies (Roudi 2012) which could interrupt or partly reverse fertility decline. However, pro-natalist policies have not been implemented in these two countries, and thus, the outcome of these new policies are yet to be seen.

\subsubsection{East Asian Countries and Territories}

Fertility decline in Asia began in the late 1940s in Japan where the TFR dropped from 4.5 in 1947 to 2.0 in 1957. It continued a slow decline to 1.5 in 1994 and 1.3 in 2002 (Retherford and Ogawa 2006). Fertility was high in Singapore, South Korea, and Taiwan in 1960 with TFRs of around 6.0, but declined rapidly in the 1970s and 1980s (Choe and Park 2006; Tsuya et al. 2009; Yap 2009). In Singapore, fertility dropped to replacement level by 1975, to below 1.5 in 1998 and to below 1.3 in 2003 (Yap 2009). TFR in South Korea and Taiwan reached below replacement level about a decade later than in Singapore, in 1983 and 1984 respectively. The decline then proceeded rapidly and the TFR in these four countries dipped below 1.3 in the early 2000s. Since then TFR in Japan climbed slightly to 1.4 in 2010 but it remained at ultra-low level in other countries, reaching 1.2 in Singapore and South Korea and 0.9 in Taiwan (statistical offices, various countries and years). Indeed, national statistical offices in the region assume that fertility in the region will stay very low (Basten 2013a). Fertility trends are considerably less certain in North Korea, where only limited data are irregularly released by the government and official institutions; Spoorenberg and Schwekendiek (2012) show the period TFR around replacement level in two Census years, 1993 (2.16) and 2008 (2.00), with a possible intermediate dip during the periods marked by famine and economic collapse.

Rapid economic development, increasing level of education among women, their higher labour force participation and effective national family planning programs initiated in the 
1960s (excluding Japan) are considered to be major forces behind the rapid fertility decline in all of these countries (Choe 2006; Tsuya et al. 2009; McDonald 2009). Fertility declines in recent decades are mostly due to delayed onset of childbearing, resulting in part from increasing age at first marriage combined with still low levels of non-marital births (Frejka et al. 2010; Jones 2007; Bumpass et al. 2009). Persistent gender inequality marked by limited involvement of men in household work and childrearing have contributed to these trends (see Box 2).

The importance of having a son while fertility levels were falling to below replacement level, combined with modern medical technology that allowed parents to identify the sex of fetus, and easy access to induced abortions produced an unusually high sex ratio at birth in South Korea, Taiwan, and Singapore before the preference began to weaken (Chung and Das Gupta 2007). In contrast, fertility behaviour in Japan is not associated with son preference (Park and Cho 1995).

In Japan, South Korea, Taiwan, and Singapore, higher education for men is associated with higher probability of marrying, but also results in a slower pace of marriage. Among women, higher education is associated with lower probability of ever marrying and slower pace of marriage. As a result, a large proportion of men with low levels of education and women with high levels of education remain unmarried into their late $30 \mathrm{~s}^{7}$ Education differentials in marriage notwithstanding, fertility decline proceeded almost simultaneously in most social groups. Especially in South Korea there was a remarkable convergence in fertility by education, indicating that rising education level contributed only a little to the observed fertility decline (Yoo 2013). At the same time, Anderson and Kohler (2012) argued that under competitive conditions typical for East Asia, the desire of parents to provide their children with top education makes children very costly in terms of both time and money. This "education fever" constitutes an important force behind very low fertility in the region.

\subsubsection{China}

While a notable fertility reduction had already been observed in some Chinese cities in the 1950s and 1960s (Lavely and Freedman 1990), nationwide fertility decline did not begin until the early 1970s under the later, longer, fewer family planning policy. During that decade, China's TFR fell from about 6.0 to about 2.5 children per woman. In the $1980 \mathrm{~s}$, following the enactment of more proscriptive family planning regulations, the TFR fluctuated between 2.3 and 2.9 (Yao 1995). These fluctuations were largely observed in period TFR, whereas cohort fertility continued to decline during this period (Guo 2008; Zhao and Guo 2010). China's fertility recorded another sharp reduction in the early 1990s when the TFR fell to below replacement. Since then it declined further to around 1.6 in 2000. While many studies have suggested that China's fertility has remained that low or fallen to a lower level in the first decade of the 21st century (Cai 2008 and 2010; Guo 2009; Retherford et al. 2005; Scharping 2005; Zhao and Zhang 2010; Zheng et al. 2009), there is some controversy over the 'true' fertility rates of China (see Box 1). Morgan et al

\footnotetext{
${ }^{7}$ Since the late 1990s new marriage behaviour has emerged in Taiwan, Singapore, and South Korea where men, especially with lower levels of education, are increasingly marrying foreign-born women (Kim 2007).
} 
(2009) estimate that the 1976-80 birth cohorts will reach fertility well below replacement threshold and will have about 1.7 births per woman.

\section{Box 1: Finding China's period fertility rate}

While the low fertility rates reported in the text are supported by the preliminary results of China's 2010 census which was of a high quality according to the National Bureau of Statistics (Ma 2011), the rates differ markedly from those reported by China's National Population and Family Planning Commission who suggests that China's TFR has been 1.8 since the mid-1990s (National Strategy on Population Development Research Group 2007). The UN's 2010 World Population Prospects (WPP) stated that China's TFRs were 1.80, 1.70, and 1.64 for 1995-2000, 2000-2005, and 2005-2010, respectively (UN 2011). However, China's 2010 census recorded only 222 million children aged $0-14$. If these results were indeed accurate, China's TFRs for 1996-2010 would be significantly lower than those suggested by both the Chinese government and the United Nations Population Division (Cai 2011; Zhao and Chen 2011). In line with that, the 2012 WPP released in 2013 lowered the estimate of the TFR in China in 2000-2005 to 1.55 (UN 2013) and changed the projected TFR trajectory (Sobotka et al. 2013).

This confusion arises partly from the fact that China's demographic data were often collected by different government departments for different purposes, which resulted in some inconsistencies. In addition, the sharp fertility reduction in the early 1990s was not expected at the time, which led government officials and researchers to believe that the reported low fertility was caused by serious under-registration (Zeng 1996). Some demographers questioned this notion and further examined China's fertility decline in recent years (Cai 2008 and 2010; Zhao and Zhang 2010). Similar changes in how the data are viewed have not yet been observed among policy makers. Officially endorsed fertility figures are most likely to have over-estimated China's fertility for more than a decade.

China's unique history of family planning regulations has undoubtedly impacted its recent demographic history. The later, longer, fewer family planning programme played a major part in driving down fertility in the 1970s. However, recently some scholars have argued that the macro-level effect of the restrictive 'one-child policy', introduced in 1978 and applied in 1979 has been overstated (Cai 2010). Firstly, the policy was not universally implemented, with many exceptions made for rural areas, ethnic minorities, or couples with a daughter. Indeed, Gu et al (2007) show that in the late 1990s 11 percent of couples were allowed to have two or three children and as many as 54 percent were allowed a second child if their only child was a girl. ${ }^{8}$ Second, the fertility decline seen in much of China echoes that seen elsewhere in much of East Asia (see Section 1.4.9). As such, economic and social development can be argued to be a major driver as much as policy (Wang et al. 2013). There is currently a significant policy debate regarding ending or at least reforming the family planning restrictions.

\footnotetext{
${ }^{8}$ This has not prevented, however, the spread of sex-selective abortion, leading to skewed sex ratios at birth (SRB, males per hundred females), estimated at around 120 in 2005-7 (Das Gupta et al. 2009: Figure 1). Mini-census data for 2005 show that in 5 out of 31 provinces there were over 125 males per 100 females born as of 2005, while only three provinces reported "normal" SRBs around 105 (Eberstadt 2011).
} 
In East Asia and in China in particular, growing evidence indicates a deviation from the two-child norm prevalent in Europe and North America. In China, 2001 national data show a mean desired number of children among married women aged 20-29 of 1.50 for urban areas and 1.75 for rural women (Zhang 2004). A number of regional surveys in both urban and rural settings have reported ideal family sizes around these figures (Basten and $\mathrm{Gu}$ 2013). In Taiwan and Hong Kong, surveys of young people indicate levels similar to China, of around 1.5-1.7 (Basten 2013b). While deliberate under-reporting of fertility ideals is widespread in China, the similarities to Hong Kong and Taiwan are indicative of such low ideals being 'genuine' in China.

China's fertility is likely to stay at current low levels - or decline further-even if family planning restrictions are relaxed (Zheng et al. 2009). Like many other populations in East Asia, China is experiencing a significant change in its reproductive culture. China's traditional marriage patterns are going through a great transition, with age at marriage and proportion remaining single having increased and likely to increase further. Divorces, sex outside marriage, and same sex partnering are likely to become ever more acceptable (Wang and Zhou 2010). These changes are likely to spread from urban to rural areas. All of these factors could lower fertility, although some of the fertility declines may be caused by the temporary effect of rising age at childbearing.

\subsection{Regional Trends: Common Issues and Key Factors}

This overview of regional fertility developments shows that a trend toward low fertility has become a defining feature of the demographic landscape in a number of countries whose fertility levels were considered to be "too high" only two or three decades ago. With the notable exception of sub-Saharan Africa, all major global regions appear to be firmly set on a path to low fertility. Furthermore, the epicentre of lowest fertility moved away from the "Western World" to East Asia and some formerly communist countries in Central and Eastern Europe.

Paradoxically, some of the countries that were at the forefront of the march to subreplacement fertility in the 1960s-1970s, especially the Nordic countries and the United States, now register close-to-replacement and relatively stable (or even slightly rising) cohort fertility rates (Sobotka 2008a; Myrskylä et al. 2013, see also Section 1.4). This evidence gives rise to the possibility that countries with very low fertility may eventually witness a recovery to levels close to replacement once broader societal conditions become more conducive to having children (Myrskylä et al. 2011), especially if the predominant family size ideal remains fixed at around two children. Equally possible, however, are other alternative scenarios, either of a continuing diversity in low fertility as currently seen in Europe, or a global move to very low fertility levels, with widespread childlessness and a widespread one-child family ideal (see also Section 5.2).

Having outlined major trends in contemporary low fertility settings, the next section explores some of the key factors driving these patterns as highlighted by the experts and the literature. 


\section{Explaining Past and Future Fertility Trends: Theories and Empirical Evidence}

\section{1 'Meta-theories' of Low Fertility and Family Changes}

There are many overarching theories that have been employed to explain recent fertility patterns and differences in the countries covered in this working paper. The very basic contour of the global fertility decline has been provided by the concept of the demographic transition. This 'theory' of population, which has been applied, adjusted and critiqued continually since first proposed in the mid-1940s (Notestein 1945) envisages a shift from high mortality and high fertility to stabilisation at low levels of mortality and fertility around replacement level. However, the presence of below-replacement fertility both before and after the publication of the theory suggests that it has relatively little - in its unmodified form - to say concerning currently low fertility settings.

One of the most widely used concepts is an overarching narrative of the Second Demographic Transition (SDT) (van de Kaa 1987 and 1994; Lesthaeghe 1995 and 2010). This theory links dramatic changes in family behaviour - including sustained belowreplacement fertility, extensive postponement of marriage and childbearing, and the rapid rise of cohabitation and births outside of wedlock - with a transformation in values, emphasis on individual self-fulfilment, the massive rise in higher education and changing gender roles. A closer investigation of the link between the progression of the SDT and fertility revealed a strong correlation with childbearing at higher reproductive ages (the 'recuperation' component, Lesthaeghe 2010), and an unexpected positive correlation between the SDT and the level of period fertility rates in Europe (both conventional and adjusted; Sobotka 2008a). The SDT was also shown to be closely associated with the approval of voluntary childlessness (Merz and Liefbroer 2012).

The decline in marriage and the rise in partnership instability have been surprisingly little connected with fertility declines, at least in Europe. In most of the traditional low-fertility countries (with the important exception of Japan), marriage has become ever less relevant for reproduction and childbearing has increasingly shifted outside marriage, especially to cohabiting unions. In 2011, almost $40 \%$ of births in the European Union took place outside marriage; in the United States the corresponding share was $41 \%$ in 2010. Eight European countries, including Bulgaria, France, Sweden and Slovenia, registered more than a half of all births outside marriage; in Spain, where only one out of ten births took place outside wedlock in the early 1990s, 37\% births were extramarital in 2011. European countries with high shares of non-marital births have, on average, higher fertility rates, suggesting that permissive attitudes to less conventional living arrangements go hand in hand with more opportunities for women and couples to form a family (Billari and Kohler 2004; Sobotka and Toulemon 2008; see also Section 1.4.3 on Western Europe). The spread of less stable family forms together with rising divorce rates and, in some countries, higher frequency of single motherhood, increased the exposure of children to the experience of living with one parent only, typically with the mother (Heuveline et al. 2003, Perelli-Harris et al. 2012). The evidence on the impact of union instability on fertility is mixed or slightly negative (Thomson et al. 2012, Bélanger et al. 2010) as three contrasting mechanisms can be identified. Union break-up means a disruption in family life which negatively affects the likelihood of having another child in the subsequent period when most of the women and men live without a partner. However, the formation of a new union provides an 
opportunity to have another child, a decision which also signals the commitment of the new partners to each other and is often expected to "cement" their relationship (Griffith et al. 1985). At younger ages, partnership instability may lead to the delay of family formation, as many women and men are unable or unwilling to form a lasting union, which is often seen as a precondition for parenthood. On balance, the aggregate effect of union instability depends on the age at first union formation, family stage (and age) in which divorce or dissolution takes place, the share of women who re-partner after separation and the speed with which these new partnerships are formed (e.g., Thomson et al. 2012, Beaujouan and Solaz 2012).

The finding on the positive correlation between SDT progression and fertility rates is also related to the debate on the possible reversal of the relationship between economic and social development and fertility, fuelled by the studies suggesting that at advanced levels of development (as measured by the GDP level or by the Human Development Index (HDI)) fertility decline stops or even reverses. These studies (see Myrskylä et al. 2009; OECD 2011; Luci and Thévenon 2011) have turned on its head the widely accepted notion that more development generally equals lower fertility. However, the hypothesis on the reversals between development and fertility is not universally accepted: for example, these studies have been criticised for the indicators used, countries omitted from the analysis, for relying on the period TFRs that are affected by tempo effect and other data issues (e.g. Furuoka 2009). In a more recent study revisiting their earlier work, Myrskylä et al. (2011) indicate that the development-fertility reversal can also be traced with the completed fertility rates for women born in 1970. Furthermore, they show that the positive effect of development (HDI index) on fertility is limited to childbearing at later ages $(30+)$, suggesting that there is a positive association between development and the recuperation of the previously postponed births. This link is conditioned by the level of gender equity in the society, with countries scoring low on gender equality registering declining fertility even at very advanced levels of development (see also Section 2.3.3).

Another influential notion in most international projections is the concept of convergence between countries of fertility to a given level. This idea has for many decades informed the long-term population projections produced by the United Nations (which envision that fertility will universally rise towards the replacement level) and prevailed in long-term fertility scenarios beyond 2050 by the WIC as described in Section 5.2. However, the extent to which convergence of fertility in the long run should be interpreted as a metatheory in its own right rather than a concept designed for statistical and computational convenience is an open question.

Related to the previous concept is an idea of 'feedback' effect. Demeny (2004:142) observed that the UN's medium projections 'implicitly assume that the trend toward lower birth rates... will elicit negative feedbacks that by the middle of the twenty-first century will bring fertility back to near-replacement levels everywhere." This is derived from an implicit assumption of a homeostatic response by humans to ensure continuity in (at least) replacement levels of population. However, Demeny also observed that positive feedbacks were "equally plausible... reinforcing a tendency for further falls in fertility." As a consequence of population ageing, individuals needing to provide for their old age have an increased incentive to accumulate human capital and savings and to acquire pension benefits. This could result in the institutionalisation of many of the elements discussed above that are driving low fertility in East Asia. Indeed, such a situation has been 
formalised in the so-called 'Low Fertility Trap' hypothesis (Lutz et al. 2006). First, population decline fuelled by sustained low fertility leads to fewer women of reproductive age and, hence, fewer births. Second, through socialisation and social learning, family size ideals are influenced by the experiences of young people who grow up in an environment with few children (e.g. few siblings, absence of larger families). Hence, children will figure less prominently in their own image of a desirable life. Finally, rapidly ageing societies drive pessimism among the young regarding their own economic opportunities. This, combined with widening consumption opportunities, can lead to an ever greater gap between aspirations and income - a gap which childbearing would only further exacerbate. Should each of these conditions be met, then reversing fertility decline would prove to be extremely difficult.

When considering heterogeneous concepts including those outlined above, it is important to examine the contribution of more specific drivers in fertility change - in other words, the issues which underlie these grand theories and how they interact with choices over the life course including timing of fertility. For example, many features of the SDT are barely nascent in much of East Asia. Therefore, we explore in greater depth some of the main issues and determinants behind the fertility changes outlined in Section 1 and, ultimately, those further explored in the survey of experts. These include the impact of fertility postponement; cultural factors relating to ideals and intentions, religion and gender equality; family policies; immigration; biomedical aspects and education. Before we do so, however, it is crucial to consider the effect of fertility postponement upon how we measure contemporary fertility.

\subsection{Fertility Postponement and its Impact on Period Fertility}

Across the developed world, parenthood has been shifted to ever-higher ages (Kohler et al. 2002, Sobotka 2004b). In Western, Northern and Southern Europe as well as Japan, the mean age of mothers at first birth has reached 28-30 years, 4-6 years later than in the early 1970s (Schmidt et al. 2012). The frequency of childbearing has increased most rapidly at advanced reproductive ages, including women aged over 40 (Sobotka et al. 2007; Prioux 2005).

This "postponement transition" (Kohler et al. 2002) has multiple roots. The expansion of higher education and the resulting later age of completing education and entering of the labour market (as well as the concomitant increase in the share of women entering the labour market) have been repeatedly identified as important factors (Blossfeld and Huinink 1991; Gustafsson and Kalwij 2006; Goldin 2006; Ní Bhrolcháin and Beaujouan 2012). Other factors include the spread of hormonal contraception, rising economic and employment uncertainty in young adulthood, decline of marriage, the rise of more unstable forms of partnerships, and the spread of new values incompatible with parenthood (Kohler et al. 2002; Goldin and Katz 2002; Sobotka 2004a; Mills and Blossfeld 2005; Goldin 2006; Mills et al. 2011; Leridon 2006; Nettle 2011).

This fertility postponement temporarily affected period fertility rates, as some births that would otherwise have taken place in a given year were shifted into the future, potentially leading to more dramatic assessments of fertility change than would otherwise be the case. The resulting tempo effect (or tempo distortion), which is the difference between the 
observed and hypothetical fertility in the absence of birth postponement, has become widely debated in the literature (Luy 2011; van Imhoff 2001, Schoen 2004; Ní Bhrolcháin 2011) and has emerged as one of the key explanations for very low fertility levels observed in many rich societies (Kohler et al. 2002; Sobotka 2004b; Bongaarts and Sobotka 2012). A number of methods have been proposed to account for the tempo effect and compute tempo-adjusted period fertility rates (e.g., Bongaarts and Feeney 1998 and 2006; Kohler and Ortega 2002; Bongaarts and Sobotka 2012). The Bongaarts and Feeney (1998) method became most prominent (although not universally accepted; see e.g. Schoen 2004). As a result of tempo effect, depressed period fertility rates are often incorrectly interpreted as implying similarly low levels of cohort fertility in the future. Sobotka and Lutz (2011) demonstrate that these interpretations may lead to dramatic assessments of fertility trends. Empirical analysis based on tempo-adjusted period fertility indicators suggests that in the absence of the shifts in fertility timing, the period TFR in the European Union around 2008 would have been by almost 0.2 higher, at 1.77, than the observed TFR of 1.59 (VID 2012). Large cross-country differences exist, however, in the estimated size of this effect (Goldstein et al. 2009, Bongaarts and Sobotka 2012, VID 2012).

Fertility trends will continue to be affected by changes in the timing of births. In Europe the pace of increase in the mean age at first birth diminished after 2000 and the "postponement transition" was seemingly coming to an end in some countries by 2008 (Bongaarts and Sobotka 2012). However, the recent economic recession has brought a renewed postponement of births, leading to additional downward pressure on period fertility (see Section 2.4 and Box 3). In contrast, developing and middle-income countries with low fertility typically report earlier ages at childbearing with most only beginning to experience a shift towards later parenthood, which may depress their period TFRs for decades to come (Bongaarts 1999, Rosero-Bixby et al. 2009). Exceptions, such as Iran, do exist where low TFR and early childbearing co-exist. It is likely that a number of such middle-income countries will eventually reach a late childbearing pattern with a mean age at first birth over 30 (Abbasi-Shavazi et al. 2009b; Hosseini-Chavoshi et al. 2013). ${ }^{9}$ More countries and subpopulations will also move closer to the estimated upper limit, with the mean age at first birth around 32 (Goldstein 2006), after which the late timing of births might start having a strong negative impact on completed fertility and childlessness.

Postponement of childbearing has a critical biological dimension. The higher a woman's age when she attempts to become pregnant, especially above 35 years, the longer the waiting time for a pregnancy to occur, resulting in a lower chance of achieving a pregnancy and a higher risk of miscarriage if there is a pregnancy (Schmidt et al. 2012; Menken 1985; see also Section 2.7.1). Furthermore, man's age has been identified as an independent risk factor for infertility (Dunson et al. 2004; Section 2.7.2). Consequently, couples delaying childbearing face an increased risk of not realizing their childbearing plans due to lower completed fertility and higher involuntary childlessness (Leridon 2008, te Velde et al. 2012; Section 2.7.1 and 2.7.3).

\footnotetext{
9 At present, a number of countries approach the mean age of mothers at first birth of 30, with Switzerland (302 in 2011) being the first larger country to reach this threshold, followed, closely by Spain (30.1 in 2011) (computations based on Eurostat 2012).
} 
Rising infertility at higher childbearing ages implies an increase in the demand for assisted reproduction (ART) as well as elevated multiple birth rates (Tarín et al. 1998, Schmidt et al. 2012; Section 2.7.3). In addition, higher maternal and paternal ages are linked to an increased risk of pregnancy complications and adverse reproductive outcomes. However, positive influences of rising age at childbearing include psychological maturity, lower income loss for the mothers, and a higher level of happiness among the parents (Joshi 2002, Miller 2011, Myrskylä and Margolis 2012).

\subsection{Cultural and Social Forces in Fertility Ideals, Intentions and Reality}

\subsubsection{Fertility Intentions}

Where modern contraception makes it easy for couples to prevent unwanted pregnancies, fertility preferences are key determinants of reproductive behaviour and fertility trends (Bongaarts 2001; Schoen et al. 1999; Billari et al. 2009). Yet, the number of children individuals intend to have often surpasses the number they actually achieve by the end of their reproductive career (Testa 2012a). Constraints on meeting intentions include not having a suitable partner, experiencing partnership instability, fecundity impairments and unexpected events that may lead to a downward revision of reproductive intentions (Iacovou and Tavares 2011; Barber 2001; Liefbroer 2009). While childbearing intentions can also move upward, especially as family size grows, these shifts are less frequent than downward adjustments.

A two-child family appears to be the dominant ideal of Europeans, which has become entrenched over time according to the Eurobarometer surveys conducted in 2001, 2006, and 2011 (Testa 2006 and 2012a; Spéder and Kapitány 2009, Adsera 2006). The mean intended family size is also concentrated at around two children in all European countries, with a notable exception of Austria and Germany, which show, according to some surveys, low ideal and intended family size (Goldstein et al. 2003). The temporal trend is marked by a remarkable stability with the exception of Greece and Portugal, where an abrupt and pervasive decline in family size ideals has been observed between 2006 and 2011. This decrease is most likely linked to the recent economic recession, which was particularly severe in these countries (Testa 2012a).

The Eurobarometer survey, which is only cross-sectional, shows that more than one third of European women and men stop childbearing with fewer children than initially desired (Testa 2012a). In addition, the share of people reporting a family bigger than the size actually desired amounts to 10-15 percent. Hence, the use of lifetime fertility intentions for forecasting purposes has its limits due to considerable challenges in measuring both intentions and their uncertainty (Morgan 2001). Negative reproductive intentions (not wishing to have a child) are usually more reliable predictors of subsequent behaviour than the positive ones (Rovi 1994).

Because of a lack of adequate data, most studies on fertility are based upon the female perspective. However, some evidence on gender differences in intentions exists. In Europe, women generally indicate a slightly larger family size ideal than men, and they also display smaller inconsistency between ideal and actual family size (Testa 2012a). Analysis based on couple data show that men and women have equal influence over the final reproductive decision (Thomson and Hoem 1998; Thomson 1997) and therefore have equal power in 
negotiation if a conflict arises between them (Jansen and Liefbroer 2006). However, the emotions leading up to the final decision are often gendered. For instance, women's baby longing has stronger influence on the decisions to have a second and third child compared to men's (Rotkirch et al. 2012). In settings characterised by low gender equality where women have the main or the sole responsibility for childcare, such as in Italy and Austria, women also have a greater influence on childbearing decisions than men at the early stages of the family formation process (i.e. at parities zero and one) (Testa et al. 2011; Testa $2012 \mathrm{~b}$ ). This may also be the case in countries with high share of single mothers, where women may decide to have a child "on their own". Typically, the disagreement between partners favours the one who does not want to have a child. This couple approach increases the predictive power of fertility intentions (Beckman et al. 1983).

In the US, the aggregate correspondence between intended and actual fertility is generally higher than in Europe, largely due to high share of unplanned pregnancies and unintended births (Section 1.4.1). Furthermore, there is growing evidence in East Asia that the twochild norm that is dominant in Europe may be much more fluid in that region (Basten 2013b). This could have profound consequences for future fertility trends (Section 1.4.10).

\subsubsection{Religion}

A review of studies referring to the 1950s and early 1960s documented the higher fertility of Catholics compared to other religious groups and the non-affiliated for Western countries (Jones und Nortman 1968). This was mainly attributed to the prohibition of artificial contraception by the Catholic Church. Marked fertility differences by religious affiliation had by-and-large disappeared by the 1970s (Westoff und Jones 1979; Derosas and van Poppel 2006), but a gap to the non-affiliated persists (Philipov und Berghammer 2007; Hackett 2008). Moreover, some religious minorities diverge from average fertility levels (Skirbekk et al., 2010). Muslims have a higher number of children than members of other religions in Europe but there is convergence over time (Westoff and Frejka 2007; Pew Research Center 2011). Religious affiliation is an important correlate of family size in parts of Asia (Morgan et al. 2002), but less so in some Latin American countries (Heaton 2011). Higher levels of fertility are observed in many countries with Muslim majorities, even though they have fallen over recent decades (Pew Research Center 2011).

Studies report clear fertility differences by religious intensity for Western countries, often measured by church attendance or self-assessed religiosity (Philipov and Berghammer 2007; Zhang 2008). In explaining why religious people have larger families, scholars refer to the influence of religious teaching, the role of church-based social networks and the coping function of religion (Chatters and Taylor 2005). The socio-economic traits of adherents also matter as does the status of the religion within the social and economic order of society (Goldscheider and Uhlenberg 1969; McQuillan 2004).

In some contexts, religious fertility differences have a crucial impact on the future religious composition of a population (Hout et al. 2001; Kaufmann 2010; Skirbekk et al. 2010). The way in which the share of religious people in a country is related to fertility rates is, however, unknown. One may argue that the erosion of religion should yield a negative effect on fertility, but examples of secular countries with high fertility rates (e.g. Sweden, France) and vice versa suggest that the link may be more complex. 


\subsubsection{Gender Equality}

At the societal or institutional level gender equality includes whether women and men are offered similar opportunities for educational attainment, economic participation, health and survival, and political empowerment. When women are offered similar educational and employment opportunities as men but these opportunities are severely restricted by having children, women react by having fewer children and having them later in life. Empirical evidence connecting gender equality at the societal level to fertility faces methodological challenges (Mills 2010) and has been less rigorous. In a large meta-analysis of the central reasons for birth postponement in advanced societies, Mills et al. (2011) suggested that gender equality plays a key role.

Gender equality can be examined at the societal (political empowerment), institutional (provision of child care and parental leave), household (division of labour) and individual level (gender role attitudes). In the latter two cases, the term "gender equity" is often used, referring to "fairness and opportunity rather than strict equality of outcome" (McDonald 2013: 983). A number of aggregate indices measuring the status of women and different aspects of gender equality have been proposed since the mid-1980s (Bericat 2012). Gender systems determine the division of labour and responsibilities between the sexes, as well as the rights and responsibilities allocated to men and women, and are therefore considered crucial for understanding fertility patterns (McDonald 2013, 2000a, 2000b; Mason 1997).

The literature on household gender equity stems largely from Becker's (1981) argument that women's increased economic independence results in higher relative opportunity costs of childbearing via forgone earnings during childbearing and care periods, thereby generally lowering fertility. Miller (2011) demonstrated that a year of delayed motherhood increased women's lifetime earnings by 9 percent. Additional research has shown that unequal gender roles in the household and, specifically the perpetuation of the male breadwinner/female homemaker model, force women to choose between a career without children or remaining in the home (Oláh 2003; Miller et al. 2004; Mencarini and Tanturri 2004; Cooke 2004; Mills et al. 2008). The lack of sustained improvement in gender inequality in the household is considered as a core underlying determinant of very low fertility (McDonald 2000a and 2000b), particularly in East Asia (See Box 2). This discrepancy between new public opportunities and sustained domestic obligations is sometimes referred to as the 'incomplete gender revolution' (Esping-Andersen 2009).

Empirical results linking egalitarian gender role attitudes to fertility are mixed, particularly in relation to men (Westoff and Higgins 2009; Goldscheider et al. 2010). Some studies suggest that men's more gender-egalitarian roles result in higher fertility (Kaufman 2000; Puur et al. 2008), while others find the opposite (Westoff and Higgins 2009), and still others identify a U-shaped effect, where men with either traditional or egalitarian views report higher ideal family sizes (Miettinen et al 2011). 


\section{Box 2: Living arrangements, gender roles, and their relationship to fertility in East Asia}

Current family behaviour including marriage, childbearing, gender roles, and living arrangements in Japan, China, South Korea, Singapore, and Taiwan reflect both the influence of the Confucian family tradition and the rapid economic and social changes of the second half of the $20^{\text {th }}$ century.

The family system based on Confucian ideals emphasises proper roles and relationships based on gender, generation, and age. The basic purpose and function of the family was preservation of lineage and prosperity. Under a family system based on patrilineal descent, the most important obligation of a person was to marry and produce a son. Marriage was mandatory, and early marriage was common. Co-residence with parents was the norm for both men and women until marriage, and for the eldest sons even after marriage. A woman's position in a family changed drastically from being a daughter to being a daughter-in-law with low status upon marriage; however a married woman attained a high status within the family by bearing and rearing a son (Choe 2006; Choi 1970; Mason, Tsuya, and Choe 1998; Tsuya et al. 1991).

Meiji restoration in Japan in the $19^{\text {th }}$ century and the establishment of republics in other East Asian countries in the twentieth-century provided the legal basis for equal rights for women. It took until the second half of the $20^{\text {th }}$ century, however, for substantial changes in family behaviour and gender roles to occur, in tandem with rising levels of education for women, rapid economic growth, urbanization, and greater geographic mobility. Now, women and men are marrying at increasingly later ages, and the proportion of people who never marry is rising (Jones 2007). Typical family size has decreased to two or fewer children and it has become less common for grown children to reside with their parents. Most women work outside home before marriage, and a substantial proportion continue to work after marriage and having children.

However, the persistence of traditional norms in East Asian countries has resulted in patterns of family behaviour different from those experienced in the West. The strong patrilineal and patriarchal family traditions, for example, have kept out-of-wedlock childbearing at very low levels (Bumpass et al. 2004; Bumpass et al. 2009; Jones 2007), with the civil code in Japan requiring registration of a birth of a child in his/her father's family registry. In South Korea, the family law was changed in 2005, abolishing the household headship system and making birth registration a stand-alone document. However, it is not yet possible to see whether this has had a large effect on the attitude and behaviour of the general public. A child whose father is unidentified experiences serious social stigma. The divorce rate was low until the 1990s. Although women, including married women, are participating in paid employment at increasingly higher levels, men rarely take on domestic roles (McDonald 2009; Rindfuss 2004; Tsuya et al. 2005). In addition, long-standing preferences for boys combined with very low fertility and the spread of sex-selective abortion led to an emergence of distorted sex ratios at birth on China, Korea, and Taiwan (Section 1.4.9). Finally, participation in housework and childcare responsibilities has remained persistently low among Asian men, which some scholars have suggested plays a role in discouraging partnership formation and childbearing for (increasingly better educated) women (Ishii-Kuntz et al. 2004). 


\subsection{Employment, Economic Uncertainty and Fertility}

The fertility literature has long highlighted the relevance of both aggregate and individual economic conditions for the timing and number of births. Economic events and economic uncertainty alter current and future demand for children among couples (Butz and Ward 1979; De Cooman et al. 1987). Sobotka et al. (2011) note that, overall, fertility has exhibited a pro-cyclical relationship with economic growth for more than a hundred years. However, the effect is small and difficult to identify since most recessions have been shortlived and fertility developments were often dominated by stronger and longer-lasting shifts, including the fall of fertility to low and very low levels in most European countries and East Asia in the 1970s-1990s.

As noted earlier, Becker's (1981) microeconomic model of fertility offers a good analytical tool to explain the conflicting impacts of economic conditions on childbearing decisions. Childbearing is time-intensive relative to other activities, and its associated opportunity cost can be measured by the potential wage of the mother. Whereas increases in men's work mainly entail an income effect that raises the demand for children, higher female wages give rise to a combination of income and substitution effects since they result in an increase in the cost of a child relative to other "goods". Accordingly, women (particularly those with high potential wages) may restrict their fertility and trade-off children for less time-demanding alternatives if the substitution effects are important.

In this context, a woman's temporary unemployment is a good time for childbearing, and fertility should be counter-cyclical, as in the US during the 1960s and early 1970s when contraceptive access also improved (Becker 1981; Butz and Ward 1979). However, most analyses have found a negative relationship between different measures of unemployment and first births both in long time series (Rindfuss et al 1988) and for recent periods (De Cooman et al. 1987 for the UK; Macunovich 1996 for the US; Kravdal 2002 for Norway; Hoem 2000 for Sweden; Adsera Kravdal 2002; Adsera 2011 for EU; Neels et al. 2013 for Europe; Goldstein et al. 2013). The association between unemployment and fertility is complex and heterogeneous across age, parity, institutional frameworks (labour regulation, types of contracts, unemployment benefits) and the length and acuteness of economic shocks, as these factors mediate opportunity costs of having children. In a recession, women who are at a point in their life-cycle when human capital accumulation is crucial may postpone childbearing to acquire more work experience or education. The pervasive long-term and youth unemployment characterised by the recent recession is bound to have a large negative impact on household permanent income. It may render childbearing unattractive not only for those directly affected by unemployment but also for those threatened by it - as documented for the Great Depression era (Becker 1981; Murphy 1992) and for the periods of high unemployment in Europe during the 1980s and 1990s (Adsera 2011). While the majority of short-lived recessions only seem to affect the tempo of fertility (Lee 1990), severe crises also had an impact on the quantum of fertility as women who postponed for lengthy periods of time did not have all the children they intended (Sobotka et al. 2011). In addition, with persistent unemployment, partnership formation is delayed (and with it, childbearing), particularly in Southern Europe or East Asia where fertility outside marriage was, and still is, relatively rare. Likewise, parents may invest more per child and reduce their family size to improve their future outlook (Easterlin 1976) and young adults may prolong their educational training (Kohler et al. 2002). 
The association between employment and fertility is weaker in countries where the family trade-offs are minimized by the availability of permanent public employment, and support for working mothers through flexible work schedules, generous leaves or abundant and affordable childcare (as in Scandinavia) (d'Addio and d'Ercole 2005; Matysiak and Vignoli 2008). Conversely, short-term contracts with meagre provisions and high turnover that expanded rapidly during the 1990s, particularly among the youth in Southern Europe due to previous strict regulation and dualisation of the labour market, do not offer any of those guarantees and are associated with further depression of fertility (Adsera 2011a). Both individual unemployment experience and aggregate economic shocks matter (Adsera 2011b), and in some places the latter matter the most (see Kravdal 2002 for Norway).

A major challenge for this literature is to find the appropriate way to measure economic conditions, both aggregate and individual. Declines in GDP tend to be associated with corresponding declines in fertility (Goldstein et al. 2009). However, once other covariates are introduced, such as unemployment, the relationship weakens or disappears (see Adsera and Menendez 2011 for Latin America). This is, arguably, partly caused by the effects family and social policies have in offsetting some of the adverse effects of the recession. While measures of consumer sentiment or perception of the crises fit better, unemployment appears to be the most enduring relationship (Sobotka et al. 2011). Recent papers have employed new methods to deal with the problem of endogeneity of unemployment measures. Del Bono et al. (2012) use unexpected plant closings in Austria as a statistical instrument to study fertility changes after job displacement and find fertility decline in the short and medium term, mostly due to the impact of career interruption rather than income changes. 


\section{Box 3: The impact of the recent economic recession}

The economic recession that started in 2008 has marked an end to the first concerted increase in period total fertility across the developed world since the Baby Boom era of the 1950s1960s, which occurred between the late 1990s and 2008 (Goldstein et al. 2009, Bongaarts and Sobotka 2012). The evidence for the years 2009-2012 suggests that in many countries total fertility rates stopped rising in 2009-2010 and subsequently declined in 2011-12 (VID 2012, Goldstein et al. 2013, Lanzieri 2013). This is in line with a pro-cyclical association between economic trends and fertility rates that characterized developed countries in recent decades (Sobotka et al. 2011; Adsera 2011b; Neels et al. 2013). However, there was considerable variation in fertility changes by country, age, and birth order, which suggests that different segments of the population responded differently to the early stage of the recession (Goldstein et al. 2013, Lanzieri 2013).

This trend reversal in fertility has thus far been limited to Europe, the United States, Australia and Canada-regions affected by the economic downturn. Moreover, large cross-country differences can be observed in recent fertility trends. The US shows a clear pattern of reversal, with a period TFR peaking at 2.1 in 2007 - the highest level since 1971 - before falling to 1.88 in 2012 (Livingston and Cohn 2012), while in Europe the evidence is mixed. An average TFR for the 37 European countries shows period TFR stabilising at 1.58-1.59 in 2008-2010 and subsequently declining to 1.55 in 2011 (Figure 3, left panel). Of these 37 countries, as many as 26 experienced a decline by 0.02 or stronger, four had stagnating fertility rates (between -0.01 and +0.01 ) and only seven recorded some fertility increase $(+0.02$ or more). If countries with problematic data are removed (i.e., countries where post2011 census revisions of population data made time series incomparable between 2010 and 2011; see note below Figure 3), only three European countries (Belarus, Malta and Ukraine) experienced rising fertility in 2011. This decline strongly contrasts with the situation before the onset of the recession: in 2008, 35 countries experienced rising fertility and only two saw a stable trend.

The trend towards fertility decline has been more pronounced in countries and regions that experienced stronger economic downturns and faster increases in unemployment (Sobotka et al. 2011, Livingston 2011 for the states of the U.S.). Figure 3 plots the TFR trends in 20002011 in the most populous European countries (with population over 20 million) as well as Australia, Canada, and the United States. It illustrates clearly the heterogeneity in fertility "responses" during the initial stage of the economic recession. Among these large countries, only the US, Romania, Spain and, to a smaller extent, Australia and Canada have seen a reversal in the previous trend of increasing fertility. A more common pattern, with the fertility increase coming to a halt, was typical of many large European countries, including France, Italy, Russia, and United Kingdom. Finally, Germany stands out for its stable period TFR. This heterogeneity makes it difficult to incorporate explicitly the possible future effects of the recession on fertility into fertility scenarios for the next five years (see Section 5.1 and Appendix 1).

(Box 3 continued on the next page) 


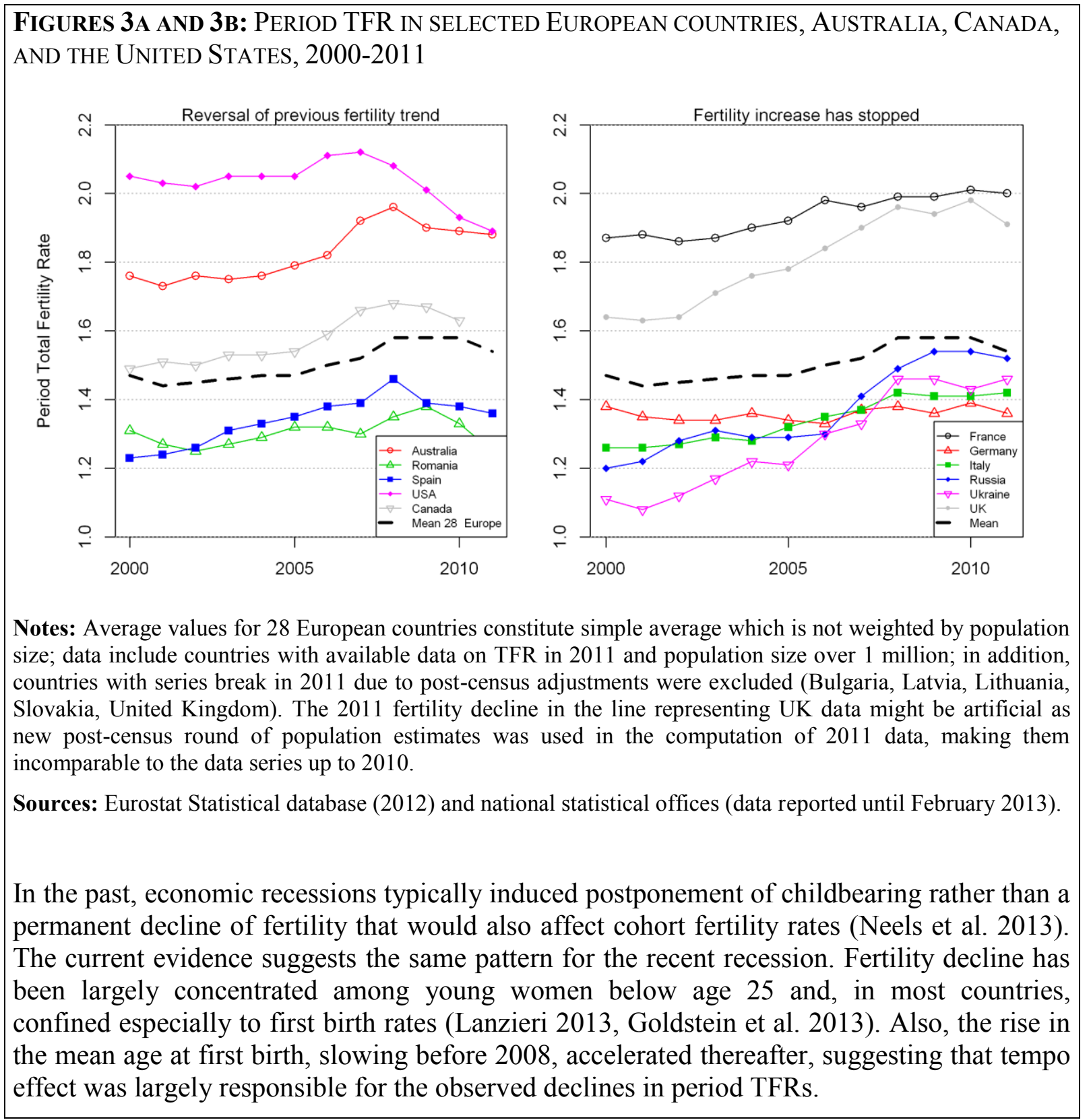

\subsection{Family Policies}

Family-related policies cover a spectrum of interventions that range from explicitly pronatalist measures through "softer" regulations that help people to balance work and family life and have the number of children they desire. Policies helping parents balance work and family are central to mobilising female labour supply, promoting gender equity, increasing labour income of couples, and ensuring the financial sustainability of the welfare states (Gornick et al. 1997; OECD 2011, Saraceno et al. 2012). Furthermore, family policy interventions can play a role in combating child poverty and ensuring equal opportunities for children from different backgrounds (Bradshaw and Mayhew, 2006). 
A key differentiating characteristic of policies across countries is whether they emphasise financial assistance, entitlements to leave work after a birth or the provision of childcare services (OECD 2011). There is no convincing evidence of cross-national convergence in family policies (Gauthier 2002). Different mixes of these three policy instruments are rooted in welfare state histories, as well as prevailing attitudes towards families, the government's role, and current family patterns. Thévenon (2011) provides an in-depth description of cross-country differences and similarities in the policy mix created to support families in OECD countries. The Nordic countries (Denmark, Finland, Iceland, Norway and Sweden) provide comprehensive support for working parents with very young children (under age three) through a combination of generous leave arrangements after the birth of a child and widely available childcare services (Björklund 2006). While Englishspeaking countries (Ireland, the United Kingdom, Australia, New Zealand and, to some extent, Canada and the United States) provide much less support in time and in-kind for working parents with very young children, financial support is more generous - if primarily targeted to low-income families and preschool children (McDonald and Moyle, 2010). Not all of these countries offer the same level of support, with Canada and the United States lagging behind the others. Western and eastern European countries form a more heterogeneous group occupying an intermediate position. Among these countries, France and Hungary stand out by offering rather generous support for working parents as compared to the other countries in their respective groups. In East Asia, policy provision ranges from the laissez-faire approach of Hong Kong up to the more comprehensive measures enacted in Japan and Taiwan (Chen et al. 2012; Frejka et al. 2010). However, across the region, the relatively low tax rates and, in some cases, high public budget deficits mean that investment in family policy is often limited.

Not all policies succeed in promoting the conditions necessary for individuals to start or enlarge their families. The evidence on the effect of family policies on fertility is inconclusive (Sleebos 2003; Gauthier 2007). Interestingly, the increase in fertility rates prior to the onset of the recent economic recession has been steeper in countries where female labour market participation has also risen markedly and where women have more opportunities to combine work and childbearing. Hence fertility rates are now higher in countries with high rates of female employment, while the opposite situation prevailed thirty years ago (Engelhardt and Prskawetz 2004; Billari and Kohler 2004; OECD 2011). Recent research has emphasised the contribution of family policies to this reversal (D'Addio and Mira d'Ercole 2005, Hilgeman and Butts 2009, Luci and Thévenon 2012). In particular, policies that help parents balance work and family life (leave entitlements, but especially the availability of childcare services for children below age 3 and part-time work) are found to encourage fertility (see Thévenon and Gauthier 2011 for a literature review).

\subsection{Migrants' Fertility}

With generally rising mobility, migration has contributed to population increase in many low-fertility countries that would otherwise be experiencing declining population (Coleman 2009). In 2011, around one out of ten residents in the EU was born in another country (Eurostat 2013). The US has 13 percent of foreign-born residents, while Australia and Canada have over one fifth of their population born abroad (Martin and Midgley 
2010). The share of migrants is relatively high in Russia as well. A high share of immigrants, typically younger and with higher fertility, implies that migrants contribute significantly to the number of births in the host country. Around 2005, births to immigrant women accounted for 15 to 25 percent of all births in the United States and many Western European countries including the Netherlands, France, United Kingdom, or Sweden (Sobotka 2008b).

In most low-fertility countries migrants have higher fertility than the native-born women (Sobotka 2008b). This difference can be quite substantial, reaching as high as one child per woman, when measured with the conventional period TFR. Migrant women in France had a high TFR level estimated at 2.89 in 2008 as compared with 1.89 for the women born in France (Pla and Beaumel 2012). Similarly, migrants in the US, especially Hispanics, have had higher fertility rates for many decades - although recently the notion of high Hispanic fertility has been contested (Parrado 2010). On the contrary, Australian migrants' fertility has been found lower than for the native born (Abbasi-Shavazi and McDonald 2000). There are massive differences between groups of migrants, as well. For instance, in Sweden, where detailed statistics are available for main groups of migrants, the TFR among immigrants in 2009 ranged from below 1.8 among women born in BosniaHerzegovina, Finland or Thailand, up to 4.0 for women born in Somalia (SCB 2010: Table 2.2.14).

Despite having on average higher fertility rates, migrant women in many low-fertility countries have achieved sub-replacement fertility. According to the recent data for 20072011, all migrant or foreign women combined had a period TFR below 2.0 in Austria, Germany, the Netherlands, Spain, and Denmark (national statistical offices; see also Figure 4 below). In contrast, migrant fertility remained at about or slightly above the replacement level (2.0-2.3) in Italy, Greece (data for 2005, Tsimbos 2008), Norway, Sweden, and the United Kingdom (national statistical offices and Tromans et al. 2009), whereas it stayed above 2.6 in the US in 2010 (estimate based on Livingstone and Cohn 2012) and approached the high level of three births per woman in France in 2008 (Pla and Beaumel 2012). In most low-fertility countries fertility of migrants has declined considerably since the early 1980s (Figure 4), contributing to a gradual fertility convergence between migrant and "native" women. Moreover, the recent economic recession has negatively affected fertility rates of migrants more than those of "native" women and in several countries including Denmark, Spain, United Kingdom, and the United States migrant fertility fell sharply between 2008 and 2011 (Livingstone and Cohn 2012: Figure 4). 
Figure 4: PERIOD TFR AMONG IMMIGRANT (OR FOREIGN) WOMEN IN SELECTED EUROPEAN COUNTRIES, 1990-2011

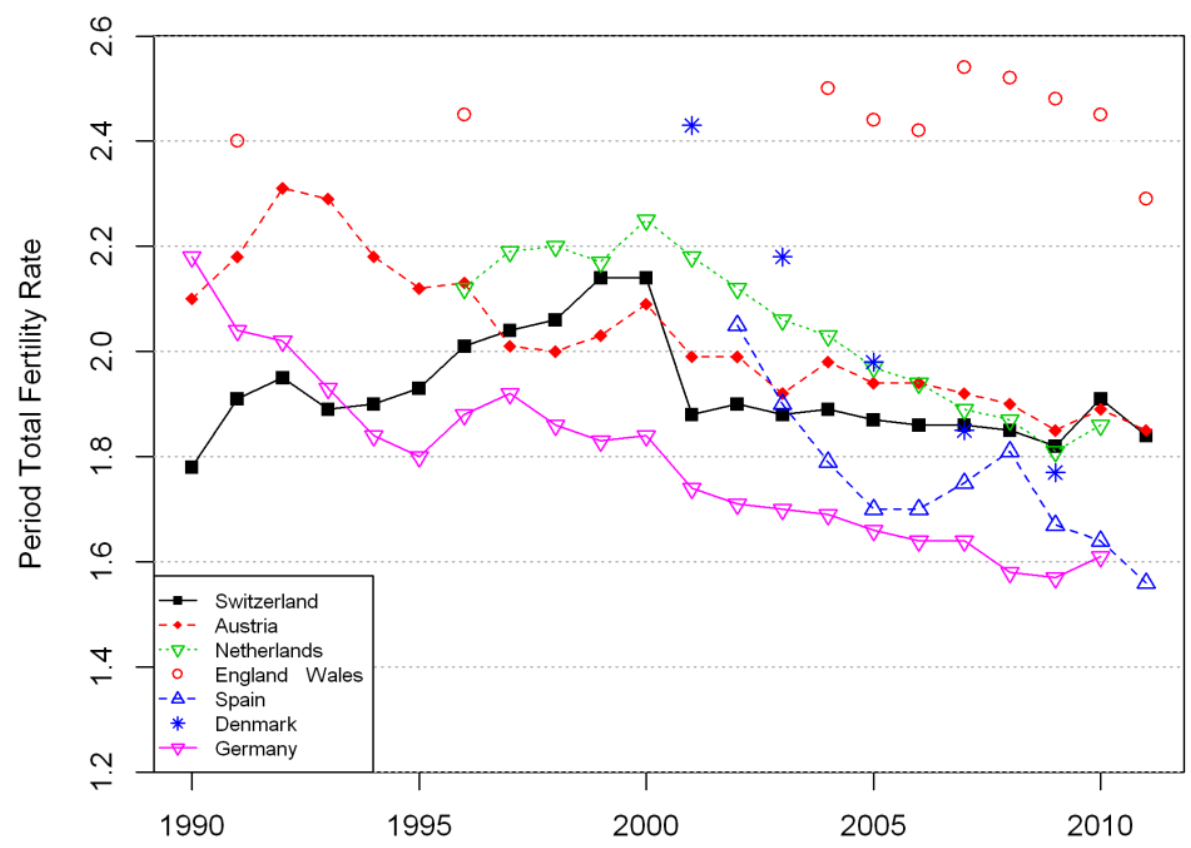

Notes: Data pertain to immigrant women in Denmark, England and Wales, Netherlands and Austria since 2002. Other data pertain to women with foreign citizenship. Data for Denmark are for five year period centred in a given year and exclude migrants of Danish origin.

Sources: National statistical offices, Sobotka 2008b.

In many low-fertility countries there is a common misconception that birth rates among immigrants have a significant influence on fertility rates (e.g. Héran 2004). Also the increase in fertility in Europe in the early 2000s has been often falsely interpreted as an outcome of high immigration (see Tromans et al. 2009 disputing this for the UK). These views are not supported by the evidence as fertility rates in that period increased the most among native-born women, while they often stagnated or even declined among immigrants (Goldstein et al. 2009; Figure 4 above). In most European countries with sizeable immigration, migrants' fertility had a small positive effect on country TFR in 2007-2008, ranging from 0.03 in Germany to 0.13 in England and Wales in absolute terms. In smaller regions with high immigration, this effect was often much stronger: in Vienna in 2009, fertility of immigrant women has lifted the overall TFR for all women by 0.28 in absolute terms (Zeman et al. 2011). In contrast, in the Netherlands, fertility of migrants and women born in the country (including the second generation of migrants) has broadly converged, and in at least one country, Denmark, migrants' fertility has fallen below that of the nativeborn women as of 2008. Finally the daughters of immigrants, representing the second generation of immigrants, typically have fertility rates similar to fertility among the women without migrant origin. This rapid convergence to the fertility patterns of the host country has been illustrated even for higher-fertility populations of Turkish and Moroccan origin in the Netherlands (Garssen and Nicolaas 2008). One important exception is the elevated fertility among the second- and third-generation of Mexican-origin migrants in the US (Frank and Heuveline 2005). 
Little is known about the fertility impact of emigration. Short-term migration is likely to have a negative effect on fertility as many couples face temporary separation or have to relocate. Long-term emigration probably does not have a significant effect on fertility rates among the women staying in a country, but it could distort official statistics on birth and fertility. One telling example is Lithuania, where a downward population adjustment due to emigration, following the 2011 population census, combined with an ex-post inclusion of births to Lithuanians living abroad (16 percent of births reported in 2011) led to an artificial upturn in the period TFR from 1.6 in 2010 to 1.8 in 2011 (information provided by Statistics Lithuania).

\subsection{Biomedical Factors}

Huge individual variability in fecundability (Dunson et al. 2002) presents women and men in reproductive age with two contrasting challenges: how to prevent undesired pregnancies from occurring and how to achieve pregnancy if and when one is ready to have a child. Current low fertility rates in rich countries have been reached thanks to the widespread use of modern contraception throughout much of women's reproductive lives (Skouby 2004) and, in many countries, due to relatively widespread use of abortion (Sedgh et al. 2012). Still, given that 47 percent of pregnancies and 22 percent of births in the more developed countries are estimated as unintended, it is clear that not all sexually active women and men consistently use reliable contraception when not planning to bear children: (Singh et al. 2010).

This section reviews three key issues where biomedical factors and assisted reproduction influence fertility rates: 1) infertility and its age pattern, 2) the notion of deteriorating male reproductive capacity, and 3) assisted reproduction and its potential role in fertility trends at higher childbearing ages.

\subsubsection{Infertility and Sterility}

Analysing trends and variation in infertility and sterility is difficult as different concepts and definitions are used and modified over time; also medical, epidemiologic and demographic definitions of infertility vary (Habbema et al. 2004; Leridon 2007; Mascarenhas et al. 2012ab). ${ }^{10}$ It is now common in the medical field to define as "infertile" a couple that has been unable to conceive after a defined exposure to unprotected intercourse. This period may vary from 12 months to five years. It would be more

\footnotetext{
${ }^{10}$ WHO defines infertility as "a disease of the reproductive system defined by the failure to achieve a clinical pregnancy after 12 months or more of regular unprotected sexual intercourse" (Zegers-Hochschild et al. 2009: 2686). Major differences between definitions exist in the "waiting period" and age span defining infertility. A related term "sterility" denotes inability to conceive (e.g., Leridon 2004), whereas "impaired fecundity" includes women who are not surgically sterile and "had experienced difficulties conceiving or bringing a pregnancy to term during their lifetime" (e.g., Macaluso et al. 2010). These medical definitions of infertility differ from "traditional" demographic approaches where infertility means the absence of live birth during specified period of time or during reproductive life. However, this can be due to the fact that the couple is sterile or because it is using means to avoid a birth. It is only in a context where family planning is assumed to be absent that infertility can be equated with sterility.
} 
appropriate to report explicitly "one-year infertility rates" or "5-year infertility rates" but this is rarely the case. In this section we will use the word "infertility" in this broad sense.

Data on infertility have mostly been collected for higher-fertility, less-developed countries. Boivin et al. (2007), using a wider definition of infertility that includes women reporting current "difficulties in carrying a child" ("subfecundity"), showed that in selected rich countries current prevalence of infertility ranged from 3.5 percent in Australia (1988) to 16.7 percent in Russia (1998). Lifetime infertility prevalence in these countries varied even more, from 6.5 percent in Norway (1985-95) up to 26.4 percent in the United Kingdom (1993). These estimates vary so widely in part because infertility definitions differ, and because infertility is affected by different age patterns of childbearing across countries. Mascarenhas et al. (2012b) produced global and regional standardised estimates of primary (absence of a first live birth) and secondary infertility (absence of a live birth among women with at least one child) cumulated for couples over a five-year period of unprotected intercourse. Using these definitions, primary infertility was very low and amounted in 2010 to 1.5 percent globally (1.9 percent among child-seeking women), with little variation by country and region. Secondary infertility varied considerably more: the global average was 2.9 percent for all women and 10.2 percent for child-seeking women (Mascarenhas et al. 2012b). These data also show that very few women experience infertility from an early age on. While infertility prevalence is often computed for women, male-factor infertility strongly contributes to observed infertility of couples (Thonneau et al. 1991; CDC 2011).

Relatively few studies have examined infertility trends over time. Mascarenhas et al. (2012b) showed there were no strong shifts globally and in high-income countries between 1990 and 2010, especially when age-standardized data were used. Rich evidence exists on infertility trends in the US. Mosher and Pratt (1985) reported a decline in infertility between 1965 and 1982 whereas more recent analysis by Stephen and Chandra (2006) covering the period 1982-2002 found a gradual infertility decline up until 1995, which was particularly pronounced among older childless couples. These and other studies do not lend support to the notion of a general increase in infertility over time (see also Oakley et al. 2008 for the UK).

The key factor in infertility is age. Among men, fertility is usually maintained until high age, but it is negatively affected by age-related degenerative changes to sperm and testes, as well as erectile dysfunction (e.g., Kühnert and Nieschlag 2004; Sartorius and Nieschlag 2009). As a result, male age has an independent impact on couple's fecundity, and higher male age $(>40)$ has detrimental effects especially in combination with advanced reproductive age of the woman (de la Rochebrochard and Thonneau, 2003). While the share of sterile men is estimated at about 15 percent worldwide, estimating the scale and impact of possible male subfecundity is much harder (Schmidt and Munsteret al. 1995). Male subfecundity may, ultimately, be important, especially in affecting the spacing of births rather than fertility levels (Leridon and Slama 2008). For women, age imposes much stricter limits to their ability to reproduce as the number and the quality of their oocytes (eggs) decline rapidly (Broekmans et al. 2007). Infertility, sterility, the frequency of miscarriages, and pregnancy complications increase gradually among women aged 30-39 and then surge after age 40 . By age 40 almost 17 percent of women are permanently sterile, while as many as 35 percent of women will remain childless if starting their first 
pregnancy effort at that age, mainly because the rate of foetal wastage increases rapidly after age 35 (Leridon 2008).

In the US the share of married childless women with impaired fecundity reaches 39 percent at age 35-39 and 47 percent at age 40-44 (CDC 2012). Age-related infertility increase coupled with the ongoing trend towards delayed parenthood (Section 2.2) leads to rising numbers of women and couples having difficulties conceiving. More and more women in low-fertility countries remain childless at age 35 and above; at the same time, an ever higher share of these women intend having a child in the future (Sobotka 2013 for Austria, Hagewen and Morgan 2005: Table 1 for the US). Many of these childless women will not be able to conceive naturally or carry their pregnancy to term. Section 2.7.3 below discusses to what extent they can successfully resort to assisted reproduction.

\subsubsection{Deteriorating Male Reproductive Health?}

Carlsen et al. (1992: 609) stated in a meta-analysis of studies published between 1938 and 1990 that "there has been a genuine decline in semen quality over the past 50 years," a finding partly confirmed in a more sophisticated analysis by Swan et al. (2000). Regional studies from Europe and Asia have demonstrated heterogeneity in the results (Paasch et al. 2008; Jorgensen et al. 2002; Iwamoto et al. 2007, Rolland et al. 2013). The ESF Science Policy Briefing (2010: 7), prepared by some of the leading scientists in the field, voiced concern about "significant adverse trends in reproductive health problems in young men." The research suggesting decline in sperm quality has, however, been challenged by some studies that question the methods and data, particularly of the meta-reviews (Fisch 2008; Lerchl 1995). The few studies based on the measurement of the time to conception, notably in the UK (Joffe 2000) and Sweden (Scheike et al. 2008), have not found evidence of a declining trend in fecundity. Overall, there are many conflicting findings and no consensus on this issue (Merzenich et al. 2010; Bonde et al. 2011; Fisch and Braun 2013).

The reported risk factors for declining semen quality (measured by sperm counts, motility, and morphology) include the effect of chemicals such as xeno-oestrogens and lifestyle impacts of tobacco, obesity and stress (He et al. 2008; Zorn et al. 2008; Jensen et al. 2004; Sharpe and Skakkebaek 1993). Declining sperm quality could play an important role in shaping levels of reproductive success within certain sub-groups of society and, eventually, affect aggregate fertility rates (ESF 2010). Furthermore, increasing age of fatherhood is a significant determinant of declining semen quality and reproductive success (Frattarelli et al. 2008). In the context of increasing age of first birth and a generally greater social acceptance of older fathers, this factor could play a prominent role in the future.

\subsubsection{Fertility Postponement and Assisted Reproduction}

Data on assisted reproduction (AR), although incomplete for many countries, indicate continuing increase in its use, including by women at higher reproductive ages (Ferraretti et al. 2012; Sobotka 2013). According to AR registries in European countries, between 0.5 percent (Turkey) and 4.6 percent (Denmark) of children born in 2008 were conceived via AR (Ferraretti et al. 2012); the average for European countries with available data was 1.6 percent, comparable to the US (1.5 percent in 2009). Assisted reproduction has a very minor positive effect on aggregate fertility rates in rich countries (Sobotka et al. 2008, 
Habbema et al. 2009; ESHRE 2010) although its "net impact" is difficult to estimate as some of its users would otherwise achieve a spontaneous conception (Pinborg et al. 2009).

To what extent can AR compensate for infertility linked to postponing childbearing to higher reproductive ages? The contribution of AR using women's own oocytes is relatively small. A simulation by Leridon (2004) showed that an ability of AR to overcome agerelated infertility falls dramatically with age. Fewer than 30 percent of the births 'lost' by postponing conception attempt from age 35 to age 40 could eventually be 'compensated' by in-vitro fertilisation. In the United States in 2009, only 18.1 percent of AR cycles using non-donor oocytes at age 42 resulted in pregnancy, with 8.6 percent resulting in a live birth. Leridon and Slama (2008) simulated population-level impact on fertility of additional postponement of childbearing and 'compensatory' use of AR technology. In the contemporary French population, an additional shift in age at pregnancy attempts by 2.5 years was estimated to lead to a five percent decline in fertility rate (from 2.00 to 1.90), of which only one fifth $(0.02)$ would later be made up through AR use. Despite this evidence, many women erroneously believe that AR can help them to overcome infertility at high reproductive ages (Maheshwari et al. 2008; Hewlett 2002).

Much higher success rates have been achieved with AR using donor oocytes from healthy young women. The AR success rate is then unaffected by recipients' age (Toner et al. 2002) Slightly above 50 percent of US women obtaining a treatment with donor oocytes achieved pregnancy until their late 40s (CDC 2011, Figure 47). Pregnancy rates remains high even among post-menopausal women in their 50s (Grossman et al. 2012In contrast, the share of successful IVF treatments with own oocytes resulting in live birth falls continuously from around 50 percent at age 30 to almost nil at age 45 .. The number of AR cycles with donor oocytes has risen rapidly, especially among women above age 40 (Sobotka 2013). However, relying on donors implies women will have offspring who carry someone else's genetic endowment. Recently, oocyte cryopreservation (OC), or "egg freezing" has emerged as a major breakthrough (Setti et al. 2012) that may give women more autonomy in reproductive decisions and erode the age boundaries of reproductive ages (Wyndham et al. 2012). Ideally, women using OC would have their oocytes harvested at prime reproductive ages, and cryopreservation would then preserve them for possible later use with the help of AR. Assisted reproduction using oocytes vitrified at younger ages, especially until early 30s, achieves similar success rate as AR with donor oocytes (Cobo et al. 2011). Although number of births after OC has increased (Noyes et al. 2009), there is still lack of long-term data about success rates and possible drawbacks of using AR with OC after many years of cryopreservation. Moreover, the OC remains costly (van Loendersloot et al. 2011), as well as being a rather invasive procedure. It involves a need for earlier-life decisions about reproductive intentions later in life as well as uncertainty about its successful use (see discussion on demographic aspects of OC in Sobotka 2013).

\subsection{Education}

Conventional demographic wisdom holds that fertility levels among women have a negative relationship to educational attainment (e.g., Skirbekk 2008; Castro Martín 1995). The causal direction of the relationship seemed clear because education was typically completed prior to the time when women started having children. Now in low fertility countries, where massive expansion of high education has taken place and the education 
process has extended well into the fecund years, the causality question has become murkier and the education-fertility association has become more varied (Kravdal and Rindfuss 2008; Andersson et al. 2009; Neels and De Wachter 2010; Cohen et al. 2011).

The expansion of higher education in developed countries, particularly among women, has been a major factor behind the postponement of parenthood and the emergence of very low period TFRs in the final decades of the twentieth century (Billari and Kohler 2004; Ní Bhrolcháin and Beaujouan 2012; Sobotka 2004a). First, there is a normative expectation that women still in school are not ready for motherhood. In this context, the ever expanding time spent in education further delays first births (Blossfeld and Huinink 1991; Kravdal 2004). As a result, women with higher levels of education have a later mean age at childbearing (Andersson et al. 2009; Mills et al. 2011) and, during the transition from lower to higher levels of education the associated fertility postponement leads to lower levels of period fertility. Second, a higher level of education entails enhanced human capital and a higher earnings potential, on which women may want to capitalise in the labour market. This implies that higher educated women have more to lose by staying at home to provide childcare - a situation aggravated by the persistence of traditional gender role division, particularly in East Asia (see Box 2). These higher opportunity costs of childbearing may contribute both to the delay and decline of fertility (Kravdal 2004; Lappegård and Rønsen 2005; Gustafsson 2005). But education effects are likely not confined to financial issues. Higher levels of education prepare one for jobs and careers that are more interesting, creative and intrinsically rewarding. An increased orientation toward a career in the labour market may motivate educated women to further postpone motherhood until they have gained work experience, established their position in the labour market, and accumulated sufficient material resources to afford starting a family (Kravdal and Rindfuss 2008; Mills et al. 2011). Third, field of study can also be important for fertility timing. One reason is that different subject areas imply differential earning potentials in the labour market after graduation (e.g., fine art compared to engineering). The choice of study discipline also tends to both reflect and mould a person's attitudes, including those related to family formation (Martín-García and Baizán 2006; Hoem et al. 2006; Van Bavel 2010a). Postponement has been more limited among graduates from disciplines in which stereotypical attitudes about gendered family roles prevail and in which a large share of the graduates are female (Van Bavel 2010a).

Whereas the effects of education on the timing of entry into parenthood are well documented and reasonably consistent, the effect on fertility quantum is much less clear (Kravdal and Rindfuss 2008). The aforementioned postponement effect, higher opportunity costs of childrearing, and stronger career orientation should lead to lower levels of completed fertility, and there has been empirical support for this effect (e.g. Kohler et al. 2002). However, women with higher levels of education are more likely to be able to afford the costs associated with raising children, even more so if they are partnered with highly educated males (which is usually the case).

The empirical record on the relationship between educational attainment and completed fertility is little studied. In the Nordic countries, the fertility gradient by level of education has almost disappeared for women, and parity progression ratios to a second and third child are positively associated with women's education level (Kravdal and Rindfuss, 2008; Andersson et al. 2009; Tesching 2012). In Belgium, Neels and De Wachter (2010) reported crossovers in fertility and education association, with above-average completed fertility 
found among women with tertiary education born in the 1950s. There are also difference by parity, with Adsera (2011b) observing a U-shaped relationship between educational attainment and third births across the EU. However, when parity-specific patterns are disregarded, research, in most countries shows a continuation of the negative educationfertility differentials for women (Davie and Mazuy 2010, van Agtmaal-Wobma and van Huis 2008, Sobotka 2012, Musick et al. 2009; Retherford et al. 2004). We review the empirical evidence on trends and cross-country variation in education-fertility differentials in low-fertility countries in Sections 5.3.1-5.3.5.

Our expectation is that countries that have the least developed institutional support for a combination of motherhood and employment will have both the steepest negative education-fertility gradient and the lowest levels of completed fertility. The evidence suggests that the relation between education and the number of children strongly depends on the social context. A key factor here is the practical availability and cultural acceptability of non-family childcare, which differs dramatically across countries for children below age three (OECD 2011; Liefbroer and Merz 2010). Childcare facilities may greatly mitigate the opportunity costs of childbearing, which are known to be highest for highly educated women (Kravdal and Rindfuss 2008). It has been found that formal childcare availability has a positive effect on second birth rates in Europe, but only for highly educated women (Van Bavel and Różańska-Putek 2010). The development of organised childcare and other institutions promoting gender equity in family life has probably contributed to the diminishing gradient between women's level of education and their fertility (Kravdal and Rindfuss 2008).

Although we have attempted to give a comprehensive overview of all the major factors shaping fertility, our review has limitations. We have paid relatively scant attention to the slowly accumulating literature on male fertility determinants, levels and patterns. Some potentially relevant factors were not discussed because the literature is relatively undeveloped, the evidence on their relevance is limited, or simply because the lack of space precludes discussing every possible driver of fertility. Examples of such "neglected" factors include type of settlement and the potential role of urban-rural differentials, population density, and environmental and climate-related factors. Similarly, this working paper has not covered widely enough the ongoing transformation in family and living arrangements and its multiple links to childbearing behaviour. Also we have not discussed potentially important psychological factors operating at both societal and individual levels, such as how the degree of trust, insecurity, sense of control, and, more generally, ideologies, fads and fashions related to childlessness or having children, influence fertility decisions. With the exception of economic uncertainty and the more specific case of anomie during the post-communist transition in Central and Eastern Europe (Philipov 2003; Philipov et al. 2006), the literature is very limited and usually dated. Of potential relevance as a fertility-limiting factor in the future may be the ideology of intensive mothering prevalent in many affluent countries. In the long-run increased "price of parental time" may clash with the widespread notion that parenthood, especially motherhood, should be child-centred, emotionally involving, and time-consuming (Arendell 2000). 


\section{Expert Survey and Results of Expert Meeting: Summary of Findings}

When we look to the future, how can we discern the likely track of fertility rates? Which of the forces and issues discussed in Section 2 will have the most impact on such future trends? In this context, we employed a 'low fertility' module within the survey discussed in Chapter 1 of Lutz et al. (forthcoming) to elicit both quantitative information regarding likely future trends and qualitative information regarding the validity and potential impact of possible drivers of these trends. In the following section we discuss the design of the survey module and outline the findings.

\subsection{Introduction}

The Low Fertility Module (LFM) of the survey sought to gather information regarding numeric estimates of future fertility as well as its underlying determinants in countries defined as having low fertility. For a full discussion of the selection procedure as well the list of countries involved, see Appendix 2. Firstly, respondents were presented the baseline TFR estimate for 2010 as published by the Population Reference Bureau (PRB 2011) and asked to provide point projection and 80 percent confidence interval (CI) range for the TFR in 2030 and 2050. These estimates are at the heart of fertility scenarios prepared for the low-fertility countries and described in Section 4 below. Secondly, respondents were asked to assess the impact and validity of a series of qualitative statements regarding future drivers of fertility. Finally, respondents were asked whether they wished to reassess their initial TFR forecasts after performing the qualitative exercise. Experts could add additional countries or regions for which their assessment was valid. They could also comment on the survey or on individual arguments.

In this section we outline the design and construction of the LFM, followed by a description of the characteristics of respondents. We then introduce the qualitative statements regarding likely drivers of future trends of fertility and analyse the responses in total by region and in some cases by individual country. Given the emphasis on education and human capital in this project, we analyse responses pertaining to education-related arguments separately in Section 3.4.

\subsection{The Survey}

\subsubsection{Survey Design and Evaluation}

The broad tenets and workings of the survey are outlined in Chapter 1 of Lutz et al. (forthcoming). Here we briefly outline the main concepts and how they have been adapted for use in this low fertility module.

Each module of the expert survey contained numerous arguments. These arguments took the form of a statement on future trends that might affect population dynamics. The statements were formulated in a neutral way, without explicitly referring to their likely consequence on fertility, mortality, or migration. It was deemed important not to give respondents preconceived judgments about the way diverse social, cultural, biomedical, health, policy and economic developments may affect population. For instance, one 
argument in the LFM of the survey reads: "Men and women will increasingly share the burden of housework and childcare". ${ }^{11}$ Each argument is grouped into a series of forces. These are the broad themes that encompass most of the main determinants of low fertility and broadly reflect the discussion in Section $2 .^{12}$ These forces (and respective number of arguments) in the LFM were:

- Cultural and social forces in fertility ideals, norms, and desires (9)

- Partnerships, living arrangements and gender differences (9)

- Role of policies (9)

- Employment and economy (9)

- Biomedical and timing of parenthood (7)

- Education (3)

For each argument, respondents were asked to gauge its expected future likelihood or validity and its impact pertaining to the year 2050. These are defined and interpreted as follows:

1. Validity, ranging from 0 to 1 , gives an indication whether a given argument is likely to be true, based on five predefined response options and the validity score attached to them. The complete phrasing and response options are illustrated in the example below:

\begin{tabular}{|l}
\hline \multicolumn{1}{|c|}{ Module: Low fertility countries } \\
Force: Role of policies \\
Argument: Government will take an increasingly pro-natalist stance \\
(e.g. through communication campaigns and family policies)
\end{tabular}

\footnotetext{
${ }^{11}$ For a complete list of all of the arguments, see Appendix 4.

12 The order of the arguments was randomised within the forces, and the order of the forces was also randomised to minimise fatigue effect.
} 
2. Impact, also called conditional impact, represents an assessment of the hypothetical influence of a given trend on fertility (mortality, migration). The predefined range was from -1 (strongly negative) to +1 (strongly positive). Specifically, the respondents were asked

Regardless of your answer above, if the above argument were completely true, what effect would this have on future levels of cohort fertility in country?

\begin{tabular}{|l|l|l|l|l|}
\hline $\begin{array}{l}\text { Strongly } \\
\text { decreasing } \\
(-1)\end{array}$ & $\begin{array}{l}\text { Moderately } \\
\text { decreasing } \\
(-0.5)\end{array}$ & $\begin{array}{l}\text { None } \\
(0)\end{array}$ & $\begin{array}{l}\text { Moderately } \\
\text { increasing } \\
(0.5)\end{array}$ & $\begin{array}{l}\text { Strongly increasing } \\
(1)\end{array}$ \\
\hline
\end{tabular}

3. Finally, validity and conditional impact are assessed in combination to define a net impact. This was computed in two steps. Firstly, the validity score and conditional impact score were multiplied resulting in a net impact which is, by definition, smaller or equal to the conditional impact and can range from -1 (strongly negative) to +1 (strongly positive), with the results presented on-screen. ${ }^{13}$ Subsequently, the experts were allowed to adjust the net impact so that it better reflected their expectations. Thus, we have frequently obtained two alternative measures of the net impact for each argument, one computed in a standardised fashion and the other adjusted by the respondent. We use the latter measure in our analyses and further computations as it better reflects respondents' views.

Mean likelihood (validity), mean conditional impact, and mean net impact on fertility were calculated for each argument, with means computed globally, for regions and for selected countries. These were calculated as simple averages over all respondents from a given country or region. Alternative approaches, such as weighting responses of experts by the population size of their countries of expertise, were rejected as this could give disproportionately strong influence to experts from large countries with a very small expert base.

In the analysis of responses in the low fertility module, a complementary indicator - an index of disagreement-was computed for each of the three main indicators. It gauges the level of consensus among the experts over the validity and impact of different arguments. When all responses point in one direction, the index of disagreement falls towards 0 ; when the experts are split into two opposing groups of the same size, the index reaches a maximum value of 1 . The cut-off point for delineating two diverging groups was set at 0.5 for the validity measure (recall that responses ranking below 0.5 signal disagreement with the argument's validity and vice versa) and 0 for impact and net impact. The index of disagreement is computed by relating the number of respondents holding a minority view (either positive or negative) to the number of respondents supporting a majority view.

Finally, we calculated indicators pertaining to the broad forces. First, force weights express the relative importance of a given force or cluster of arguments, as assessed by the respondents. This sums up to 100 percent (or 1) for all clusters combined. Again, we

\footnotetext{
${ }^{13}$ A zero net impact is achieved either because the respondent considered the given argument invalid (,,very likely to be wrong") or expected that the argument would have no impact on fertility. For the example above, the net impact would be calculated as $0.75 * 0.50=0.375$.
} 
compute mean cluster weights overall and by regions and countries as a simple average across all experts in a given country or region. Aggregate net impact represents a sum of net impacts computed for each expert across all 46 arguments. The more negative the score, the more arguments were suggested to have a negative impact on future fertility, and vice versa. Combined net impact, in contrast, summarises net impact across different arguments by country, region or for all analysed countries. It is computed either for individual forces or for all arguments combined. We computed it as a simple sum of the net impact for all the arguments considered. It can therefore reach values outside of the range of the net impact for individual responses $(-1$ to +1$)$.

We then analysed experts' estimates pertaining to the future level of period Total Fertility Rates in 2030 and 2050. These mean values are computed for countries and regions, as well as globally. They differ from the indicators above in that they are weighted by population size of the countries in each region in order to better reflect expected regional and global fertility levels. Finally, voluntary data regarding respondents' age, gender, country of origin and place/nature of work were collected as well as comments concerning either missing arguments or the structure of the survey. The survey as a whole was extensively tested with an estimated completion time of about 20-30 minutes.

\subsubsection{Feedback and Testing for Bias}

A number of respondents left valuable feedback that helped us evaluate the exercise. In terms of the survey itself, some respondents found it too long and there were concerns that some arguments were missing ${ }^{14}$ or of limited relevance to particular countries and regions. However, the latter concern could easily be addressed by rating these arguments as unlikely to be correct or as having no potential impact on fertility. Conceptually, some respondents expressed concern about making period TFR estimates for the future and about the time scale involved. Generally, however, most feedback was positive.

One method by which we could evaluate broader consistency and integrity of responses by individual respondents was to compare the aggregate argument score (see Section 3.2.1 above) for each expert with their estimate of the expected change in the period total fertility rate (TFR) between 2010 and 2050. It can be expected that the experts who thought that many of the factors presented will negatively affect future fertility should also, on average, forecast that fertility levels will decline. This 'internal logic' is, indeed, in evidence in Figure 5, which depicts a good correspondence between the direction and the strength of the aggregate argument score on the one side and expected fertility change on the other side (correlation coefficient is 0.38 ).

\footnotetext{
${ }^{14}$ Several broader factors have been repeatedly mentioned as missing in the survey: ethnic and socioeconomic population diversity within a country, urban-rural differences, changes in family planning policies, adolescent fertility, microeconomic cycles and economic crises, and climate change and environmental disasters.
} 
FigURE 5: AGGREGATE NET IMPACT AND ESTIMATED TFR CHANGE IN 2010-2050 (INDIVIDUAL EXPERTS, ALL LOW FERTILITY COUNTRIES COMBINED)

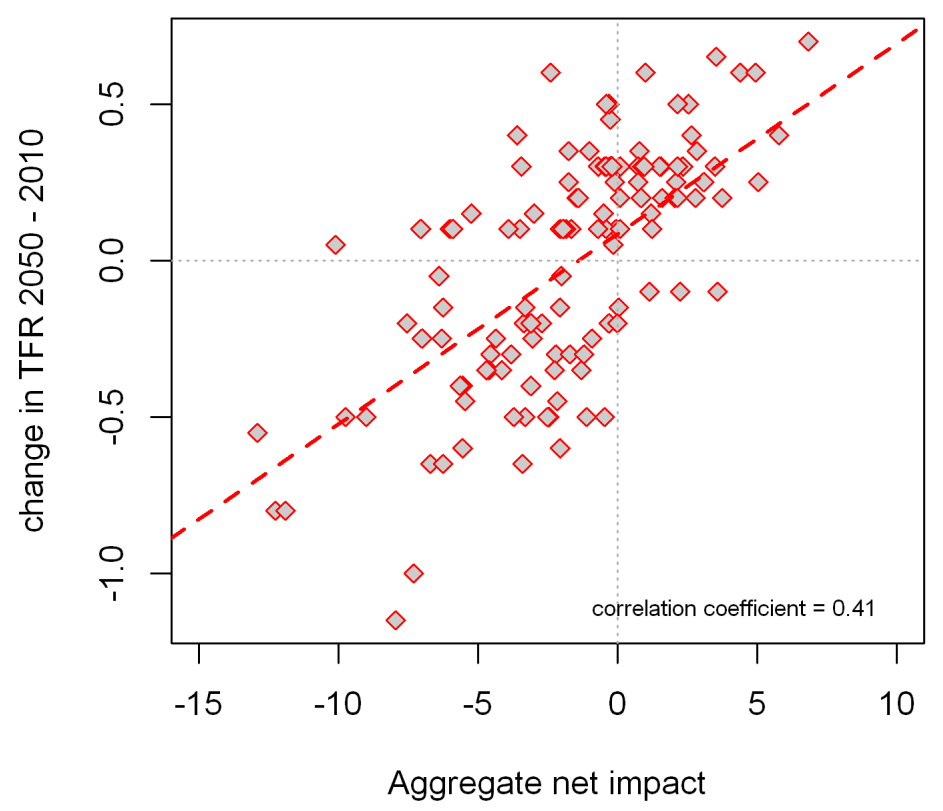

We were also concerned that the implied trajectory, or direction, of the arguments should be as balanced as possible, i.e. that a similar number of arguments pointed towards higher and lower fertility. One method of testing for any systematic bias was to analyse the extent to which respondents altered their initial estimates of TFR in 2050 as a consequence of performing the qualitative exercise. If experts disproportionately lowered their estimates, for example, then it would suggest that our arguments may have been geared towards a negative impact on fertility, potentially biasing projection scenarios that were largely based on expert's expectations (see Section 4). If the arguments were disproportionately leading in one direction, this could fundamentally alter the total projection exercise and create either a downward or upward bias.

A changed estimate of TFR in 2050 was found in 32 of the 184 questionnaires. However, as Figure 6 demonstrates, the directionality is far from uniform. Indeed, the number of respondents who revised their estimates up or down is almost identical. This suggests that our arguments were generally not biased towards indicating either lower or higher fertility futures. 


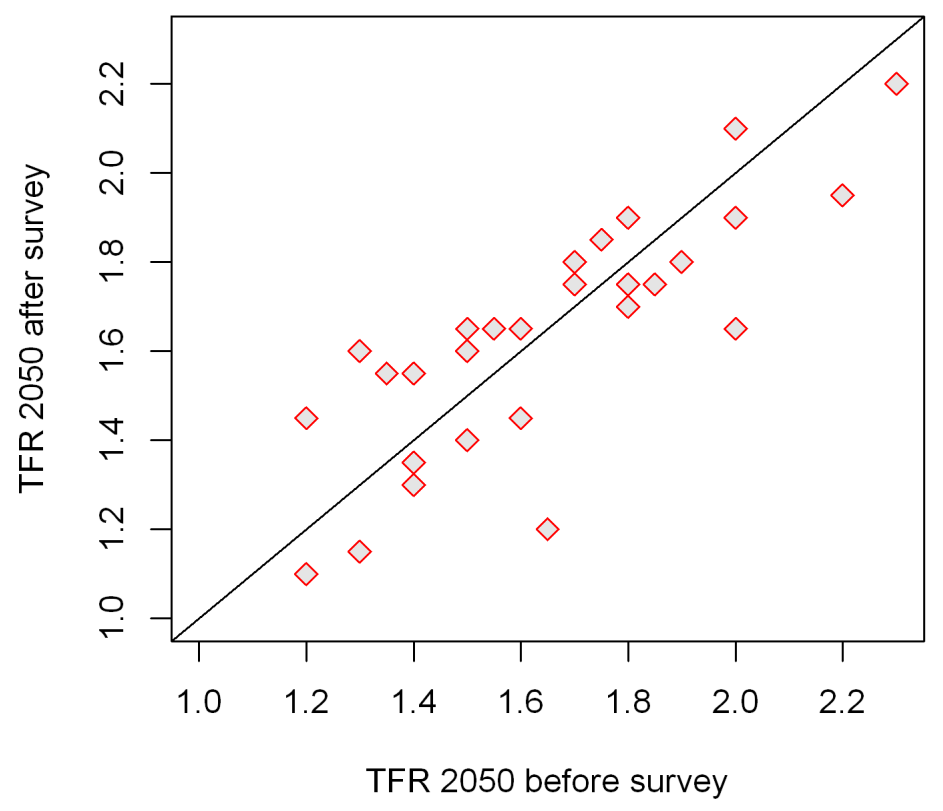

A final check was performed by examining the net impact of the 46 arguments. Overall, 26 were deemed to have a negative effect while 20 were suggested to have a positive impact.

\subsubsection{Respondents}

Altogether, 184 questionnaires on the low-fertility module of the survey have been completed by more than 170 experts (some experts chose to make two or more assessments; 110 experts revealed their full names). Appendix 3 gives a full breakdown of the respondents' profiles. The vast majority come from an academic background. Altogether, for 14 countries five or more experts have provided assessments, with the United States by far the most popular country (22 assessments), followed by China (14 assessments), Italy (12), and Germany (9). A number of experts have assessed countries outside the traditional low-fertility regions of Europe, Northern America, Japan, Australia and New Zealand. Clearly, despite uneven coverage of some countries-with no expertise provided for France with a population of 64 million and 7 assessments for Sweden with a population of 9 million - the assessments mirror quite well the wide geographical spread of low fertility today, with particularly good coverage of China, Brazil, Japan, Mexico, Turkey, and Iran.

\subsection{Results}

\subsubsection{An Overview Using CIRCOS Plots}

In Figure 7 we summarise the general results of the survey using a Circos plot (Krzywinski et al. 2009). Around the outside of the plot are abbreviated versions of the arguments and their associated code (for the complete list of all arguments, see Appendix 4). The arguments are clustered into their associated forces, which are labelled in the centre (e.g. 'Education' and 'Culture'). 
FiguRE 7: CIRCOS PLOT SHOWING A GLOBAL OVERVIEW OF FORCES AND ARGUMENTS

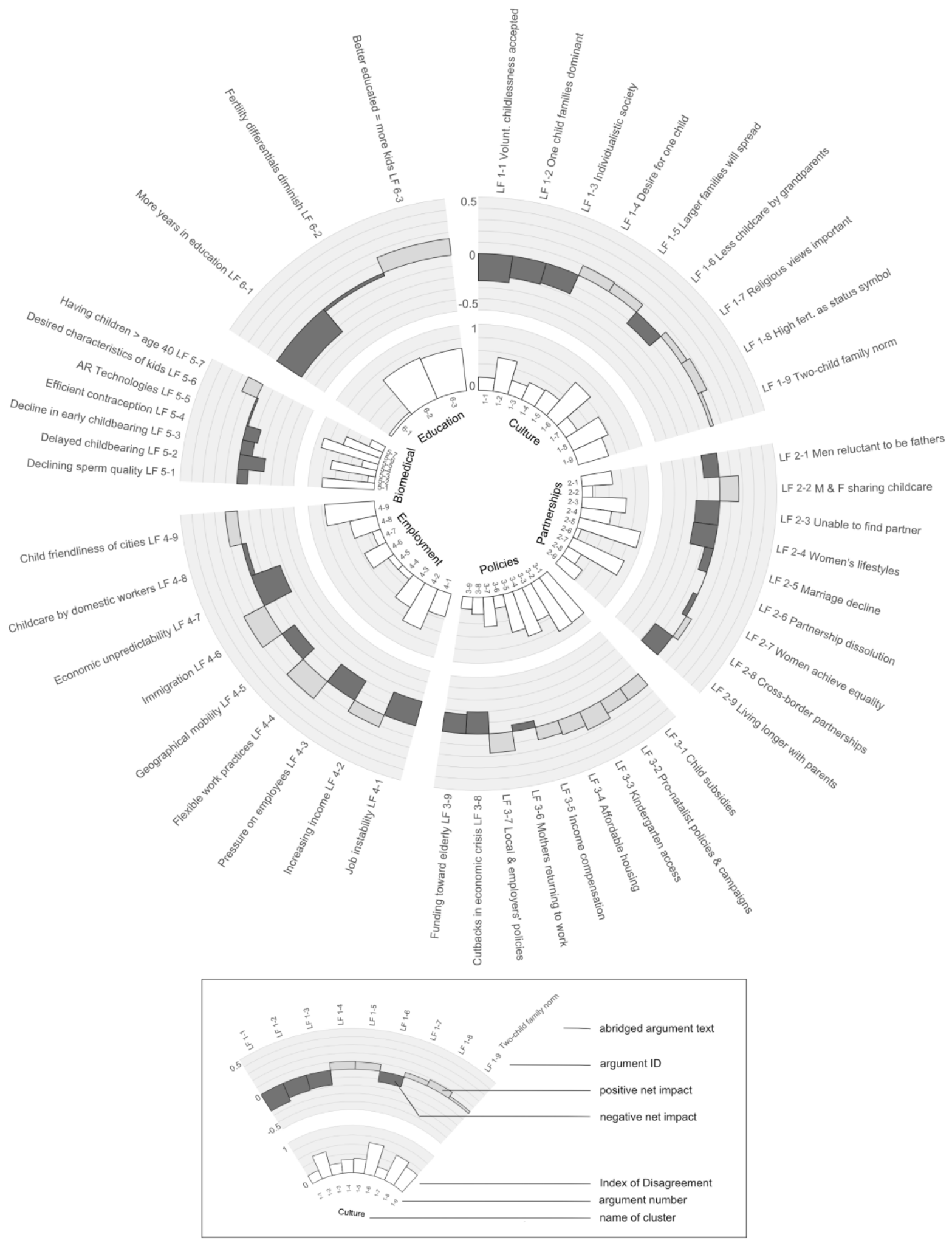




\subsubsection{The Relative Importance of Different Forces (Width of Sections)}

When considering the 'overall' forces alone, respondents felt that Forces 1 and 4, namely, "Cultural and social forces in fertility ideals, norms, and desires", and "Employment and economy" were the most pertinent for shaping future fertility trends. These forces were weighted as 0.230 and 0.221 respectively. Forces 2, 3 and 6 concerning "Partnerships, living arrangements, and gender differences", "Role of policies", and "Education" respectively, are gathered together in a second-tier cluster $(0.162,0.156$ and 0.156 respectively), while Force 5, which concerns issues relating to biomedicine (including infertility and assisted reproduction) and the timing of parenthood, was ranked last (0.077).

In Figure 7, these weights are translated into the width of the segments devoted to each force irrespective of the number of constituent arguments. Note, for example, the different sizes of the "Culture" and "Biomedical" forces. In terms of directionality, of the six groups only "Policies", broadly defined, were deemed to have a positive net impact on fertility, while "Partnerships, living arrangements and gender differences" were expected to have the most depressing effect. However, without further exploring the impact of individual arguments, which often run in the opposite direction within each broad force, this general finding is difficult to interpret (see below). Finally, there are sizeable regional differences in terms of the net impact of both the entire set of groups and individual groups of arguments by region. We address the regional differences in arguments later in Figure 8, and in Table 2.

\subsubsection{Mean Net Impact (Outer Circle)}

As discussed above, the mean net impact of an argument is derived from a combination of the stated validity of a given argument with its conditional impact (i.e. the impact it would have if it were completely true). ${ }^{15}$ In Figure 7 those arguments that were deemed to have a positive net impact are shaded in lighter grey, while those perceived to have a negative impact are shaded darker.

Across the entire survey, the arguments perceived to have the strongest net positive impact on fertility related to immigration from higher fertility countries, increasing flexibility in work practices, the provision of universal childcare and other family policies, and increased gender equity in the performance of housework. Regarding the strongest net negative impact, uncertainty in individual life course planning and the related arguments concerning job instability among the young and an inability to find the right partner were key. Two related arguments of spending more years in education and the postponement of childbearing were also expected to place a downward pressure on fertility, suggesting that most respondents expected continuation of the trend towards later timing of childbearing in

\footnotetext{
${ }^{15}$ Values of conditional impact, or the impact of an argument "if it were completely true", are difficult to interpret in that they can represent somewhat of a counterfactual in some cases. For example, the strongest negative conditional impact of -0.51 is that "One-child families will become dominant" - a highly logical response, especially outside of East Asia. However, the mean likelihood of this is just 0.41 , which is among the top three arguments reported unlikely to be right. As such, when combined with the suggested validity, the mean net impact is -0.19 , making this the tenth strongest argument in terms of negative impact upon fertility. Generally speaking, however most of the strongest arguments in terms of conditional impact on raising or lowering fertility were similar to those measured by mean net impact.
} 
the next decades. ${ }^{16}$ Finally, the argument that "Women will follow lifestyles incompatible with motherhood" also had strong negative mean net impact on fertility. This suggests that different facets of increased gender equality may have contrasting impacts on fertility that largely offset one another: while on balance a stronger engagement of men in household tasks is expected to give some boost to fertility, women's more independent lifestyles are likely to put a downward pressure on fertility rates.

\subsubsection{Validity of Arguments and the Index of Disagreement (Inner Circle)}

The validity of an argument is key to determining its net impact as well as giving useful evidence of the confidence which respondents have in the continuation of key social, cultural and economic processes affecting fertility.

The continuation of two related trends towards ever longer time spent in education and delayed childbearing were deemed to be the most valid arguments, followed by partnership dissolution and re-partnering, increased flexibility in work practices, geographical mobility and the growing acceptability of voluntary childlessness. In contrast, respondents thought that the role of religion in shaping family attitudes and the share of large families (defined relatively) were the least valid arguments, followed by the statement that 'men are increasingly reluctant to become fathers'. ${ }^{17}$

To demonstrate the importance of measuring both validity and impact, it is worth considering a particular argument in Table 1. Argument 2.6 "Partnership dissolution and re-partnering will become more common" was deemed very valid, but its mean net impact was precisely $0.0 .^{18}$

\footnotetext{
${ }^{16}$ The respondents were explicitly asked to consider the effects of given argument on cohort fertility-in that case it might be argued they expected that the negative influence of prologned education and postponed childbearing will be permanent, also affecting cohort fertility quantum (e.g., via increased infertility related to shifting childbearing to late reproductive ages). It is likely, however, that some of the respondents focused on period fertility, expecting that education and the related fertility postponement will temporarily reduce it, mainly through tempo effect.

${ }^{17}$ Note, however, that there is considerable variability in answers to the presented questions, and even the arguments generally deemed as "most likely to be wrong" were found "likely to be right" by a significant share of respondents. For instance, regarding the third "most invalid argument" that men will be increasingly reluctant to become fathers, almost a quarter of repondents (22\%) thought it is more right than wrong and another quarter (27\%) indicated that it is as likely to be right as it is to be wrong.

${ }^{18}$ As we discuss in the following section, there was a very high level of disagreement among experts over the conditional impact of this likely trend and therefore mean net impact happened to average out at zero.
} 
TABLE 1: ARGUMENTS DEEMED MOST AND LEAST VALID

\begin{tabular}{l|lll}
\hline $\begin{array}{l}\text { Argument (abbreviated, see full version in Appendix 4) } \\
\text { Most likely to be right }\end{array}$ & Group & $\begin{array}{l}\text { Validity } \\
\text { score }\end{array}$ & $\begin{array}{l}\text { Mean net } \\
\text { impact }\end{array}$ \\
\hline 6.1 More young adult years spent in education and training & 6 (Education) & 0.78 & -0.26 \\
5.2 Delayed childbearing yet more common & 5 (Biomedical) & 0.75 & -0.23 \\
2.6 Partnership dissolution and re-partnering more common & 2 (Partnership) & 0.73 & 0.00 \\
4.4 Work practices will become more flexible & 4 (Economy) & 0.71 & 0.19 \\
4.5 Geographical mobility will increase & 4 (Economy) & 0.70 & -0.14 \\
1.1 Voluntary childlessness increasingly accepted & 1 (Culture) & 0.70 & -0.24 \\
\hline Most likely to be wrong & & & \\
1.7 Religious views on family will gain importance & 1 (Culture) & 0.33 & 0.06 \\
1.5 The share of groups with larger families will increase & 1 (Culture) & 0.36 & 0.09 \\
2.1 Men increasingly reluctant to become fathers & 2 (Partnership) & 0.41 & -0.14 \\
\hline
\end{tabular}

More interesting, however, is the extent to which respondents disagreed over the validity of a given argument. This is measured by index of disagreement in the inner circle of Figure 7. The index ranges from 0.0 which would imply that all of the experts shared a similar view (either joint agreement or joint disagreement with the statement), up to 1.0, which implies half of the respondents agreed and half disagreed (Section 3.2.1). As Figure 7 shows, the arguments with the highest indices of disagreement of 0.84 or above were related to the further decline of marriage (argument 2.5, index of disagreement 0.94), continued barriers to assisted reproduction (5.5), the elimination of gender inequalities in the public sphere (2.7), and the role of governments through either taking an explicitly pronatalist stance (3.2) and increasing spending on child subsidies and tax benefits (3.1).

Clearly, there was significant disagreement among respondents concerning the institution of marriage, the accessibility of assisted reproduction and the likelihood that women achieve equality with men. Respondents were also divided on the likelihood of governmental intervention either through explicitly pro-natalist policies or through more general family policy initiatives. In each of these cases, the mean net impact is minimal.

These disagreements can also reflect regional differences in the responses on important factors shaping contemporary fertility. In the next section we examine differences by region in terms of both forces and arguments.

\subsubsection{Regional Differences in Net Impact of Arguments}

Figure 8 represents the responses to each argument differentiated by the relevant region. This should be read in conjunction with Table 2 which shows the two arguments that respondents deemed to have the strongest positive and negative impact on future fertility trends for each individual region (see Appendix 3 for listing of all the countries with at least one respondent within each region). Table 2 also shows the net impact of all forces 
combined for each region, i.e. the overall general direction in which the responses suggest fertility will go. ${ }^{19}$

Regional variation concerning "Cultural and social forces in fertility ideals, norms, and desires", and "Partnerships, living arrangements and gender differences" was broadly similar, with respondents for Latin America reporting a strong association between these forces and future rates of fertility compared to Europeans (excluding Central and Eastern Europe), who felt these forces would contribute to either only a small decrease or, in the case of Western Europe, a very small increase. Interestingly, respondents for Japan stated that 'Partnerships, living arrangements and gender differences' was the force which would have the most depressing effect on future fertility - a feature that concurs with our discussion on gender roles in Section 2, especially Box 2.

The role of policies was felt to have a potentially depressing effect upon fertility among respondents for North America, perhaps mirroring widespread scepticism about the possibility of launching more comprehensive set of family-related policies there, but a generally positive effect among respondents for Europe and Asia. We explore the causes of this contrast below. The net impact of employment and economy was generally small across the regions (with the exception of Mexico and Iran), with the opposing impacts of individual arguments largely cancelling out. Biomedicine and the timing of parenthood were held to have a universally depressing effect on fertility across the regions, with Latin America (-0.90) and Western Europe (-0.18) as high- and low-impact extremes.

\footnotetext{
${ }^{19}$ Similar analysis conducted separately for major low-fertility countries is presented in Sobotka et al. (2013).
} 

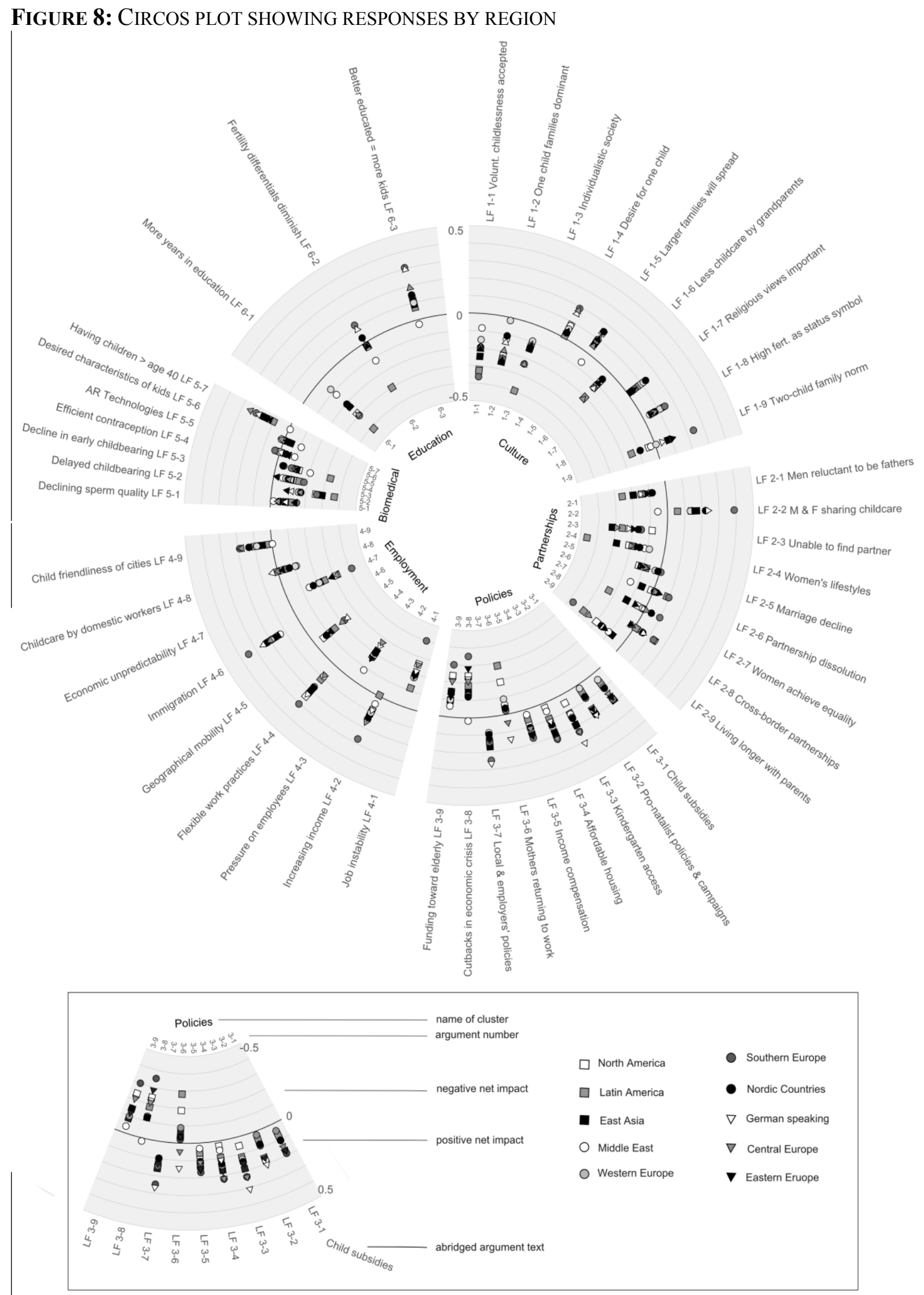
TABLE 2: TOP TWO ARGUMENTS DEEMED BY RESPONDENTS TO HAVE THE STRONGEST MEAN NET IMPACT ON FUTURE TRENDS OF FERTILITY, EITHER POSITIVELY OR NEGATIVELY

\begin{tabular}{|c|c|c|c|}
\hline $\begin{array}{l}\text { Region and } \\
\text { net impact of } \\
\text { all forces } \\
\text { combined } \\
\end{array}$ & Code & Abbreviated argument* & $\begin{array}{l}\text { Mean } \\
\text { net } \\
\text { impact }\end{array}$ \\
\hline \multirow{4}{*}{$\begin{array}{l}\text { North America } \\
(-2.20)\end{array}$} & 4.4 & Work practices become more flexible & +0.24 \\
\hline & 4.6 & Immigration from high fertility countries will increase & +0.20 \\
\hline & 1.1 & Voluntary childlessness is increasingly socially accepted & -0.32 \\
\hline & 4.7 & Economic unpredictability means uncertain life-course planning & -0.32 \\
\hline \multirow{4}{*}{$\begin{array}{l}\text { Latin America } \\
(-4.55)\end{array}$} & 4.6 & Immigration from high fertility countries will increase & +0.15 \\
\hline & 3.7 & Family-related policies by local governments \& employers & +0.14 \\
\hline & 6.1 & Ever more years of life enrolled in education & -0.41 \\
\hline & 2.4 & Women will pursue lifestyles not compatible with motherhood & -0.46 \\
\hline \multirow{4}{*}{$\begin{array}{l}\text { East Asia } \\
(-1.47)\end{array}$} & 4.4 & Work practices become more flexible & +0.20 \\
\hline & 3.3 & Government will provide universal nursery / kindergarten access & +0.19 \\
\hline & 5.2 & Delayed childbearing will become yet more common & -0.30 \\
\hline & 2.3 & Harder to find the right partner to form a family & -0.31 \\
\hline \multirow{4}{*}{$\begin{array}{l}\text { Western Asia / } \\
\text { Middle East } \\
\text { (Iran, Turkey) } \\
(-1.86) \\
\end{array}$} & 3.2 & Government will take an increasingly pro-natalist stance & +0.17 \\
\hline & 4.6 & Immigration from high fertility countries will increase & +0.13 \\
\hline & 4.1 & Unemployment and job instability among under-30s will increase & -0.19 \\
\hline & 5.4 & Broad availability and use of efficient contraception & -0.20 \\
\hline \multirow{4}{*}{$\begin{array}{l}\text { Western } \\
\text { Europe } \\
(\mathbf{- 0 . 3 1 )}\end{array}$} & 4.6 & Immigration from high fertility countries will increase & +0.19 \\
\hline & 5.7 & Assisted reproduction will allow routine childbearing at ages $40+$ & +0.17 \\
\hline & 4.3 & Employers will put more pressure on their employees & -0.18 \\
\hline & 4.7 & Economic unpredictability means uncertain life-course planning & -0.21 \\
\hline \multirow{4}{*}{$\begin{array}{l}\text { Nordic } \\
\text { countries } \\
\mathbf{( - 0 . 3 7 )}\end{array}$} & 4.6 & Immigration from high fertility countries will increase & +0.23 \\
\hline & 2.2 & Men and women will increasingly share housework and childcare & +0.22 \\
\hline & 6.1 & Ever more years of life enrolled in education & -0.20 \\
\hline & 4.3 & Employers will put more pressure on their employees & -0.20 \\
\hline \multirow{4}{*}{$\begin{array}{l}\text { Southern } \\
\text { Europe } \\
\text { (-0.32) }\end{array}$} & 2.2 & Men and women will increasingly share housework and childcare & +0.39 \\
\hline & 4.6 & Immigration from high fertility countries will increase & +0.35 \\
\hline & 4.1 & Unemployment and job instability among under-30s will increase & -0.40 \\
\hline & 4.7 & Economic unpredictability means uncertain life-course planning & -0.41 \\
\hline \multirow{4}{*}{$\begin{array}{l}\text { Austria, } \\
\text { Germany, } \\
\text { Switzerland } \\
(+0.26) \\
\end{array}$} & 3.3 & Government will provide universal nursery / kindergarten access & +0.32 \\
\hline & 6.3 & Better educated women will want more children and pursue a career & +0.30 \\
\hline & 4.3 & Employers will put more pressure on their employees & -0.25 \\
\hline & 4.7 & Economic unpredictability mean uncertain life-course planning & -0.32 \\
\hline \multirow{5}{*}{$\begin{array}{l}\text { Central } \\
\text { Europe } \\
(-1.07)\end{array}$} & 5.7 & Assisted reproduction will allow routine childbearing aged $40+$ & +0.25 \\
\hline & 3.3 & Government will provide universal nursery / kindergarten access & +0.24 \\
\hline & 2.3 & Harder to find the right partner to form a family & -0.29 \\
\hline & 4.7 & Economic unpredictability means uncertain life-course planning & -0.31 \\
\hline & & Continued on the next page & \\
\hline \multirow{4}{*}{$\begin{array}{l}\text { Eastern } \\
\text { Europe } \\
(\mathbf{- 0 . 8 9 )}\end{array}$} & 4.4 & Work practices become more flexible & +0.19 \\
\hline & 3.4 & Increased provision of affordable housing for families/young adults & +0.18 \\
\hline & 3.8 & Retrenchment of family support when economic conditions worsen & -0.28 \\
\hline & 4.7 & Economic unpredictability means uncertain life-course planning & -0.28 \\
\hline
\end{tabular}

Notes: *See Appendix 4 for full text of all arguments

In terms of positive impacts, immigration from higher fertility countries was among the top two arguments in six regions, including the Middle East but not German-speaking countries. Increasing flexibility in work practices was among the top two reasons in North America, East Asia and Eastern Europe. Policy is clearly deemed as important, with three 
related arguments concerning childcare provision, social housing and the role of local government and employers reported as a leading argument in five regions. Indeed within German-speaking countries, there is logical consistency between the top two arguments of "Government will provide universal nursery / kindergarten access" and "Better educated women will want more children \& pursue a career". Respondents in Iran and Turkey emphasised the expected role of government pronatalism, mirroring the new emphasis given to supporting higher birth rates there (Section 1.4.8). Curiously, respondents for Nordic countries and Southern Europe - traditionally at different ends of the domestic gendered division-of-labour - both agreed that an increase in male contribution to childcare and housework is likely to positively influence fertility in the future. Finally, for Western and Central Europe, the role of Assisted Reproductive Technology (ART) was deemed as important.

Aside from the economy, the more generic argument concerning delayed childbearing was prominent in East Asia and the Middle East, while in Latin America and Central Europe the related issue of ever more years spent in education was also cited. Other unique, region-specific arguments include the growing acceptability of voluntary childlessness in the United States; work-related geographical mobility in German-speaking countries; the pursuit of lifestyles by women that are incompatible with childbearing in Latin America and the increasing inability to find the right partner in East Asia. Each of these top-ranking arguments 'makes sense', especially when linked back to our thematic and region-specific reviews in Sections 1 and 2.

In conclusion, there are large differences between regions in terms of the validity and impact of different arguments, of which we highlight only the most prominent features. Several key themes can be detected across the regions, especially regarding immigration, family policy and economic uncertainty. However, there are also unique factors that are particularly salient for a given region. 


\section{Box 4: Expert views on current economic uncertainty by country}

In terms of expected negative effects on fertility, the role of economic uncertainty and job security in general, and the current economic recession explicitly are clearly highlighted by the respondents. At least one of the related arguments of "Economic issues mean uncertain life-course planning" and "Unemployment and job instability among the under-30s will increase", ranked among the top two arguments in all regions except for East Asia, Latin America and Nordic countries. It is no coincidence that these are the regions that have escaped from the recent recession relatively unscathed. Likewise, it is no surprise that these two arguments resonated particularly well in Southern Europe, where economic uncertainty is expected to have the strongest negative impact on fertility.

We can disaggregate further by examining the responses for particular countries. Table 3 shows responses to the two arguments above for countries with four or more respondents. Clearly, the experts for Italy and Spain were the most pessimistic, while those for Brazil, China and Iran appear generally less concerned. Japan is an interesting example, in that the emphasis was especially placed upon job security for the under-30s rather than the more general economic uncertainty and life planning. It is curious that Austria and Germany should score so high, especially given that both countries have weathered the recent economic recession relatively well.

TABLE 3: IMPACT OF ECONOMIC UNCERTAINTY UPON FUTURE OF FERTILITY, MEAN NET IMPACT

\begin{tabular}{llll}
\hline $\begin{array}{l}\text { 4.1 Unemployment and job instability } \\
\text { among the under-30s will increase }\end{array}$ & $\begin{array}{l}\text { 4.7 Economic unpredictability means } \\
\text { uncertain life-course planning }\end{array}$ \\
\hline Italy (N12) & -0.52 & Italy (N12) & -0.53 \\
Japan (N6) & -0.28 & Spain (N7) & -0.36 \\
United States (N22) & -0.26 & Austria (N7) & -0.35 \\
Austria (N7) & -0.26 & Germany (N10) & -0.35 \\
Turkey (N5) & -0.26 & Mexico (N6) & -0.34 \\
Sweden (N9) & -0.25 & United States & -0.31 \\
Spain (N7) & -0.22 & Australia (N5) & -0.26 \\
Germany (N10) & -0.20 & Czech Republic (N6) & -0.23 \\
Czech Republic (N6) & -0.19 & China (N14) & -0.20 \\
Mexico (N6) & -0.18 & Turkey (N5) & -0.18 \\
Iran (N9) & -0.14 & Brazil (N7) & -0.15 \\
China (N14) & -0.10 & Iran (N9) & -0.14 \\
Brazil (N7) & -0.10 & Japan (N6) & -0.10 \\
Australia (N5) & -0.08 & Sweden (N9) & -0.08 \\
\hline
\end{tabular}




\subsection{A Focus on Education}

A key element of this exercise is to examine the role of education in shaping population futures. This will be seen in both Section 5 below (and Lutz et al. forthcoming) which presents population projections by educational level as well as by age and sex. In this section, we explore the arguments concerning education in greater depth and consider their significance.

Taken together as an overall force consisting of three arguments education appears to have a relatively marginal negative impact at the global level, returning a net impact on fertility of -0.14 (recall that this number does not pertain to any specific indicator). There are, however, important regional differences. For example, in Latin America the net impact of the education force is -0.64 , indicating an expected massive fertility-depressing effect of rising educational level in the region (compared to -0.06 for the group of arguments pertaining to policies and -0.40 for employment and the economy). Meanwhile, in German-speaking Europe education had a positive effect of +0.19 - second only to the policy cluster, in fact indicating an expectation that high levels of education will increasingly be compatible with motherhood.

\subsubsection{Education Arguments}

The education component of the survey contained three arguments:

- 6.1 'People will spend ever more years of their young adult life enrolled in education and professional training on the job'

- 6.2 'Fertility differentials by level of female education will diminish'

- 6.3 'There will be a new trend for better educated women to have more children and simultaneously pursue a professional career'

The validity of these arguments and their conditional as well as net impacts are depicted for all low-fertility countries combined in Figure 9, while the net impact is also shown by region in Figure 8. Regional variation in expert expectations regarding the impact of education on future fertility is further analysed in Section 5.3.5. 
FIGURE 9: VALIDITY, IMPACT AND NET IMPACT (WITH INDICES OF DISAGREEMENT AS BLACK DOTS) FOR ALL COUNTRIES IN LOW FERTILITY DATASET
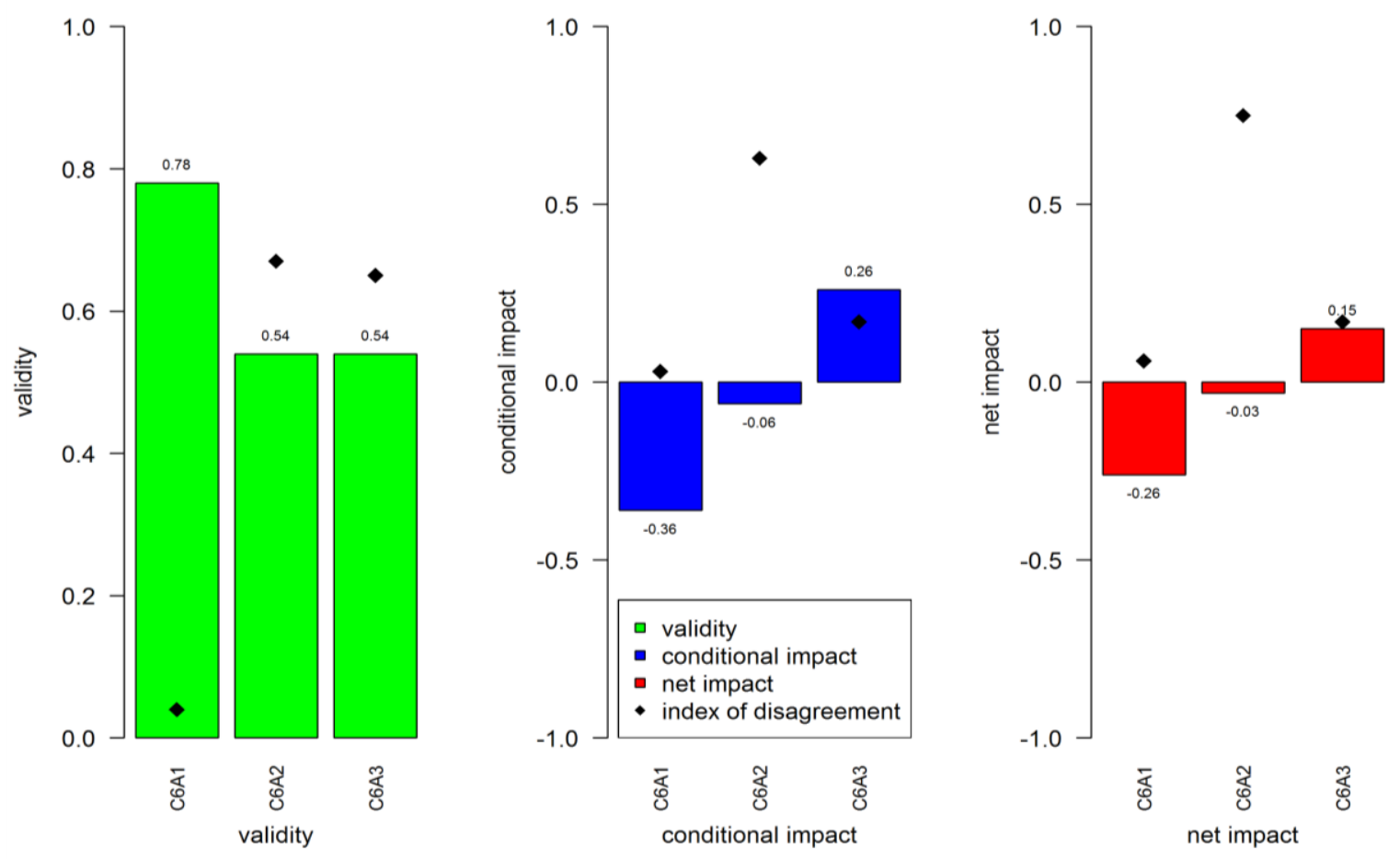

The intimation in argument 6.1 is that as more and more people spend increasing periods of their adult life enrolled in education (usually tertiary education), which is frequently perceived as being incongruous to raising children, a depressing effect on fertility could ensue. There was generally very strong agreement that the amount of time spent by young people in education would increase. Indeed, on a global level this was the most likely scenario across all the arguments. Not surprisingly, most respondents predicted this would have a negative effect on fertility. The global mean net impact was -0.26 . After "Individual life-course planning becoming ever more uncertain", this argument had the strongest individual net impact among the 46 arguments in the exercise and was negative in all regions. With regard to regional variation, this argument was found to have smaller impact in Western Europe (-0.08) and Middle East $(-0.12)$. The strongest negative impact was envisioned for Latin America (-0.41) and South Europe (0.30). ${ }^{20}$

The second and third educational arguments (6.2-6.3) approach the widely discussed topic of the possible convergence of fertility among women with different levels of education discussed in Sections 2.7 and 5.3.1-5.3.5). This could take place either because higher educated women will be able to have more children (argument 6.3), or, presumably, due to further reductions in fertility among women with low levels of education. Unlike argument 6.1, 6.2 saw significant levels of disagreement among the respondents in terms of both validity and impact, suggesting considerable ambiguity among respondents on whether achieved level of education will remain an important differentiating factor in fertility. For argument 6.3, meanwhile, most respondents agreed on the conditional impact of the

\footnotetext{
${ }^{20}$ For regional differences in validity and conditional impact, see Figure 15 in Section 5.3.5.
} 
argument if true, but there was significant disagreement on the likelihood that highly educated women will achieve higher fertility in the future.

As Figure 8 shows, the regional variation within responses to argument 6.2 is relatively slight, with a congregation around no overall impact, with the exception of Latin America and Middle East. Argument 6.3, meanwhile, revealed some interesting regional variations. Respondents in Southern Europe and German-speaking Europe reported the highest net impact of better educated women having more children combined with a career (both about 0.3). When we compare this to East Asia, Latin America and Middle East, where the net impact was perceived to be virtually non-existent, we might conclude that this represents the two European regions envisioned to progress through Esping-Andersen's (2009) 'incomplete gender revolution,' with the East Asian countries trailing well behind.

\section{Quantitative Forecasts of Future Fertility Levels: Experts' Views}

\subsection{Introduction}

The development of assumptions for the projection exercise was a multi-stage process. In step one, respondents to the survey were asked to provide point (main) and range (covering 80 percent confidence interval) estimates for period TFR in 2030 and 2050. In step two, these estimates were analysed and interpreted by an invited group of experts in low fertility at a meeting in Vienna in December 2011. ${ }^{21}$ These experts focussed on discussing the likely long-term fertility trends through 2050 in major low fertility countries such as China, the United States, Brazil, Japan, Russia, Germany, and Iran as well as in countries representing broader regions (e.g., Sweden for the Nordic countries). They also discussed possible factors and mechanisms influencing fertility in the very long-term horizon through 2200. Finally, in step 3 numerous adjustments to the projections have been made jointly by the WIC teams working on low-fertility countries, high-fertility countries, databases (including data on education-fertility differentials) and defining and implementing projection scenarios (see Section 5 and Chapter 9 of Lutz et al., forthcoming). During this process, future fertility rates have been forecasted for every country in the "low-fertility" group (see Appendix 2), including the countries with no expert evaluation or expert discussion, by means of implementing regional averages. To assure consistency in

\footnotetext{
21 Altogether, the organisers (Basten, Sobotka, and Zeman) and 20 invited experts participated in the meeting, of which twelve were from abroad and eight from the Vienna area (WIC / VID / IIASA researchers). Here we provide the complete list of all participants and their institutional affiliation at the time of the meeting: Alicia Adsera, Princeton University; Margareth Arilha, NEPO / UNICAMP (Brazil); Bilal Barakat, IIASA, VID; Jan Van Bavel, University of Leuven; Francesco Billari, Bocconi University, Milan; Stuart Basten, University of Oxford; William Butz, VID, IIASA; Minja Kim Choe, East West Center, Hawaii; Joshua R. Goldstein, MPIDR, Rostock; K. S. James; Institute for Social and Economic Change (India); Leiwen Jiang, National Center for Atmospheric Research, Boulder; Samir KC, IIASA; Tomáš Kučera, Charles University, Prague; Wolfgang Lutz, VID, IIASA, Vienna University of Economics and Business; Elsie Pamuk, IIASA; Dimiter Philipov, VID; Anna Rotkirch, Population Research Institute, Helsinki; Warren C. Sanderson, State University of New York at Stony Brook and IIASA, Vienna; Tomáš Sobotka, VID; Vegard Skirbekk, IIASA; Olivier Thévenon, INED, Paris and OECD, Paris; Kryštof Zeman, VID.
} 
projections within broad geographical regions, future fertility in Latin America, South-East Asia and most of West Asia and Middle East (except Iran, Israel and Turkey) was projected using a forecasting model applied by the researchers analysing "high fertility countries" in the WIC projections exercise (see Chapter 4, Lutz et al., forthcoming). In addition, the scenarios of fertility by level of education have been specified (Section 5.3.6 below). In this section we concentrate on presenting the opinions of the respondents in the survey.

One of the key elements of the exercise was to obtain predictions of period TFRs by the respondents for 2030 and 2050. These not only form the basis for the projection scenarios, especially the main variant, but are also a means of providing a local expert-based "bottom-up" comparison to the model-derived assumptions from the UN World Population Prospects (UN 2011) ${ }^{22}$. In this section we outline some of the key findings, presented as global results across all analysed countries, world regions and selected countries. Regional means were created as population-weighted averages for all countries within each region with available responses by at least two experts. We use final point projections of the TFR that the experts had a chance to revise after assessing all the arguments pertaining to the future fertility trends.

\subsection{Overall Trends}

\subsubsection{Global Trends}

The overwhelming global message from the survey is that respondents expect that fertility will stay below the replacement level to 2050, even should the current negative tempo effect eventually lose relevance. As Table 4 shows, among the experts who changed at least some of the predefined future TFR values (point, low, or high estimate; $\mathrm{N}=174$ out of the total of 184), the overwhelming majority thought fertility would remain below replacement to 2050, with about one-sixth expecting it to reach a very low level of 1.3 or below. Even in the high variant - or the expert-defined upper level of the 80 percent confidence interval - over one-third of experts anticipated that fertility would remain below two children per woman. Because recent fertility rates were very low in many countries, more experts expected a TFR increase between 2010 and $2050(\mathrm{~N}=75)$ than expected a decline $(\mathrm{N}=61)$. Only few expected that these increases or declines would be of a large magnitude of 0.5 or higher.

\footnotetext{
${ }^{22}$ For more details on deriving the United Nations set of probabilistic fertility fertility projections see Alkema et al. (2011), Raftery et al. (2012), and the supporting documentation to the UN population projections (UN 2012).
} 
TABLE 4: EXPERTS' PROJECTION OF THE PERIOD TFR IN 2050 (FINAL MAIN ESTIMATE OF ALL LOW-FERTILITY COUNTRIES SURVEYED; SELECTED RESULTS)

\begin{tabular}{|c|c|c|}
\hline & $\mathrm{N}$ (experts) & $\%(\mathrm{~N}=174)$ \\
\hline \multicolumn{3}{|l|}{ Point estimate of the TFR in 2050} \\
\hline 2.0 or higher & 26 & 15.2 \\
\hline ...of which above 2.1 & 13 & 7.6 \\
\hline 1.5 or lower & 53 & 30.5 \\
\hline ...of which below 1.3 & 24 & 13.8 \\
\hline \multicolumn{3}{|l|}{ TFR in 2050 will be... } \\
\hline Lower than in 2010 & 61 & 35.1 \\
\hline$\ldots$ of which by 0.5 or more lower & 19 & 10.9 \\
\hline Higher than in 2010 & 75 & 43.1 \\
\hline ...of which by 0.5 or more higher & 11 & 6.3 \\
\hline Same as in 2010 & 38 & 21.8 \\
\hline
\end{tabular}

These expectations differ considerably from the higher TFR values projected by the 2010 round of the UN population projections (UN 2011). Figure 10 shows the mean point projections of the TFR in 2050 for each country with at least two participating experts, as contrasted with the UN medium projection. In 27 out of 31 countries the experts expected lower fertility in the future than the UN projection; the four exceptions are Argentina, Brazil, Mexico and Georgia. In as many as twelve countries the experts expect the TFR to be at least 0.3 lower than the median UN projection in 2050; this discrepancy surpasses 0.5 for Japan and 0.4 for Russia and Romania. The experts expect sizeable fertility declines (by 0.2 or more) and/or stagnation at a low level (1.6 or lower) for the majority of the most populous low-fertility countries, including China, Iran, Russia, Turkey Italy, and Japan (see also Table 5 below). These expectations paint a rich- and medium-income world where many smaller countries may retain fertility rates relatively close to the replacement levels, but some of the major countries experience persistent low fertility. Overall, the UN model predicts TFRs for the total group of analysed countries of 1.70 in 2030 and 1.84 in 2050; the respondents' mean projection is 1.58 and 1.57 , respectively. ${ }^{23}$ Overall, the number of countries with a TFR below 1.5 is expected to diminish, and most countries are expected eventually to fall in a broad range between 1.50 and 1.99 (Figure 11), with 11 out of 31 countries belonging to the low fertility group (1.50-1.69) and another 13 to moderately low fertility group (1.70-1.99) as of 2050. The diminishing number of countries expected to retain very low (TFR below 1.5) or around-replacement fertility (TFR at 2.0 or higher) indicates that the experts envision a gradual trend towards convergence to moderate sub-replacement fertility for most countries. This is illustrated in Figure 10, which depicts a close correlation between the observed TFR level in 2010 and the expected TFR change between 2010 and 2050. Almost all countries with the TFR at

\footnotetext{
${ }^{23}$ Population-weighted average (using 2010 population size) for 31 countries with two or more respondents; see Table 5 for an alternative estimate of future TFR trends based on a simple average across all experts.
} 
1.7 or lower are expected to experience an increase in fertility, while almost all countries with the currently higher TFR level are expected to see future fertility declines.

Figure 13 presents a further comparison to the UN's 2010 assumptions, showing both the medium assumption and the 80 percent confidence intervals for all low-fertility countries with at least two experts in 2030 and 2050 . The UN probabilistic projection is remarkably similar to the WIC expert-base projection in its upper boundary of the 80 percent confidence intervals, but it shows progressively higher values of the main TFR estimates as well as of the lower boundary of the 80 percent confidence intervals, especially after 2025 .

Turning to a country level confirms the expectation of a low-fertility future. Among the large countries, two East Asian giants, China and Japan, are ranked at the bottom of the expected future TFR levels, with the point estimates of their TFR in 2050 of 1.31 and 1.42, respectively (see next section). These expectations contrast with much higher projected values by the UN. Given China's high share of the population of low fertility countries and, indeed, of the global population, these low expected fertility rates have strongly contributed to overall low projected TFR across the entire group of analysed countries.

FIGURE 10: PROJECTED PERIOD TFR IN 2050; MEAN POINT ESTIMATE OF THE EXPERTS AS COMPARED WITH THE UN MEDIUM VALUE, 31 COUNTRIES WITH AT LEAST TWO EXPERT ASSESSMENTS

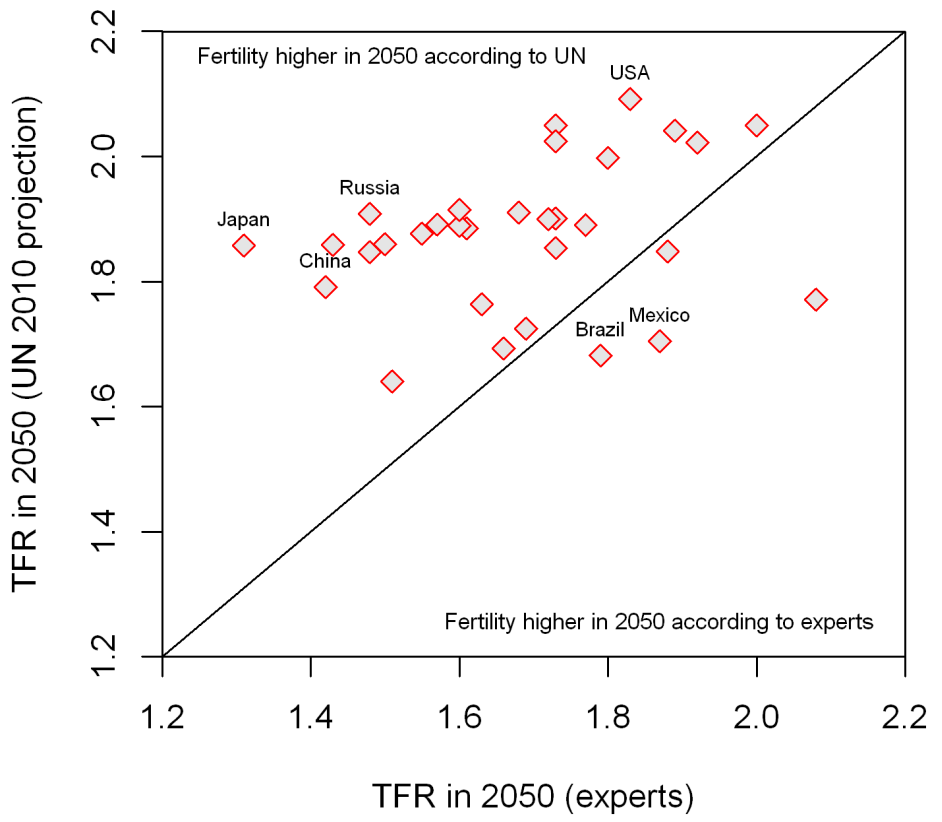


FIGURE 11: DISTRIBUTION OF THE OBSERVED (2010) AND PROJECTED (2030 AND 2050) PERIOD TFR IN 31 LOW-FERTILITY COUNTRIES WITH AT LEAST TWO EXPERT ASSESSMENTS (POINT ESTIMATE, MEAN VALUE ACROSS ALL EXPERTS FOR EACH COUNTRY)

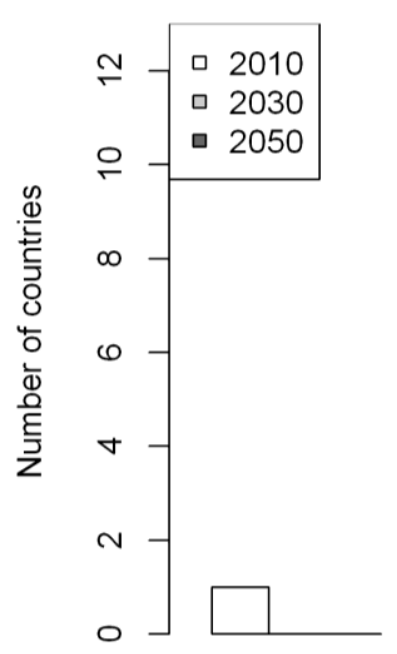

$1.00-1.29$

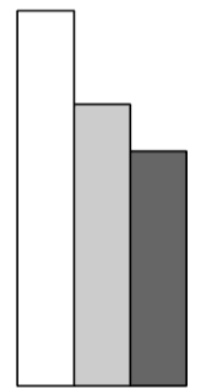

$1.30-1.49$

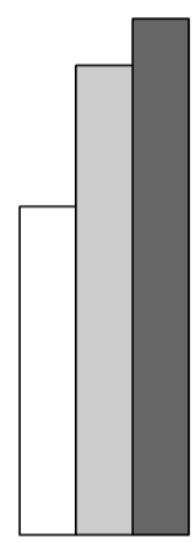

$1.50-1.69$

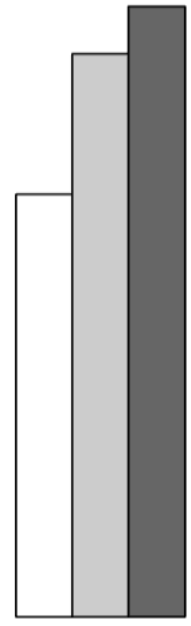

$1.70-1.99$

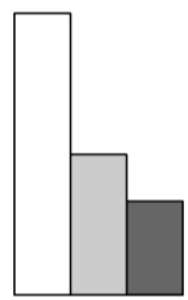

$2.00-3.10$

FIGURE 12: PROJECTED PERIOD TFR IN 2050; MEAN POINT ESTIMATE OF THE EXPERTS AS COMPARED WITH THE 2010 VALUE, 31 COUNTRIES WITH AT LEAST TWO EXPERT ASSESSMENTS

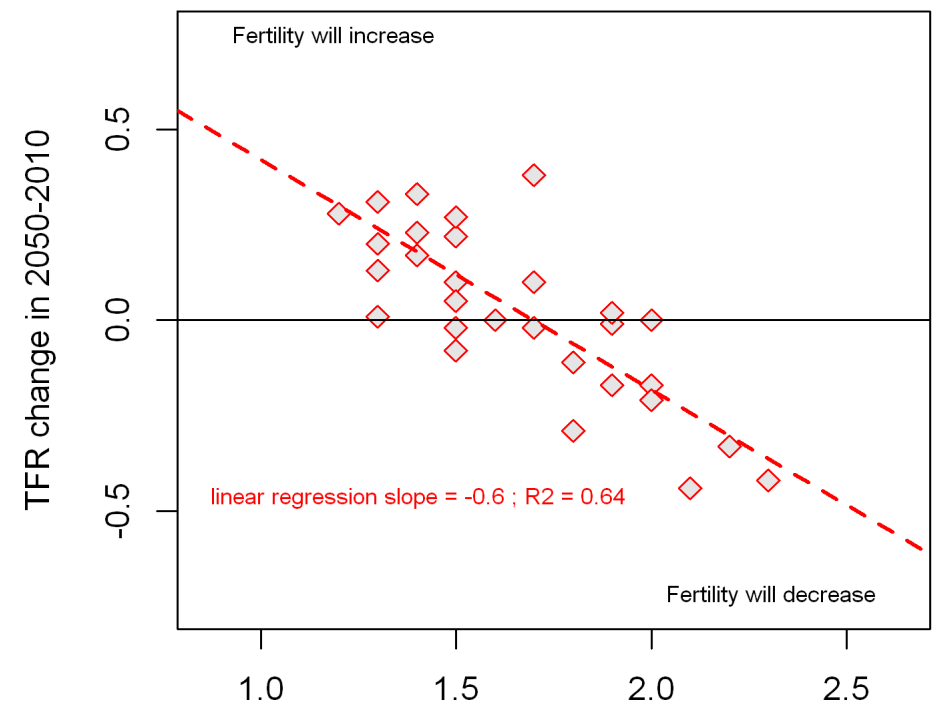

TFR in 2010 
FIGURE 13: TFR ESTIMATES AND ASSUMPTIONS (INLCUDING 80\% CI) FOR ALL LOWFERTILITY COUNTRIES COMBINED, 1980 TO 2050 AS DERIVED FROM UN 2010 WPP (PROBABILISTIC SCENARIOS) AND EXPERT SURVEY

\section{Low fertility countries}

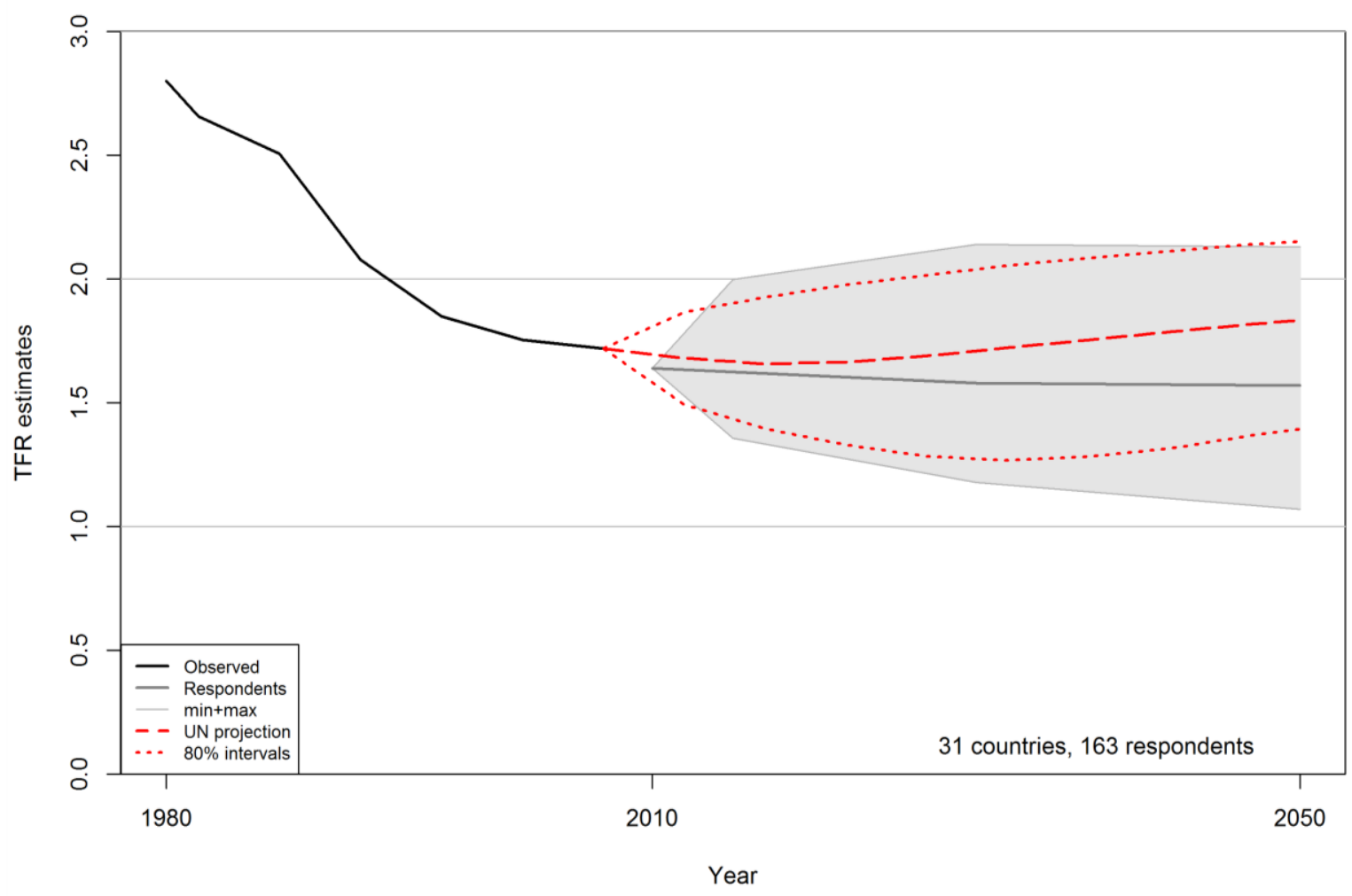

Notes: Only countries with at least two expert assessments included. Global mean weighted by population size of countries included. See Appendix 5 for similar graphs by regions. 
TABLE 5: OBSERVED PERIOD TFR IN 2010 AND PROJECTED PERIOD TFR IN 2050 IN LARGEST LOW-FERTILITY COUNTRIES AND IN SELECTED COUNTRIES REPRESENTING BROADER REGIONS; EXPERT'S EXPECTATIONS (MEAN VALUE OF POINT ESTIMATES AND 80\% CI) AND UN WPP 2010 MEDIUM PROJECTION VARIANT

\begin{tabular}{|c|c|c|c|c|c|c|c|}
\hline \multirow{2}{*}{ Country } & \multirow{2}{*}{$\mathbf{N}^{5)}$} & \multirow{2}{*}{$\begin{array}{c}\text { 2010: } \\
\text { observed } \\
\text { TFR }^{4)}\end{array}$} & \multicolumn{2}{|c|}{ 2030: mean } & \multicolumn{3}{|c|}{2050} \\
\hline & & & Expert & $\begin{array}{c}\text { UN WPP } \\
2010\end{array}$ & $\begin{array}{c}\text { Expert: } \\
\text { mean }\end{array}$ & $\begin{array}{c}\text { 80\% CI: } \\
\left.\min -m a x^{6}\right)\end{array}$ & $\begin{array}{c}\text { UN WPP } \\
\text { 2010: } \\
\text { mean }\end{array}$ \\
\hline United States & $22(19)$ & 1.93 & 1.93 & 2.09 & 1.83 & $1.38-2.30$ & 2.09 \\
\hline China & $13(7)$ & 1.45 & 1.41 & 1.61 & 1.42 & $0.93-2.09$ & 1.79 \\
\hline Australia & $5(4)$ & 1.89 & 1.83 & 2.01 & 1.73 & $1.48-2.06$ & 2.05 \\
\hline Brazil & $7(2)$ & 1.94 & 1.83 & 1.61 & 1.79 & $\ldots$ & 1.68 \\
\hline Mexico & $5(1)$ & 2.30 & 1.95 & 1.80 & 1.92 & $\ldots$ & 1.70 \\
\hline Iran & $8(1)$ & 1.90 & 1.77 & 1.36 & 1.54 & $\ldots$ & 1.64 \\
\hline Japan & $6(2)$ & 1.39 & 1.30 & 1.68 & 1.31 & $\ldots$ & 1.86 \\
\hline Turkey & $5(2)$ & 2.04 & 1.82 & 1.74 & 1.66 & $\ldots$ & 1.69 \\
\hline Czech Republic & $6(6)$ & 1.49 & 1.63 & 1.74 & 1.72 & $1.39-2.28$ & 1.90 \\
\hline Germany & $9(4)$ & 1.39 & 1.57 & 1.71 & 1.58 & $1.23-2.06$ & 1.89 \\
\hline Italy & $12(7)$ & 1.40 & 1.55 & 1.72 & 1.57 & $1.30-1.92$ & 1.89 \\
\hline Russia & $4(2)$ & 1.54 & 1.46 & 1.76 & 1.48 & $\ldots$ & 1.91 \\
\hline Spain & $6(4)$ & 1.39 & 1.58 & 1.74 & 1.68 & $1.34-2.12$ & 1.90 \\
\hline Sweden & $7(6)$ & 1.99 & 1.90 & 2.00 & 1.89 & $1.47-2.23$ & 2.04 \\
\hline United Kingdom & $4(4)$ & 1.98 & 1.99 & 1.96 & 1.92 & $1.31-2.65$ & 2.02 \\
\hline All countries - weighted ${ }^{1)}$ & 31 countries & 1.64 & 1.58 & 1.70 & 1.57 & $1.07-2.13$ & 1.84 \\
\hline All, excluding China $^{2)}$ & 30 countries & 1.75 & 1.72 & 1.76 & 1.68 & $1.18-2.16$ & 1.87 \\
\hline All countries - average ${ }^{3)}$ & $174(105)$ & 1.69 & 1.70 & 1.77 & 1.68 & $1.27-2.21$ & 1.88 \\
\hline
\end{tabular}

Notes: 1) These data show global mean TFR for all the countries with at least two expert evaluations (see Appendix 3), weighted by population size of these countries in 2010; these computations are based on 163 expert assessments.

2) These data show global mean TFR for all the countries with at least two expert evaluations excluding China, weighted by population size of these countries in 2010; computations are based on 150 expert assessments.

3) These data show simple average across all experts participating in the survey and the corresponding value for the UN projection (weighted by the number of respondents in each country)

4) 2010 TFR values are based on VID (2012), Eurostat, national statistical offices and, for China, on Zhongwei Zhao's estimate. Note that the experts participating in the online survey were shown slightly different values published by Population Reference Bureau (PRB 2011); see Appendix 1, Section A1.1 for more details.

5) Number of respondents giving valid $80 \%$ confidence interval shown in brackets

6) Figures shown only for countries with at least four respondents providing confidence intervals 


\subsubsection{Regional Trends}

In Appendix 5 we present graphs for each low fertility region analysed in this working paper (data are weighted by population size). Here we give a brief overview of the general trends (see also Table 5 above; the list of countries included in each region is provided in Appendix 3). ${ }^{24}$

For Western and Nordic Europe, the respondents broadly concurred with the UN projections of stabilisation, with the predictions centred on marginally below-replacement fertility (TFR approximately 1.9 by 2050). Meanwhile, in the lower fertility areas of Europe a more mixed picture emerges. The respondents for "German speaking" countries predicted a constant increase in TFR to 2050, albeit below those predicted by the UN. Similarly in Southern Europe, the respondents envisaged a general increase in TFR to 2030 and 2050, although again generally not at the speed predicted by the UN. Central Europe also sees notable increases in TFR, which are more closely matched to the UN model. In Eastern Europe the experts predicted a general stagnation or very slight increase in fertility. For Russia and the Ukraine, the respondents expected a slight decline in TFR to 2030 followed by recuperation to 2010 levels by 2050 .

For North America, 22 of the 25 respondents made predictions for the United States. For both 2030 and 2050, while the UN predicts stagnation at around replacement level, the respondents predicted an overall slight TFR decline from 2.0 in 2010 to the means of 1.93 in 2030 and 1.83 by 2050 . The lower boundary of 80 percent confidence interval in 2050 (1.38) was predicted to be significantly lower than the Low variant of the UN model (1.59).

In East Asia, the respondents generally predicted either stagnation or decline in TFR. In particular, the views of these respondents are at odds with the UN model moving to 2050, in that almost all the survey responses predicted a lower TFR than the UN. The 13 respondents for China generally expected stagnation at or around 1.4-1.5, while the UN's medium variant is 1.79 and the low variant 1.31. Respondents for Japan were even more sceptical about the possibility of future fertility increases and with the mean predicted TFR of 1.31 in 2050 they differed most from the UN medium-variant projection of 1.86.

Finally, for the rather heterogeneous group of Latin America (15 responses, three countries), there is a general concurrence with the UN model of continuing fertility decline.

\section{Projecting Future Fertility}

The preparation of fertility scenarios involved a complex decision-making process engaging several research teams working on the WIC Global Population Projection as well as multiple interactions with selected experts outside the teams. The key decisions concerned defining the main variant of the period TFR in 2030 and 2050, agreeing on

\footnotetext{
24 Note that the experts focused in their assessment on individual countries and regional trends are subsequently built up from these country-specific trajectories that can also be seemingly inconcistent and moving in opposite directions.
} 
long-term fertility pathway through 2200, projecting fertility trajectories by level of education, formulating low and high variants of fertility scenarios for each educational category and, finally, coordinating the teams working on the low and high-fertility countries in order to achieve a degree of uniformity in the methods used and data analysed. This section describes the development of these fertility scenarios as well as contrasts to the fertility scenario-making for the countries with higher fertility levels. More detailed materials and descriptions appear as Appendices.

\subsection{Formulating Main Scenario Point Projections for 2030 and 2050}

This section outlines the process of deriving the main TFR projection scenario for 2030 and 2050 for all countries and regions covered in this paper except for Latin America and parts of Middle East (only Iran, Israel and Turkey projected here), which are projected following the model employed for the higher-fertility countries (see Chapters 4 and 9 of Lutz et al. forthcoming; see also below). Additional information is provided in Appendix 1. The observed TFR data for the base year of the projection, 2010, originate from a variety of sources. For most low fertility countries, these data were derived from the PRB database or national vital statistics and are relatively precise, computed annually, and usable without further adjustments, given good and practically complete vital statistics coverage. Only in a few cases such as Iran and the Caucasus countries data coverage is patchy, meaning the initial TFR data should be treated as "qualified estimates", based mostly on the UN (2011) and PRB (2011) databases. The most notable exception from relatively good data coverage is the most populous country, China, where past numbers of births and fertility rates remain highly uncertain (see Box 1 above).

The point estimates of the period TFR in 2030 and 2050 (main scenario) were derived in several steps. Following experts' predictions gathered in the online survey and at the Vienna meeting where the TFR scenarios for the key countries were settled, the coordinating team (i.e., the three main authors in this working paper), in collaboration with other teams, formulated the point estimates for all low-fertility countries. This was done by selecting one or two key countries in each region for which the fertility rates in 2030 and 2050 were defined by experts. Within each region, countries for which no projected TFRs were available by the online survey experts (at least two per country) or invited experts, were assumed to follow an identical TFR trajectory as one of the key countries in that region. For instance, countries in Central Europe for which no future TFRs were available from the experts survey were assumed to follow the same trajectory as either the Czech Republic (a higher-fertility pathway) or Hungary (lower-fertility pathway); the definition of the key countries and the decision to which key country each individual country was attached was mostly done by the low-fertility coordinating team (see details on deriving future TFR trends by country in Appendix 1).

Finally, a complete TFR trajectory has been constructed for 5-year periods from 20102014 to 2045-2049, assuming a linear trend between the starting-year value and the two years for which the TFR was already projected, 2030 and 2050. However, the initial fiveyear projection period, 2010-2014, constitutes an exception whereby in countries with an increasing TFR trajectory through 2030, the rise occurs only after 2015 and the TFR in 2010-2014 remains identical with the most recent observed data, usually for 2011 and in some cases for 2012. This is a simple effort to account partly for the effect of the ongoing 
economic recession, during which fertility rates are likely falling in most countries (see Section 2.4). Since there was heterogeneity of country-specific TFR trends in Europe during the recent recession (see Box 3) and the future course of the recession and economic recovery were unknown at the time fertility scenarios were developed, a 'conservative' strategy was employed, assuming no TFR increase in the initial period rather than modelling its potential temporary decline.

To derive uncertainty intervals around the main (point) TFR estimates, two possibilities were considered. First, the more flexible and less standardised option was to define low and high projected TFR representing $80 \%$ confidence interval (CI) on the basis of experts' assessment of country-specific CI in 2030 and 2050 (see Sections 4.2.1 and 4.2.2). The second option followed quite "traditional" solutions, providing a standardised and easilyderived estimate for all countries, namely, using either a relative or a fixed absolute interval around the main TFR estimate. Initially, the first option was selected, which allows both reflecting the experts' views and mirroring the likely future regional differences in uncertainty about fertility trends, which should be higher in regions undergoing rapid fertility changes in last decades, such as Middle East. However, this solution became impractical due to low response rates in some countries where many respondents did not provide assessment about the likely future uncertainty in their TFR estimates and also due to implausibly high variation of these estimates between some countries belonging to the same region. As a result, a standardised (although somewhat simplistic) solution has been chosen, assuming a low vs. high TFR interval of 20 percent around the main TFR projection in 2030, increasing to 25 percent in 2050 (see also Chapter 9 of Lutz et al., forthcoming, Section 2.2). This roughly reflects the uncertainty interval in 2050 averaged across all experts providing its assessment (Table 5 above, last line): starting with an average TFR value of 1.68 predicted by the experts for that year, a $25 \%$ range around that mean, representing $80 \%$ CI gives a TFR from 1.26 to 2.10 compared with the average of experts-defined $80 \%$ CI of 1.27-2.21. To reflect an initial sharp increase in projection uncertainty in the early projection period, further exacerbated by unstable fertility rates during the economic recession after 2008, two thirds of the estimated $80 \%$ CI observed by 2030 would open up already during the first projection period, 2010-14.

The outlined TFR projections differ considerably from how projection scenarios have been derived for the countries with high fertility, which relied less on the online survey of experts and more on the input given at an expert meeting in Kathmandu and on the modelling of future TFR trajectories. This modelling was based on the most recent observed fertility level and on the previous trajectories of fertility decline in the presently low-fertility countries (Chapter 4 of Lutz et al., forthcoming, Section D3). Since we have been able to collect comprehensive expert input covering most low-fertility regions, and also given that there are no systematic experiences of long-term TFR changes in posttransitional societies with low fertility on which such a model can be based, the scenarios for low-fertility countries did not utilise such a model. However, to prevent coherent geographical regions from following two different projection set-ups, all Latin American and most of Middle East and Southeast Asian countries were merged and their future TFR scenarios modelled by the team covering high-fertility countries (Chapter 4 of Lutz et al, forthcoming). 


\subsection{Long-Term Futures: Preparing Fertility Scenarios Beyond 2050}

Fertility forecasting has been dominated by the paradigm of the demographic transition. Fertility was thought to fall from a high comparatively stable level to a low comparatively stable level. This transition was considered to be irreversible, so once a low enough level of fertility was achieved it would never increase. The textbook versions of the demographic transition generally show a crude birth rate and crude death rate converging, leading to a cessation of natural population growth (Caldwell 1976; Szreter 1993). This homeostatic convergence towards long-term stationary population would imply, given current and projected very low (and further declining) mortality levels, fertility rates stabilizing at around two births per woman.

However, this stylised model does not fit the empirical evidence on post-transitional fertility and, arguably, gives no guidance about future fertility trends (Lutz 2007). In one country after another, this post-transitional stage has been associated with at least a brief, but often persistent, era of fertility being below the replacement-level threshold (see Section 1). Therefore, achieving a long-term equilibrium of fertility and mortality levels remains very uncertain. ${ }^{25}$ The key issue is whether below-replacement fertility is a temporary phenomenon or whether the long-term future of most rich countries implies a continuation of low fertility rates.

Four arguments are commonly put forth to suggest that fertility rates may eventually increase in countries with low fertility rates. First, period TFR declines to very low levels have been to a large extent fuelled by the postponement of childbearing to higher ages (Kohler et al. 2002; see Section 2.2). This postponement will eventually come to an end, paving the way for a modest rise in period TFRs fuelled by fertility increases ("recuperation") at higher childbearing ages (Bongaarts 1999; Sobotka 2004a, Frejka 2011), as observed in many rich countries between the late 1990s and 2008 (Bongaarts and Sobotka 2012; Goldstein et al. 2009). Second, cohort fertility rates in most countries with low fertility never declined to such low levels as period TFRs did (Frejka and Sobotka 2008). Indeed, recent fertility trends for some countries could be extrapolated into slight increases in the completed cohort fertility of women born in the 1970s (Myrskylä et al 2013; see Section 1.3). Third, intended family size among men and women of reproductive ages in Europe as well as North America remains remarkably stable at or slightly above two children (Testa 2012a, see Sections 2.3.1 and 1.4.1); if couples were to fully realize their fertility intentions, fertility rates would increase. Finally, low fertility rates may be seen as a transitory stage during which society adjusts to the host of factors associated with the Second Demographic Transition (Lesthaeghe 1995, 2010) (see Section 2.1). Once societies adapt to this new reality by, for instance, promoting gender equality and developing policies, institutions, and norms that allow easier combination of work and childrearing for couples, and possibly also medical interventions expanding the biological

\footnotetext{
25 Other macro-level uncertainties-some of which are referred to above such as the future of marriagecontribute to this. Furthermore, in the long-run, climate change might also affect fertility trends with a varied impact in different settings. However, considering uncertainties about its progression, potential (often yet unforesseen) adaptations to it and diverse pathways how it might affect fertility and reprodution, we have not produced explicit scenarios linking climate change and projected fertility.
} 
limits of human reproduction, fertility rates may recover (Esping-Andersen 2009; Sobotka 2008a; Myrskylä et al. 2011).

There are more general arguments and mechanisms that explain why fertility may rise, including long-term fertility cycles, changes in population composition through migration or fertility differentials and the concept of homeostasis, which suggests that "demographic systems" tend to converge in the long run towards an equilibrium that assures their maintenance and survival (Lutz 2006, 2007; Billari and Dalla Zuanna 2012). There are also many cogent arguments succinctly summarized by Lutz (2006) why fertility rates may fall further or remain at very low levels for extended periods of time. The most prominent among these arguments is the Low Fertility Trap hypothesis, which suggests that the longterm experience of low fertility may generate a downward spiral of declining family size ideals, births and fertility rates determined through both the normalisation of small family sizes and a political realignment towards the needs of increasingly older populations (Lutz et al. 2006; see also Section 2.1). Other potential determinants of low fertility in the future, including current trajectories of female educational attainment, are examined in Sections 2, $3.2,3.4,5.3$ and 6.2 .

Despite a wealth of arguments and hypotheses highlighted here and in other parts of this working paper, there exists little settled theory concerning the long-term future of fertility, especially in the period beyond 2050 when generations not yet born will be responsible for the reproduction of future generations. The main scenarios of global population projections produced by the United Nations (UN) continue to embrace the idea that, in the long term, fertility rates in different global regions will fluctuate around the replacement level and eventually stabilise. The 2010 medium projection variant envisions that in the more developed regions period TFR will reach 1.97 in 2045-2050 and 2.07 in 2095-2100 (UN 2011: 11, Table II.1). Also the probabilistic projection model of fertility developed on behalf of the UN by Alkema et al. $(2010,2011)$ assumes that global fertility change proceeds in distinct phases, which include a spell of sub-replacement fertility and an eventual recovery, leading to a final convergence and an oscillation around the replacement level.

The debate with selected experts in November 2011 in Vienna on the long-term future of fertility addressed two possible alternative futures: Will the rich countries become more like the United States or Sweden today, with close-to-replacement fertility levels, or will most rich countries follow the path of South Korea, reaching very low fertility levels at advanced stages of development? By definition, the long time horizon selected makes the nature of fertility scenarios highly speculative and limits the forecasters' ability to draw lessons and conclusions from the currently observed fertility trends and determinants, as well as those predicted in the next decades (see Section 1.5). Besides the arguments and evidence highlighted above, the following facts and considerations informed the discussion on long-term fertility future:

- The cohort fertility forecasts by Myrksylä et al. (2013) showed that the average completed cohort fertility of women in 37 developed countries born in 1979 would be 1.77 (see Section 1.3 above for more details). This figure is well above the period TFRs experienced in many of these countries during the last decades. More importantly, Myrksylä et al. showed that cohort completed fertility had either stopped falling or that its decline had slowed significantly in developed 
countries in every region of the world, with the exception of East Asia and some countries in Southern, Central and Eastern Europe.

- The consensus among the experts participating in the online survey was that fertility rates in most of the low-fertility countries will stay below the replacement level threshold by 2050. The overall average of the projected TFR in 2050 (main scenario) across all experts reached 1.68, i.e. 20 percent below the replacement level. These expectations deviated strongly from the UN WPP 2010 projection model (Section 4.2).

- It is unlikely that fertility levels will be the same across different countries or that fertility will remain at a stable level in one country over extended period of time (Bongaarts and Bulatao 2000). However, in the absence of a commonly agreed unifying theory on how fertility will differ between countries or how will it change over time in a distant future, a simplistic assumption of long-term crosscountry convergence and eventual stabilisation can be justified.

These considerations resulted in two competing scenarios based on the notions of longterm convergence and stabilization: one of a convergence to the fertility level of 2.0 children per woman by 2200 , i.e., close-to-replacement fertility level, and the other of a convergence to 1.75 by 2200 , i.e., a fertility level that remains moderately below the replacement level. ${ }^{26}$ An idea that fertility could fall and stabilise at very low levels close to 1.5 or below did not find support as a main scenario. Following a short discussion, a majority of experts participating in the Vienna meeting chose the latter scenario with a fertility level at 1.75 , corresponding roughly to current cohort fertility levels as well as the projected TFRs in 2050 in the set of analysed countries. This projected "target" TFR served for projecting the fertility trajectories between 2050 (an endpoint of the expertbased projection, differentiated by region and country) and 2200, using linear interpolation. ${ }^{27}$ The long-run TFR level of 1.75 might be consistent with keeping populations in many countries stable if they experience further increases in life expectancy and modest levels of in-migration. Myrksylä et al. (2012), using mortality rates forecasted by the UN, show that Europe would be able to keep its population stable by bringing in 1 migrant for every 7 live births. The mortality rates for developed countries that we use in our forecasts are generally lower than those forecasted by the UN, so population stability would be reached with even fewer immigrants.

\footnotetext{
${ }^{26}$ There has been much debate regarding the justification of convergence as a 'belief' in the specific course of future global population trends as opposed to a computional tool. In some ways, the deployment of convergence takes elements of both of these uses and interpretations. In our exercise, we embrace the latter interpretation, acknowledging that the future variance in fertility across countries will be underestimated. The debate on the global convergence in fertility levels during the last half century has been inconclusive, partly depending on the measurement and methods used (see Wilson 2001 and 2011, Dorius 2008).

${ }^{27}$ To some observers, projecting fertility and population change up to 2200 seems to encompass an absurdly long time horizon. One of the contributing authors, reviewing this chapter stated "...there are limits to our imagination. When we think in 2013 about fertility in 2200 we are in the same position as Malthus trying to make forecasts for 2000." Because of this huge uncertainty about the very long-term future, most of our projection excersise focuses on the time horizon through 2050. Likewise, education-fertility differentials are not projected beyond 2050, as their longer-term development in low-fertility countries is very uncertain.
} 
A plausible higher scenario is suggested by the analysis in Myrksylä et al. (2012). They show, using the World Economic Forums' Global Gender Gap Index, that gender inequality is a good predictor of cohort completed fertility among younger cohorts analysed. This is consistent with the arguments made by our source experts. In the scenario where gender gaps slowly disappear in the future, TFRs would converge to a higher average level of around-replacement fertility, which is consistent with that currently observed in countries with low gender gaps. A lower scenario could be driven by improvements in contraception. This is also consistent with the arguments made by the source-experts. In the US, for instance, around one-half of all pregnancies are unintended (Henshaw (1998), Finer and Zolna (2011); see also Section 1.4.1); remarkably high rates of unintended pregnancies are also typical of Latin America (Section 1.4.4) and, indeed, most of the higher-income countries (Section 2.7). Improvements in contraceptive technologies would reduce the number of unintended pregnancies and result in fewer births. However it is impossible to say precisely what the effects of improved contraception would be.

\subsection{Defining TFR Assumptions by Level of Education}

This empirically oriented section complements a more theoretical discussion on the relationship between education and fertility in Section 2.8 and gives background analysis informing fertility projection scenarios by level of education. We also discuss evidence for Latin America and Middle East, regions for which projection scenarios are formulated separately using the model for high fertility countries (except for Iran, Israel and Turkey). ${ }^{28}$

\subsubsection{Education-Fertility Differentials in Low-Fertility Settings: Empirical Evidence}

In order to produce global population projections differentiated by level of education, it was necessary to quantify current and the likely future educational differentials in fertility. Given limited data availability and the fact that education categories are often not readily comparable between countries (see Chapter 9 of Lutz et al., forthcoming), we have mostly focussed on three broad education categories, labelled as "Low" (ISCED classification 0$2)^{29}$, "Medium" (ISCED 3 or 3-4), and "High" education (ISCED 5-6). When possible, especially in countries with a high proportion of women with primary or lower level of education, we have divided the "Low" category into "Very low" education (ISCED 0-1) and "Lower secondary" education (ISCED 2). To increase data comparability between countries, we primarily used data on completed or almost completed cohort fertility collected from censuses, large-sample surveys, or registry data, using the datasets for the most recent 5-year cohorts aged 40-44 or 45-49 and over (see also Appendix 6 for more details about data and data sources). This allowed us to avoid problems inherent in estimating period fertility data by level of education, especially the instability of the data over time, problems with classifying educational categories at younger ages, especially for

\footnotetext{
${ }^{28}$ For an analysis of fertility differentials in (mostly) higher-fertility settings based on DHS data see KC and Potančoková (2013).

${ }^{29}$ In the group of countries with high fertility and generally lower levels of education, this broad category has been subdivided into four distinct categories (Chapter 4 in Lutz et al., forthcoming).
} 
women still in education, and tempo distortions that vary by level of education, mismatches in the definition of education categories between the vital statistics data on births (the numerator) and the data on educational composition of the female population of reproductive ages (the denominator), as well as missing data in both datasets. However, the use of cohort data brings an obvious drawback: these data pertain to women whose prime childbearing period was 10-20 years ago and who therefore may not represent the most recent trend in fertility by level of education.

We first focus on analysing the existing differentials in fertility by level of education, which serve as a baseline for the formulation of projection scenarios as well as for the assessments of the likely future trends in countries that still have above-replacement fertility levels. Rather than analysing absolute fertility levels, we are primarily interested in relative fertility differentials. For each country and cohort (or calendar year) analysed, we computed relative fertility indexes (RFI), which are related to the group of women with medium education (RFI=1). Our main questions and findings are summarised in the following three sub-sections.

\subsubsection{Do Fertility Differentials by Level of Education Vary by Region?}

Table 6 features the RFI for broader regions, computed for recent cohorts past prime reproductive age, as simple averages across all countries with available data (see Appendix 6 for further details about data coverage by country, region, cohorts and/or period). The expected fertility gradient shows up in all regions except Nordic countries, where the three categories analysed have identical fertility levels. Furthermore, the fertility gradient is relatively small in Western Europe, "German-speaking" countries, and Southern Europe, especially for women with higher education. In the United States women with low education have elevated fertility levels that contrast strongly with the other two categories. The strongest education gradient in fertility is observed in Latin America and Middle East regions that are in the late stage of fertility transition and where highly-educated women still form a select group whose low fertility contrasts starkly with much higher fertility among women with primary or lower education. 
TABLE 6: RELATIVE FERTILITY INDEX (RFI) BY LEVEL OF EDUCATION IN MAJOR LOWFERTILITY REGIONS; EVIDENCE FOR FEMALE BIRTH COHORTS PAST REPRODUCTIVE AGE

\begin{tabular}{|c|c|c|c|c|c|c|}
\hline \multirow{3}{*}{ Region } & \multirow{3}{*}{ \# countries } & \multicolumn{5}{|c|}{ RFI by education category } \\
\hline & & \multirow[t]{2}{*}{ Low } & \multicolumn{2}{|c|}{ of which: } & \multirow[t]{2}{*}{ Medium } & \multirow[t]{2}{*}{ High } \\
\hline & & & Very low & $\begin{array}{c}\text { Lower } \\
\text { secondary }\end{array}$ & & \\
\hline North America & 1 (US) & 1.34 & .. & .. & 1.00 & 0.97 \\
\hline Latin America & 8 & 1.44 & 1.63 & 1.20 & 1.00 & 0.81 \\
\hline $\begin{array}{l}\text { East }+ \text { SE Asia } \\
\text { (except China) }\end{array}$ & 3 & 1.29 & .. & .. & 1.00 & 0.89 \\
\hline Middle East & 3 & 1.51 & 1.57 & 1.18 & 1.00 & 0.89 \\
\hline $\begin{array}{l}\text { Western Europe \& } \\
\text { German-speaking }\end{array}$ & 5 & 1.15 & .. & .. & 1.00 & 0.96 \\
\hline Nordic countries & 3 & 1.01 & .. & .. & 1.00 & 0.98 \\
\hline Southern Europe & 2 & 1.16 & 1.24 & 1.11 & 1.00 & 0.91 \\
\hline Central Europe & 8 & 1.22 & 1.23 & 1.22 & 1.00 & 0.85 \\
\hline Eastern Europe & 4 & .. & 1.47 & 1.39 & 1.00 & 0.85 \\
\hline
\end{tabular}

Note: See more details about the data and countries included in Appendix 6. Regretfully, no data are available for China.

\subsubsection{Is There a Distinct Trend in Education-Fertility Differentials once the Overall} Fertility Declines Below a Threshold of 2.2?

This question is important for the formulation of education-fertility scenarios in the higher fertility countries that are expected to undergo a transition to sub-replacement fertility in the coming decades. The empirical evidence can be elucidated on two levels. First, purely cross-sectional data from recent surveys and censuses (figures available upon request) suggest that the differentials tend to diminish. But the correlation is weak and the spread is wide; for instance, a cohort TFR level around 1.8 is associated with a RFI of the lowereducated women of between 1.0 and 1.4. The same weak evidence of diminishing differential applies to women with higher education.

Second, more valid evidence comes from the analysis of changes in fertility differentials across cohorts experiencing declining fertility. We have assembled data for nine European countries. Focusing on what happens when completed cohort fertility declines from around 2.3 to around 1.7, the data suggest diminishing distinctiveness of the low-fertility group (with smaller "surplus" fertility as the overall fertility level declines) and a minor trend of diminishing distinctiveness of the higher-educated category (but with very weak 
significance; data and graphs available upon request). Exponential trends ${ }^{30}$ are shown in Figure 14.

FIGURE 14: RELATIONSHIP BETWEEN OVERALL FERTILITY LEVEL AND RELATIVE FERTILITY INDEX BY LEVEL OF EDUCATION, BASED ON COHORT FERTILITY DATA FOR NINE COUNTRIES (EXPONENTIAL REGRESSION, COHORTS BORN IN THE 1920S-1960S)

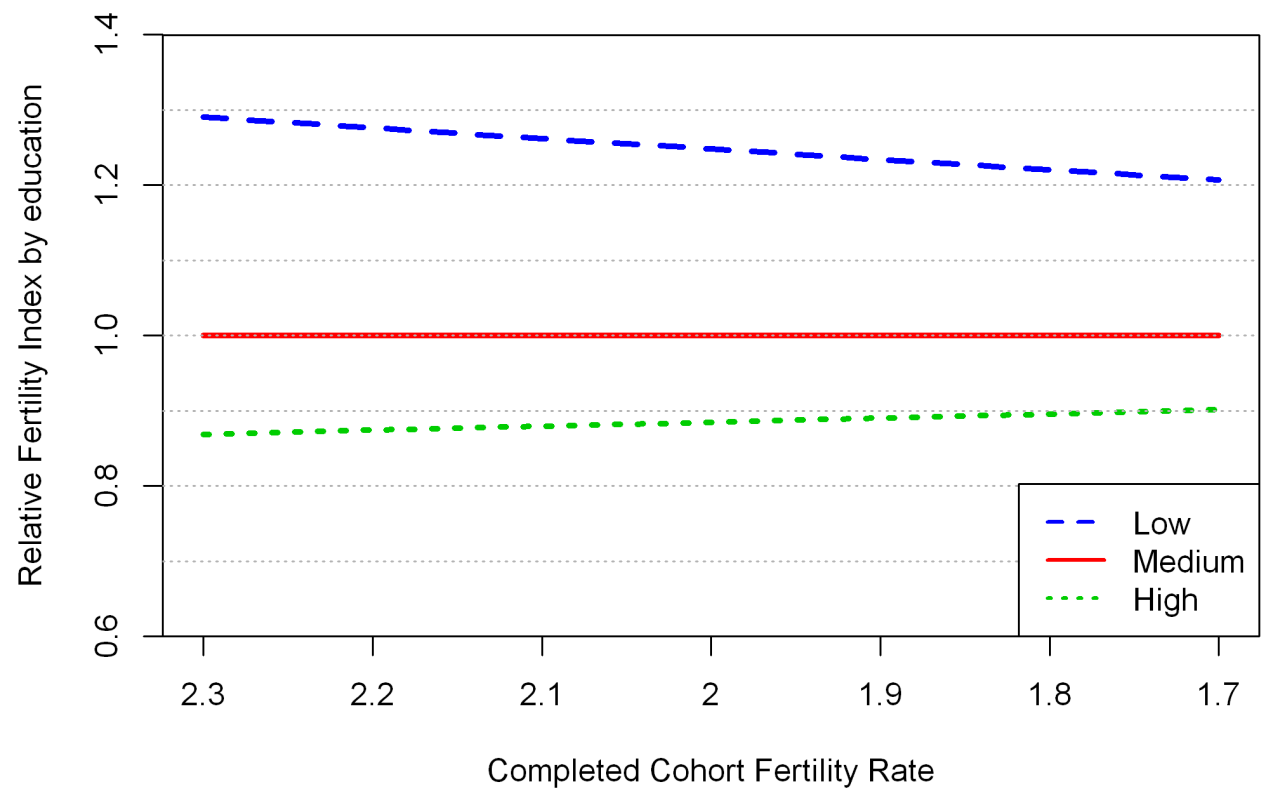

\subsubsection{Is There a Distinct Trend in Education-Fertility Differentials Across Cohorts?}

This question is addressed in Figure 15 with an expanded data set for 19 countries in three broader regions. In parallel to the evidence on gradually declining education-fertility differentials with declining fertility level described above, there is a continuous RFI decline among the lower-educated women in each of the three analysed regions. This fall was particularly impressive in Singapore, where the RFI fell from above 1.6 in the cohorts born around 1935 to below 1.2 in the cohorts born around 1960. A similar trend occurred in the South Korea, although from a lower initial RFI level. Also, in some countries of Central and Eastern Europe, especially Hungary, the RFI fell rapidly across cohorts. However, this region retains elevated fertility among the women with low education, with the mean RFI still above 1.3 in the cohorts born around 1955. In contrast, the mean RFI in Western and Northern Europe (including Austria, Germany, and Switzerland as well as Greece; no data available for other Southern European countries), has fallen below 1.1.

The RFI trends are less uniform when women with higher education are analysed in comparison with those having medium levels of educational attainment. The average mean trend in the analysed regions can be best described as a stable differential, with highly educated women having slightly lower fertility. A few countries in Western and Northern Europe (especially Belgium and Austria) registered a rapid rise in the RFI, leading in

\footnotetext{
${ }^{30}$ Exponential trend of RFI (related to 1) can be understand as linear trend of logarithm of RFI (related to 0) with intercept at $[0 ; 0]$, which prevents the crossover and enforces the convergence of RFIs.
} 
Belgium to a cross-over whereby fertility among the higher-educated surpassed that of women with medium level of education (data exclude immigrant women). In the cohorts born around 1955 the average RFI among women with higher education oscillates around 0.9 in many countries and at a lower level closer to 0.8 in Central and Eastern Europe. Romania shows a particularly steep gradient in education-fertility differentials, with relative fertility falling to very low levels among the higher-educated women. 
FigURE 15: TRENDS IN RELATIVE FERTILITY INDEX BY COHORT IN THREE BROADER REGIONS (WESTERN \& NORTHERN EUROPE, CENTRAL \& EASTERN EUROPE AND EAST ASIA); LOW AND HIGH VS. MEDIUM-EDUCATED WOMEN
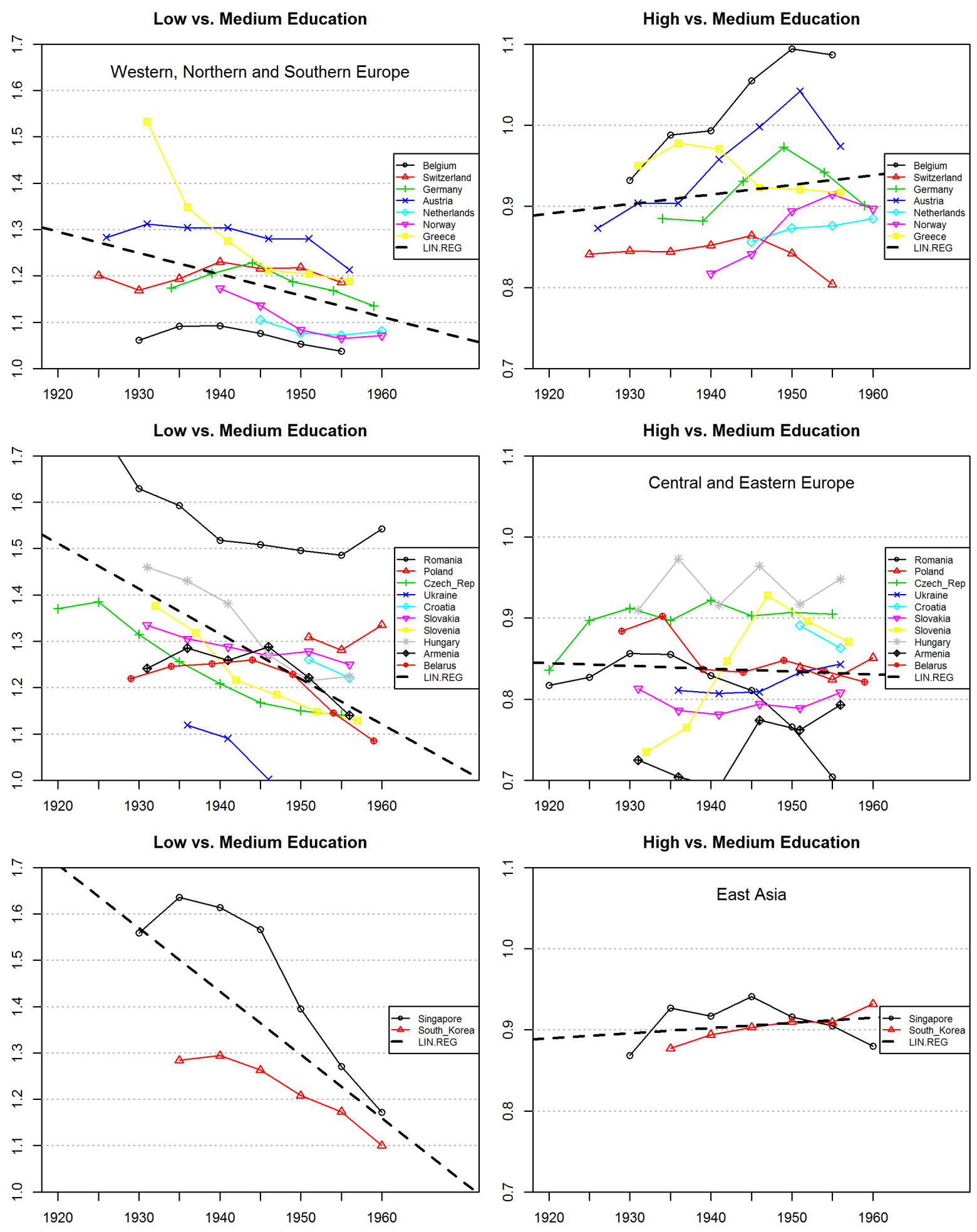


\subsubsection{Expected and Projected Future Trends in Education-Fertility Differentials}

Are future education-fertility differentials likely to diminish? A simple extrapolation of cohort trends described above suggests that in most countries fertility rates of women with low levels of education may eventually converge to those with the medium (upper secondary) education. The trend is much less clear-cut for tertiary-educated women, with a slight (but incomplete) convergence in Western, Northern Europe and East Asia and mixed trends, mostly marked by a slight rise of the negative gradient, in Central and Eastern Europe.

The experts' views about regional trends are summarised in Figure 16 (see Section 3.4.1 for a global overview). The experts expect diminishing education-fertility differentials especially in Latin America, Middle East and Southern Europe. In the former two regions, these differentials are still pronounced (Table 6 above, KC and Potančoková 2013) and the experts expect that they will diminish through a decline in fertility among the lower educated women, bringing a negative pressure on the overall fertility rate. In contrast, in Southern Europe the experts expect that a reduced education-fertility differential will materialise due to an increase in fertility of the women with tertiary education, having a positive effect on fertility. Additionally, experts indicated that a convergence in educational-fertility differentials is unlikely in the United States (argument validity of 0.39). More specific responses about the possibility of better educated women having higher fertility in the future while pursuing their career depict a strong agreement (validity $=0.75$ ) among experts from the Nordic countries (where tertiary educated women already record relatively high fertility; Table 6 and Figure 15 above) and also considerable agreement in selected other regions of Europe, German-speaking countries, Southern Europe and Central Europe (validity index above 0.6). A rather strong positive net impact of this trend on overall fertility is expected in the former two regions. Latin America shows a contrasting pattern as a majority of experts there disagreed with the expectation of increasing fertility among better-educated women (validity $=0.32$ ). 
FIGURE 16: VALIDITY AND CONDITIONAL IMPACT OF EDUCATION-RELATED ARGUMENTS 6.1 TO 6.3 BY REGION. DIAMETER OF THE BUBBLES CORRESPONDS TO SQUARED VALUE OF THE VALIDITY OF EACH ARGUMENT (RANGING FROM 0.32 TO 0.82)

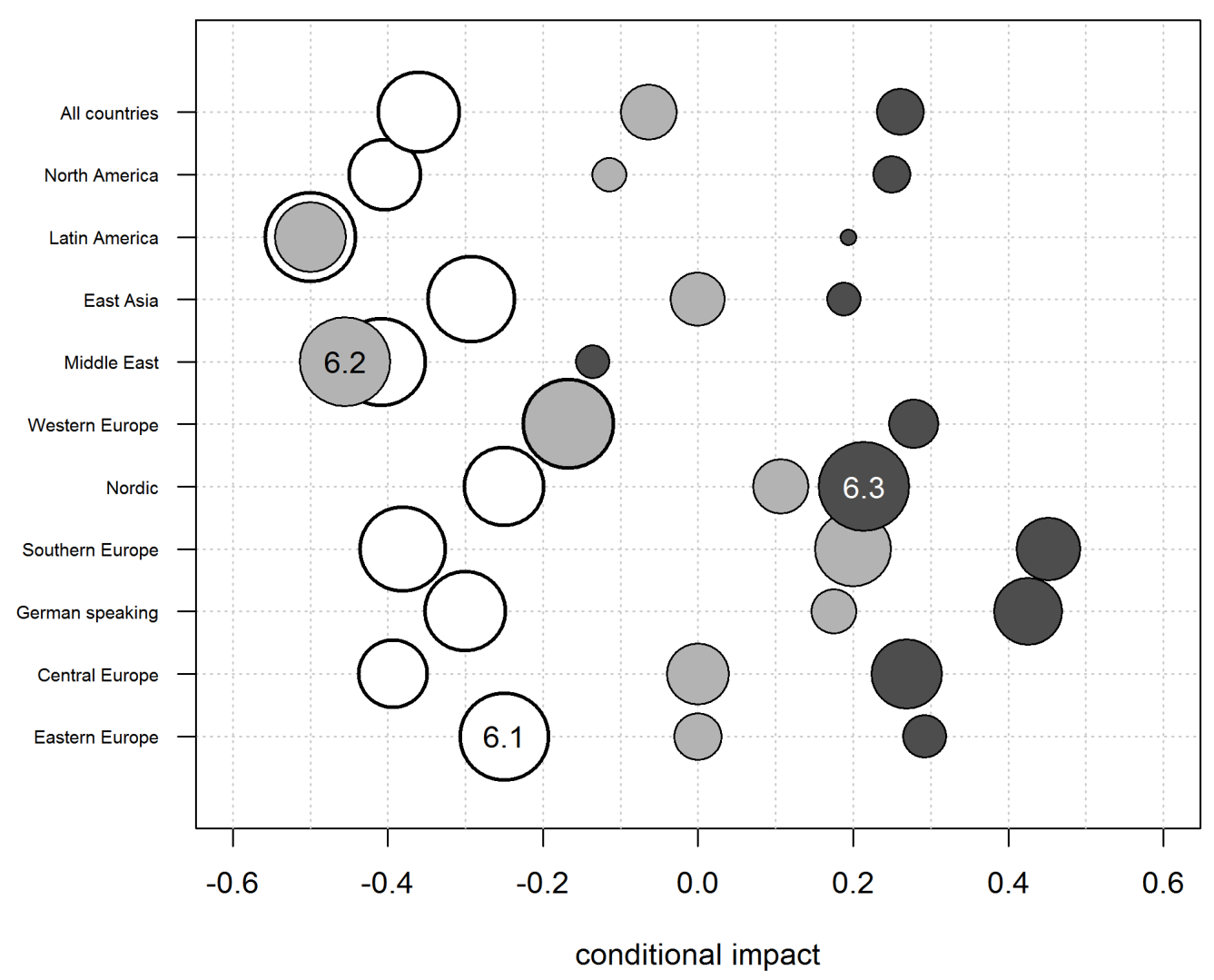

Note: Argument 6.1 (white bubbles with bold border): People will spend ever more years of their young adult life enrolled in education and professional training on the job

Argument 6.2 (light-grey bubbles): Fertility differentials by level of female education will diminish

Argument 6.3 (dark bubbles): There will be a new trend for better educated women to have more children and simultaneously pursue a professional career.

Different possibilities of how to combine the observed trends in education-fertility differentials by region with the experts' insights and expectations were considered by the co-ordinating team of the project. Given regional variation in experts' expectations and a need to produce a global set of projections (with lacking expert assessments for the higherfertility countries analysed in Chapter 4 of Lutz et al., forthcoming), a simple model which is not based on expert opinion was produced (see also Chapter 9 of Lutz et al., forthcoming). It assumes that countries with currently higher fertility level will converge by the time they reach a low fertility level with a TFR around 1.8 to average educationfertility differentials experienced at present in the set of low-fertility countries analysed here. The model combines most recent observed education-fertility differentials in lowfertility countries (Table 6 above) and the trends in these differentials at sub-replacement fertility levels (Figure 14 above). Expressed in relative fertility indexes (RFI), fixed at the level of 1.00 among the women with high (tertiary) education, women with very low education (completed primary and lower) will have a RFI of 1.42 , women with lower 
secondary education will have a RFI 1.35, and those with upper secondary education 1.14. Countries with the current TFR below 1.8 will converge to these relative differentials by 2030. Countries where lower differentials are observed at present form an exception - they are not projected to experience increasing fertility differentials in the future, but their most recently observed differentials are kept constant in the projection.

\section{Conclusion}

In this paper we have attempted to present a systematic, state-of-the-art overview of both the regional context of fertility decline in currently low-fertility settings and the possible contributions of the theoretical and empirical drivers which underpin them. Many sections have demonstrated that the locus of low fertility is increasingly moving away from "Old Europe" and towards the rapidly developing economies of East Asia, Latin America and the Middle East. In this respect, any understanding of the forces behind recent fertility decline needs to take into account changes in these settings and their particular contexts.

In the view of wide variation of fertility levels in contemporary rich and middle-income countries, a global convergence of fertility to around replacement level appears unlikely. Either continuing bifurcation in future trends of low fertility or a stronger movement towards the low fertility rates seen in East Asia - especially in rapidly developing settings - is a possible future scenario. In absolute terms, contemporary variation in posttransitional fertility in the order of one birth per woman is small. In relative terms, a period TFR of 2.0-2.1 in France, New Zealand and, until recently, the US, is almost twice as high as the period TFR of 1.0-1.2 recently recorded in Hong Kong, Korea, Taiwan or Romania. This range between East Asia on one side and France and New Zealand on the other side also roughly corresponds to the global average of the 80 percent confidence interval of the period TFR in 2050 predicted by the experts participating in the online survey, which ranged from 1.07 to 2.13 (data weighted by population size).

These vast relative differences, if they persist, will have negative repercussions for the group of lowest-fertility countries, which will face accelerated population aging and protracted population declines, especially if they do not attract sizeable immigration. Even if period fertility rates recover somewhat, as they did in much of Europe in the early 2000s, replacement level is seen by many experts as an upper boundary for the post-transitional fertility levels. However, a return of above-replacement fertility cannot be completely ruled out, although it seems incompatible with contemporary economic uncertainty as well as lifestyles, career and consumer aspirations of the majority of populations in rich countries. Past experience shows that baby booms may occur unexpectedly, taking demographers by surprise.

\subsection{Key Messages}

The regional overview of fertility trends in Section 1 has highlighted uncertainties about fertility levels and trends in China as well as the long shadow that will be cast on future population trends by the phenomenon of distorted sex ratios at birth observed there and in some other Asian settings in recent decades. With a TFR below 1.5 according to many expert estimates, China's fertility rate is probably below that of most European countries. 
It represents almost a fifth of the global population and thus exerts enormous weight in any global population and fertility estimates and projections. Yet our knowledge of Chinese fertility trends, preferences or educational and differentials remains fragmented and inadequate.

Section 2 has attempted to give a state-of-the-art review of different forces affecting posttransitional fertility. There are so many factors suggested by the literature to influence fertility tempo and quantum of individuals, social groups, countries and regions that we had to omit some of the less prominent or relatively poorly documented ones (see also below, see Balbo et al. 2013 for another recent review). Of the factors we discussed, the influence of gender equality and gender relations in different domains (education achievement, labour participation, household division of tasks, childcare) on fertility intentions, timing and level still seems to be inadequately understood, especially for men. Similarly, the existing research shows different shapes of education-fertility gradients among women in low-fertility countries, contrasting with a consistently negative link between education and fertility in higher-fertility settings. Both the literature and empirical data analysed in Section 5 indicate two contrasting patterns where the education-fertility gradient largely disappears: the "higher equilibrium" is typical of countries where educated women have good opportunities to combine family and career, such as Belgium and the Nordic countries, whereas the "lower equilibrium" is represented by Korea, where lowereducated women reduced their fertility rates to meet the very low levels recorded among the higher-educated women, possibly in response to high costs of having children, difficult housing conditions and other constraints on their fertility decisions. In most low-fertility countries a negative education-fertility gradient among women persists, fuelled also in part by higher rates of unintended pregnancies and births among the lower-educated women - a situation characteristic also for the United States. The evidence on the post-transitional relationship between education and fertility is much less clear-cut and inadequately documented for men.

Sections 3 and 4 presented the results of what we believe to be the largest global survey of expert opinion in scenario building and future fertility trends. Evaluating responses to 46 arguments, Section 3 focussed on experts' evaluation of the main factors pertaining to expected future fertility changes. Despite identifying considerable regional variation, some arguments were found as particularly relevant in most regions. Two interrelated trends of increasing enrolment in education among young adults and continuing postponement of parenthood to higher ages were singled out as two most valid arguments. In addition, rising partnership instability and "re-partnering" ranked as the third most valid argument. The arguments perceived to have the strongest impact on fertility related to immigration from higher fertility countries, increasing flexibility in work practices, the provision of universal childcare and other family policies and increased gender equity in the performance of housework. Regarding the strongest net negative impact, we might speculate about the prominent influence of the recent economic recession on experts' thinking about the longterm future of fertility: uncertainty in individual life course planning and the related arguments concerning job instability among the young and an inability to find the right partner were key. Expanding higher education was not expected to have a strong influence on fertility in most regions due to its envisioned contrasting effects on fertility: on the one side, it will contribute to additional fertility declines, arguably also due to its delaying 
effect on family formation. At the same time, experts in many regions expected that higheducated women will in the future have more children than today.

A second core component of the survey, discussed in Section 4, was to elicit point-andrange estimates for future period Total Fertility Rates in 2030 and 2050. For the entire group of low-fertility countries, nine out of ten respondents believed fertility would be below replacement rate in 2050, with one in ten expecting it to be at or below the "lowestlow" level of 1.3. In 26 out of the 30 countries examined here, the experts expected lower fertility rates in 2050 than the UN medium variant of the 2010 round of global population projections. Most populous low-fertility countries are expected to see significant declines in period TFR (Brazil, Iran, Mexico) or to retain low TFR levels not much different from the present ones (China, Japan, Russia). In this vein, European low fertility may be overshadowed by lower fertility rates in other world regions, especially in China, other parts of East Asia, Latin America, and Iran.

Finally, Section 5 has described how the input from the experts in combination with additional criteria has been translated into the set of future fertility scenarios, both medium-term until 2050 and very long-term until 2200. In line with the expert's expectations, our scenarios retain regional diversity in future fertility, with the mediumscenario period TFR in 2050 ranging from 1.40 in China to 2.00 in the Nordic countries (and 2.50 in the specific case of Israel). Only thereafter, between 2050 and 2200 does the medium scenario assumes a slow convergence to a uniform "end-point" TFR level of 1.75 which reflects more our current lack of knowledge about the factors that might play a key role in shaping regional fertility differentials in such distant future rather than a view that fertility would indeed follow a global convergence to one universal level. The fifth section has also discussed persistent contrasts in education-fertility differentials in post-transitional settings, which pose a challenge for projecting future trends in these differentials in the societies still undergoing demographic transition.

\subsection{Limitations and Moving to the Future}

Although we have attempted to give a comprehensive overview of all the major factors shaping fertility, our review has limitations. We have paid relatively scant attention to the slowly accumulating literature on male fertility determinants, levels and patterns. Clearly, this should be best studied together with women's fertility or, at a micro level, as a joint fertility decision-making process of couples. Some potentially relevant factors were not discussed because the literature is relatively undeveloped, the evidence on their relevance is limited, or simply because of the lack of space precludes discussing every possible driver of fertility. Examples of such "neglected" factors include type of settlement and the potential role of urban-rural differentials, population density, and environmental and climate-related factors. Similarly, this paper has not covered widely enough the ongoing transformation in family and living arrangements and its multiple links to childbearing behaviour. Also we have not discussed potentially important psychological factors operating at both societal and individual levels, such as how the degree of trust, insecurity, sense of control, and, more generally, fads and fashions related to childlessness or having children, influence fertility decisions. With the exception of economic uncertainty and the more specific case of anomie during the post-communist transition in Central and Eastern 
Europe (Philipov 2003, Philipov et al. 2006), the literature is very limited and usually dated.

We have also provided only a limited discussion of the links between different determinants of fertility; in particular, of how micro-, meso-, and micro-level factors interact to generate broader fertility trends (see Balbo et al. 2013 for a useful discussion). ${ }^{31}$

We would like to highlight two broader issues that deserve more attention in future research. First, more attention should be paid to analysing and discussing family size norms and ideals in different settings and population subgroups. Coleman (1998) suggests that besides normative factors there are no pertinent theoretical arguments suggesting that fertility and fertility preferences should be higher than zero. Other contributions that take for granted that parenthood and nurturing care about offspring provide a unique experience that is desirable for most individuals suggest that the preference for having one child might be the most rational outcome, also considering the emphasis on the "quality" of children (Wilson 2013; Foster 2000). Yet the overwhelming evidence for the majority of countries indicates a surprisingly strong and stable persistence of two-child family norms and ideals. Given that the actual fertility in rich countries with widespread use of modern contraception is usually lower than fertility ideals and intentions, it is important to study the experience of urban China and other settings with an emerging dominant preference for one-child families, which might herald an era of "ultra-low" fertility in these places (Basten and $\mathrm{Gu}$ 2013).

Second, more attention should be given to the unfolding "postponement transitions" (Kohler et al. 2002) in middle-income countries that have seen fertility rates falling close to the replacement level. There, the empirical experience of the countries with a long history of low fertility shows that such fertility tempo transitions can negatively affect period fertility rates for decades, often contributing to the temporary spells of very low fertility (Bongaarts 2002, Sobotka 2004a, Goldstein et al. 2009). Thus the key question is whether couples in countries such as Brazil, China, India, Iran, Mexico and South Africa will embark on a similar trend of having children at ever later ages. If they do, perhaps in part as a consequence of an expansion of tertiary education there, these countries may see decades of very low fertility, significantly below the current levels. But differently from the case of the normative shifts towards low ideal family size, some recovery of fertility can be expected once the postponement transition comes to an end and the age patterns of childbearing eventually stabilises.

Finally, the design of the global online survey of experts can be improved if it is to be repeated again in the future. Specifically, it is important to cover sufficiently the most populous countries, even at the cost of translating the questionnaire into several additional languages and explicitly targeting local experts. Experts should also be asked about broader regional trends, using pre-defined regions. Also, the range of empirical questions about the future trends should go well beyond focusing on the period TFR and uncertainty range around it. More emphasis can be given to the explicit assessments about future

\footnotetext{
31 As one of the contributing authors observed, "this topic is an unresolvable dilemma. Knowledge is continuously accumulating on specific factors and mechanisms operating to shape fertility trends. In hindsight we appear to be reasonably successful in analyzing various specific situations. But a definitive comprehensive model that can be used to determine future trends is eluding us."
} 
trends in completed fertility and fertility timing, likelihood of global fertility convergence as well as the future course of education-fertility differentials. Methodologically, it would be worth trying to address experts' tendency to put major emphasis on very recent trends, even when thinking about the far-away future. 


\section{APPENDICES \\ Appendix 1: Defining the initial TFR values in 2010 and formulating main scenario point projections for 2030 and 2050 (detailed overview)}

We discuss only countries and regions for which WIC projection scenarios were formulated using input provided by experts on low-fertility countries. Fertility scenarios for Latin American countries, for most of the Middle East region (except Iran, Israel and Turkey) and for a few other low-fertility countries have been formulated jointly with the higher-fertility countries, using a scenario model described in Chapters 4 and 9 in Lutz et al. (forthcoming). As a result, the following low-fertility countries are not discussed here: Thailand, all Latin American and Caribbean countries, Algeria, Tunisia, Mauritius, Brunei, Kuwait, Qatar, United Arab Emirates, and Lebanon.

\section{A1.1 The initial TFR level in 2010}

Most of the TFR data for European countries were computed by Vienna Institute of Demography for the European Demographic Data Sheet 2012; for a few countries, the TFR data originate from Eurostat or national statistical offices.

For most non-European countries, the 2010 TFR data are based on the 2011 edition of the World Population Data Sheet published by the Population Reference Bureau (PRB; 2011).

\section{A2.2 Deriving Medium (point) TFR estimates}

The derivation of the "medium" (point) TFR estimates proceeded in several steps described below. First, simple data cleaning took place to exclude data where the experts left the expected TFR values for 2030 and 2050 at the predefined values (which were identical to the 'starting' values for 2010). These exclusions occurred only for the experts who did not change any of the six projected TFR values (minimum, maximum, and median for 2030 and 2050), assuming that they did not want to deal with this empirical part of the survey or could not effectively manipulate the sliders with TFR estimates on their computer. For experts who changed at least one of these predefined TFR values, the medium TFR estimates were counted even when they were identical with the predefined values.

A1.2.1. The "representative countries" were the 13 most populous countries or countries with distinct fertility patterns representative of the broader region (and with at least four respondents per country): China, US, Japan, Iran, Turkey, Russia, Italy, Spain, Germany, UK, Sweden, Czech Republic and Australia.

Mean values of experts' responses to the online survey were presented at the expert meeting in Vienna. These values were either accepted or revised, if a sufficient number of participating experts thought there is a strong case for such revision. Most efforts concentrated on settling the 2050 values, while less attention was paid to the 2030 values. Revisions were mostly upwards, except for Spain. All values were rounded to the nearest 0.05. Most changes were small, except for Russia (0.30). 
Countries where invited experts changed the survey experts' mean values:

China $2030 \& 2050(1.4 \rightarrow 1.5)^{32}$

Russia $2050(1.4 \rightarrow 1.7)$

Spain $(2030: 1.55 \rightarrow 1.50 ; 2050: 1.8 \rightarrow 1.7)$

Sweden (2050: $1.85 \rightarrow 2.00)$

US $2050(1.85 \rightarrow 1.90)$

To achieve consistent trend between 2010 and 2050, a few values for 2030 were subsequently revised by the coordinating team

Sweden $2030(1.90 \rightarrow 2.00)$

Russia $2030(1.4 \rightarrow 1.5)$

Once the 2030 and 2050 TFR values were settled, most of these countries were selected as representative of a broader regional pattern, in order to derive TFR projections for the countries for which no or insufficient numbers of expert responses were elicited in the survey. Existing and expected fertility differences within broader regions warranted defining two sub-regional patterns, called "Higher" and "Lower". However, the absolute differences in projected TFRs between the two are never high, typically they amount to 0.1 (e.g., Italy vs. Spain).

Countries representative of broader regions:

Japan (East Asia)

Italy (Southern Europe Lower)

Spain (Southern Europe Higher)

UK (Western Europe Higher)

Sweden (Nordic countries)

Czech Republic (Central Europe Higher)

\section{A1.2.2. The countries with at least one expert response (additional 26 countries)}

The average across experts of the expected TFR in 2030 and 2050 was assessed. It was left the same if it fit well the broader regional pattern or was close to the regional "representative country" as defined above. It was also left the same if it differed from some other countries in the region, but represented well a specific pattern of a given country or more countries in the region. The $2030 \& 2050$ TFR estimates by experts participating in the survey were left intact for the following 11 countries: Australia, Austria, Bulgaria, Croatia, Finland, Hungary, Israel, the Netherlands, Norway, Switzerland, Ukraine.

\footnotetext{
32 After repeated discussions between low-fertility module coordinators, overall project coordinators, and several Chinese experts, the projected TFR for China for 2030 and 2050 was eventually put back to 1.4,
} 
The coordinating team changed the projected TFRs suggested by experts in cases where the projected TFRs for a given country differed from a broader regional pattern (as defined by the 'representative countries' discussed at the Vienna workshop, but also from other countries in the region) or when it diverged from the overall higher and lower boundaries expected for the medium estimates of the future TFR.

Specifically, the following rule was applied: The medium TFR estimate in 2030 and 2050 will fall between 1.4 and 2.00 (except in Israel) ${ }^{33}$.

For 11 countries, the coordinating team made minor adjustments (generally, by $<0.20$ ) to the initial experts' mean values for 2030, 2050 or both (see Section A2.6 below).

\section{A1.2.3. The countries that were not assessed by experts}

These remaining low-fertility countries were 'attached' to a representative country for a broader region and their projected TFR values 2030 and 2050 defined as identical to this representative country (see Table A.2 listing all countries by region below).

\section{A1.3 Projecting the TFR values in 2010-2015}

The recent economic recession, which hit especially the most developed countries, and the subsequent cuts in government spending have led to a huge increase in economic and employment uncertainty. This uncertainty affects especially younger men and women and is likely to negatively influence their childbearing decisions and thus also aggregate fertility rates, as evidenced in many European countries and the United States (Box 3 above). As of 2013, many low-fertility countries remain characterized by high unemployment and uncertain economic outlook. Consequently, it is unlikely their period fertility rates will resume an increasing trajectory in the near future.

In light of this evidence, our projections assume that in the countries where a TFR rise is expected between 2010 and 2030, the TFR will initially remain at the most recent observed level (for 2011 or 2012) until 2015 and only then follow a linear increase up to the projected values for 2030. In countries where a TFR decline is expected between 2010 and 2030, it is assumed to follow a linear trajectory, without any recession-induced interruption or acceleration between 2010 and 2015. A more sophisticated set of fertility assumptions for the near future, reflecting sizeable cross-country differences in their economic trends and experiences of economic recession, was ruled out because it would require separate assessments of each individual country.

\footnotetext{
${ }^{33}$ Israel is a notable high-fertility exception, where the TFR is projected in line with the single respondent's assessment: $2030=2.70 ; 2050=2.50$.
} 


\section{A1.4 Projecting TFR values beyond 2050}

The Wittgenstein Centre projections extend beyond the year 2050, which was the endpoint in the online expert survey. The Vienna workshop with invited experts discussed such long-range scenarios. A simple method has been proposed, assuming a uniform global convergence in medium TFR to a sub-replacement level of 1.75 by 2200 (Section 5.2). Using a linear approximation between the projected medium value for 2050 and this 'target' endpoint in 2200, the medium TFR can be derived for any period between these two years.

\section{A1.5 Countries where the coordinating team changed the initial experts' mean values for 2030, 2050 or both years (11 countries)}

Belgium $-1.90 \rightarrow 1.80$ in 2050, conforming to Western Europe low pattern (NL)

Canada $-1.70 \rightarrow 1.80$ in 2050 , assuming partial convergence to the higher fertility of the US

Georgia $-2.1 \rightarrow 1.70$ in 2030 and 2050 ; high values changed so that the expected fertility corresponds closer to the highest values expected for Eastern Europe (Russia) and also get closer to the expected TFR trends in the neighbouring Turkey

Greece $-1.75 \rightarrow 1.60$ in 2030 and 2050, corresponding to Southern Europe Lower (Italy)

Hong Kong - 1.1 to 1.2 in 2030 and to 1.4 in 2050; very low values shifted to correspond to Japan (East Asia) pattern by 2030 and China by 2050

Iceland $-1.9 \rightarrow 2.0$ in 2030 and $1.75 \rightarrow 2.0$ in 2050 , corresponding to the Nordic countries

Lithuania $-1.7 \rightarrow 1.65$ in 2030 and $1.8 \rightarrow 1.7$ in 2050 , corresponding to Central Europe Higher

Poland $2050(1.75 \rightarrow 1.7)$, corresponding to Central Europe Higher

Portugal $-1.7 \rightarrow 1.5$ in 2030 and $1.9 \rightarrow 1.7$ in 2050, corresponding to Spain / Southern Europe Higher

Romania $-1.4 \rightarrow 1.5$ in 2030 and 2050 ; initially low values increased above the minimum threshold; Romania defines the Eastern Europe Lower pattern

Slovenia $-1.8 \rightarrow 1.7$ in 2050, in line with central Europe Higher

Two of these countries assumed to represent a broader regional pattern:

Georgia (Caucasus region)

Romania (East Europe Lower) 
TABLE A1: LIST OF LOW FERTILITY COUNTRIES FOR WHICH PROJECTION SCENARIOS WERE FORMULATED HERE (COUNTRIES LISTED BY REFERENCE REGION; REPRESENTATIVE COUNTRIES SHOWN IN BOLD)

\begin{tabular}{|l|l|}
\hline Reference region & Country \\
\hline North America & United States \\
\cline { 2 - 3 } Australia+Oceania & $\begin{array}{l}\text { Australia } \\
\text { New Caledonia } \\
\text { New Zealand }\end{array}$ \\
\hline East Asia HIGH & $\begin{array}{l}\text { Japan } \\
\text { Korea, North } \\
\text { Korea, South } \\
\text { Singapore }\end{array}$ \\
\hline East Asia LOW & $\begin{array}{l}\text { Hong Kong SAR } \\
\text { Macao SAR } \\
\text { Taiwan }\end{array}$ \\
\hline China \\
\hline Middle East & $\begin{array}{l}\text { Turkey } \\
\text { Iran } \\
\text { Israel }\end{array}$ \\
\hline
\end{tabular}

\begin{tabular}{|c|c|}
\hline Reference region & Country \\
\hline Southern Europe HIGH & $\begin{array}{l}\text { Italy } \\
\text { Cyprus } \\
\text { Greece } \\
\text { Malta } \\
\end{array}$ \\
\hline Southern Europe LOW & \begin{tabular}{|l} 
Spain \\
Portugal \\
\end{tabular} \\
\hline Central Europe HIGH & $\begin{array}{l}\text { Czech Republic } \\
\text { Estonia } \\
\text { Lithuania } \\
\text { Slovenia } \\
\end{array}$ \\
\hline Central Europe LOW & $\begin{array}{l}\text { Hungary } \\
\text { Latvia } \\
\text { Poland } \\
\text { Slovakia } \\
\end{array}$ \\
\hline & Croatia \\
\hline Eastern Europe HIGH & $\begin{array}{l}\text { Bulgaria } \\
\text { Ukraine } \\
\text { Belarus } \\
\text { Macedonia } \\
\text { Montenegro } \\
\text { Serbia } \\
\end{array}$ \\
\hline Eastern Europe LOW & \begin{tabular}{|l} 
Romania \\
Albania \\
Bosna- \\
Republic of \\
\end{tabular} \\
\hline & Russian Federation \\
\hline Caucasus & $\begin{array}{l}\text { Georgia } \\
\text { Armenia } \\
\text { Azerbaijan }\end{array}$ \\
\hline
\end{tabular}

\begin{tabular}{|c|c|}
\hline Reference region & Country \\
\hline Western Europe & $\begin{array}{l}\text { United Kingdom* } \\
\text { Ireland } \\
\text { France** }\end{array}$ \\
\hline Western Europe & $\begin{array}{l}\text { Netherlands } \\
\text { Belgium } \\
\text { Luxembourg } \\
\end{array}$ \\
\hline "German -speaking" & \begin{tabular}{|l} 
Austria \\
Germany \\
Switzerland \\
\end{tabular} \\
\hline Nordic countries & $\begin{array}{l}\text { Sweden } \\
\text { Denmark } \\
\text { Finland } \\
\text { Iceland } \\
\text { Norway }\end{array}$ \\
\hline
\end{tabular}

Notes: * including Channel Islands

** including French Polynesia, Guadeloupe, Martinique, Réunion 


\section{Appendix 2: Selection of countries into the "low fertility" module}

Two sets of arguments pertaining to fertility have been formulated within the Wittgenstein Centre project on argument-based global population projections: one for low-fertility settings with more advanced levels of development, and another for higher-fertility settings with lower level of development. This division is somewhat subjective, with a number of countries potentially falling on the border between the two groups. We used the period total fertility rates (TFR) estimated for the period of 2005-10 by the United Nations World Population Prospects 2010 and the UN Human Development Index (HDI) for 2010 to rank the countries by their levels of fertility and development. ${ }^{34}$ The main motivation behind considering an additional selection criteria based on human development was the need to differentiate between the more affluent and more developed set of countries and all other countries in order to formulate suitable sets of arguments pertaining to likely future fertility trends. For instance, some of the questions the experts were asked on low-fertility countries pertained to immigration, assisted reproduction or family policies, and were largely irrelevant in less developed settings. Similarly, the questions on the role of child's and mother's health and child survival are largely irrelevant in higher-income settings with very low maternal and child mortality, even when they register above-replacement fertility, such as Israel.

The following criteria were used to divide countries into the "Low fertility, higher development" (90 countries and territories) and "Higher fertility, lower development" (100 countries and territories) groups:

The former group of countries with low fertility includes:

- Countries with sub-replacement period fertility (TFR below 2.10) and moderate or high level of development (HDI at 0.650 or higher). Only three countries with a TFR below 2.10 had a HDI level below 0.65 (Maldives, Myanmar and Vietnam) and were therefore included in the higher-fertility group analysed in Chapter 4 of Lutz et al. (forthcoming).

- Countries with moderate period fertility (TFR between 2.10 and 2.49) and a higher level of development (HDI at 0.670 or above). The following countries with the TFR between 2.10 and 2.49 were included: Brunei, New Zealand, Uruguay, Turkey, Azerbaijan, Argentina, Kuwait, Algeria, Mexico, Jamaica, Qatar, and Colombia;

- Countries with moderate period fertility (TFR between 2.10 and 2.49) and unknown level of the Human Development Index (which has not been computed for them). The following countries and territories with the TFR between 2.10 and 2.49 were included: Guadeloupe, French Polynesia, New Caledonia, and Réunion;

\footnotetext{
${ }^{34}$ Note that the series of the period TFR used for this selection differed from the estimates of the period TFR used in the survey to provide the initial TFR level for all countries in 2010. For the latter purpose, the more recent (2010) estimates published by Population Reference Bureau (2010, http://www.prb.org/pdf10/10wpds_eng.pdf) have been used. However, the division of countries into the higher and lower fertility groups would remain identical if the PRB data were used instead of the UN estimates.
} 
- Countries with higher period fertility (TFR at 2.50 or above) and with very high level of development (HDI above 0.85 ). Only one country, Israel, was included on this basis.

All other countries fall into the high fertility group, which therefore comprises:

- All countries with the TFR at 2.50 or above except Israel;

- Countries with the TFR between 2.10 and 2.49 and HDI below 0.670: Indonesia, Guyana, Salvador, Sri Lanka, Morocco, Bangladesh, Suriname, and Uzbekistan;

- Three countries with a TFR below 2.10 with low HDI values (below 0.65): Maldives, Myanmar and Vietnam

Table A2 below ranks all the countries with a TFR below 2.5 by their TFR (ranking from the lowest fertility up) and lists their TFR in 2005-10, their Human Development Index (HDI) in 2010 and their distribution into the low or high fertility module of the survey.

TABLE A2: COUNTRY RANKING BY THE PERIOD TFR IN 2005-10 (FROM THE LOWEST LEVEL TO THE HIGHEST) AND THEIR INCLUSION INTO THE “LOW FERTILITY” MODULE OF THE WIC ARGUMENT-BASED GLOBAL POPULATION PROJECTIONS (ONLY COUNTRIES WITH THE TFR BELOW 2.50 AND ISRAEL ARE LISTED)

\begin{tabular}{|c|c|c|c|c|c|c|c|c|c|}
\hline & Country & $\begin{array}{l}\text { Period } \\
\text { TFR } \\
\text { (UN) } \\
2005-10\end{array}$ & $\begin{array}{l}\text { HDI, } \\
2010\end{array}$ & $\begin{array}{l}\text { Fert. } \\
\text { Mod. }\end{array}$ & & Country & $\begin{array}{l}\text { Period } \\
\text { TFR } \\
\text { (UN) } \\
2005-10\end{array}$ & $\begin{array}{l}\text { HDI, } \\
2010\end{array}$ & $\begin{array}{l}\text { Fert. } \\
\text { Mod. }\end{array}$ \\
\hline 1 & Hong Kong SAR & 0.99 & n.a. & Low & 50 & Finland & 1.84 & 0.871 & Low \\
\hline 2 & Macao SAR & 1.02 & n.a. & Low & 51 & Denmark & 1.85 & 0.866 & Low \\
\hline 3 & Bosnia-Herzegovina & 1.18 & 0.710 & Low & 52 & United Arab Emirates & 1.86 & 0.815 & Low \\
\hline 4 & Singapore & 1.25 & 0.846 & Low & 53 & Lebanon & 1.86 & n.a. & Low \\
\hline 5 & Slovakia & 1.27 & 0.818 & Low & 54 & Vietnam & 1.89 & 0.572 & High \\
\hline 6 & Korea, South & 1.29 & 0.877 & Low & 55 & Sweden & 1.90 & 0.885 & Low \\
\hline 7 & Poland & 1.32 & 0.795 & Low & 56 & Brazil & 1.90 & 0.699 & Low \\
\hline 8 & Japan & 1.32 & 0.884 & Low & 57 & Chile & 1.90 & 0.783 & Low \\
\hline 9 & Malta & 1.33 & 0.815 & Low & 58 & Maldives & 1.90 & 0.602 & High \\
\hline 10 & Romania & 1.33 & 0.767 & Low & 59 & Bahamas & 1.91 & 0.784 & Low \\
\hline 11 & Hungary & 1.34 & 0.805 & Low & 60 & Martinique & 1.91 & n.a. & Low \\
\hline 12 & Germany & 1.36 & 0.885 & Low & 61 & Costa Rica & 1.92 & 0.725 & Low \\
\hline 13 & Portugal & 1.36 & 0.795 & Low & 62 & Norway & 1.92 & 0.938 & Low \\
\hline 14 & Italy & 1.38 & 0.854 & Low & 63 & Australia & 1.93 & 0.937 & Low \\
\hline 15 & Austria & 1.38 & 0.851 & Low & 64 & France & 1.97 & 0.872 & Low \\
\hline 16 & Slovenia & 1.39 & 0.828 & Low & 65 & Netherlands Antilles & 1.98 & n.a. & Low \\
\hline 17 & Belarus & 1.39 & 0.732 & Low & 66 & Tunisia & 2.04 & 0.683 & Low \\
\hline 18 & Ukraine & 1.39 & 0.710 & Low & 67 & Korea, North & 2.05 & n.a. & Low \\
\hline
\end{tabular}




\begin{tabular}{|c|c|c|c|c|c|c|c|c|c|}
\hline & Country & $\begin{array}{l}\text { Period } \\
\text { TFR } \\
\text { (UN) } \\
2005-10\end{array}$ & $\begin{array}{l}\text { HDI, } \\
2010\end{array}$ & $\begin{array}{l}\text { Fert. } \\
\text { Mod. }\end{array}$ & & Country & $\begin{array}{l}\text { Period } \\
\text { TFR } \\
\text { (UN) } \\
2005-10\end{array}$ & $\begin{array}{l}\text { HDI, } \\
2010\end{array}$ & $\begin{array}{l}\text { Fert. } \\
\text { Mod. }\end{array}$ \\
\hline 19 & Czech Republic & 1.41 & 0.841 & Low & 68 & U.S.A. & 2.07 & 0.902 & Low \\
\hline 20 & Lithuania & 1.41 & 0.783 & Low & 69 & Myanmar & 2.08 & 0.451 & High \\
\hline 21 & Spain & 1.41 & 0.863 & Low & 70 & Ireland & 2.10 & 0.895 & Low \\
\hline 22 & Latvia & 1.41 & 0.769 & Low & 71 & Iceland & 2.10 & 0.869 & Low \\
\hline 23 & Croatia & 1.42 & 0.767 & Low & 72 & Brunei & 2.11 & 0.805 & Low \\
\hline 24 & Russian Federation & 1.44 & 0.719 & Low & 73 & Uruguay & 2.12 & 0.765 & Low \\
\hline 25 & Bulgaria & 1.46 & 0.743 & Low & 74 & New Zealand & 2.14 & 0.907 & Low \\
\hline 26 & Switzerland & 1.46 & 0.874 & Low & 75 & Guadeloupe & 2.14 & n.a. & Low \\
\hline 27 & Greece & 1.46 & 0.855 & Low & 76 & Turkey & 2.15 & 0.679 & Low \\
\hline 28 & Macedonia & 1.46 & 0.701 & Low & 77 & Azerbaijan & 2.16 & 0.713 & Low \\
\hline 29 & Cuba & 1.50 & n.a. & Low & 78 & French Polynesia & 2.16 & n.a. & Low \\
\hline 30 & Moldova & 1.50 & 0.623 & Low & 79 & Indonesia & 2.19 & 0.600 & High \\
\hline 31 & Cyprus & 1.51 & 0.810 & Low & 80 & New Caledonia & 2.19 & n.a. & Low \\
\hline 32 & Barbados & 1.53 & 0.788 & Low & 81 & Argentina & 2.25 & 0.775 & Low \\
\hline 33 & Georgia & 1.58 & 0.698 & Low & 82 & Kuwait & 2.32 & 0.771 & Low \\
\hline 34 & Albania & 1.60 & 0.719 & Low & 83 & Guyana & 2.33 & 0.611 & High \\
\hline 35 & Luxembourg & 1.62 & 0.852 & Low & 84 & Salvador & 2.35 & 0.659 & High \\
\hline 36 & Serbia & 1.62 & 0.735 & Low & 85 & Sri Lanka & 2.36 & 0.658 & High \\
\hline 37 & Thailand & 1.63 & 0.654 & Low & 86 & Morocco & 2.38 & 0.567 & High \\
\hline 38 & Estonia & 1.64 & 0.812 & Low & 87 & Bangladesh & 2.38 & 0.469 & High \\
\hline 39 & China & 1.64 & 0.663 & Low & 88 & Algeria & 2.38 & 0.677 & Low \\
\hline 40 & Trinidad and Tobago & 1.64 & 0.736 & Low & 89 & Réunion & 2.40 & n.a. & Low \\
\hline 41 & Canada & 1.65 & 0.888 & Low & 90 & Jamaica & 2.40 & 0.688 & Low \\
\hline 42 & Mauritius & 1.67 & 0.701 & Low & 91 & Qatar & 2.40 & 0.803 & Low \\
\hline 43 & Montenegro & 1.69 & 0.769 & Low & 92 & Mexico & 2.41 & 0.750 & Low \\
\hline 44 & Armenia & 1.74 & 0.695 & Low & 93 & Suriname & 2.42 & 0.646 & High \\
\hline 45 & Netherlands & 1.75 & 0.890 & Low & 94 & Colombia & 2.45 & 0.689 & Low \\
\hline 46 & Iran & 1.77 & 0.702 & Low & 95 & Uzbekistan & 2.46 & 0.617 & High \\
\hline 47 & Belgium & 1.79 & 0.867 & Low & $\ldots$ & $\ldots$ & & $\ldots$ & $\ldots$ \\
\hline 48 & Puerto Rico & 1.83 & n.a. & Low & 119 & Israel & 2.91 & 0.872 & Low \\
\hline 49 & United Kingdom & 1.83 & 0.849 & Low & & & & & \\
\hline
\end{tabular}

Note: Taiwan is missing in the list as a territory not recognised by the UN, as well as Aruba, Channel Islands, Grenada, Saint Lucia, and Saint Vincent and the Grenadines. The ranking of countries by period TFR in 2005-10 was based on the UN (2011) dataset released with the World Population Prospects 2010. 
Appendix 3: Profile of respondents and country responses.

\begin{tabular}{|c|c|c|c|}
\hline Total respondents: 184 & Country (and region) of projectio & & \\
\hline Gender: & Central Europe (15) & Czech Republic & 6 \\
\hline 81: Male & & Hungary & 3 \\
\hline 62: Female & & Poland & 2 \\
\hline 41: Blank & & Croatia & 2 \\
\hline Field: & & Slovenia & 1 \\
\hline 135: Academia & & Lithuania & 1 \\
\hline 14: Government & Eastern Europe (13) & Russia & 4 \\
\hline $\begin{array}{l}\text { 11: Think tanks/Policy Institute } \\
\text { 5. Other }\end{array}$ & & Romania & 3 \\
\hline $\begin{array}{l}\text { 5: Other } \\
\text { 2: National NGO }\end{array}$ & & Ukraine & 2 \\
\hline 1: NGO & & Bulgaria & 2 \\
\hline 16: Blank & & Georgia & 2 \\
\hline Country of wark. & Southern Europe (21) & Italy & 12 \\
\hline $\begin{array}{l}\text { Country of work: } \\
\text { 26: United States }\end{array}$ & & Spain & 6 \\
\hline 14: Austria & & Greece & 1 \\
\hline 7: Australia, France, Italy, Spain, & & Portugal & 1 \\
\hline Sweden & Western Europe (9) & United Kingdom & 4 \\
\hline $\begin{array}{l}\text { 6: Brazil, Germany } \\
\text { 5: China, Iran, UK }\end{array}$ & & Netherlands & 4 \\
\hline 4: Canada, Netherlands, Turkey & Nordic (14) & Ŝ́den & 7 \\
\hline 3: Argentina, Japan, Mexico, Romania & & Norway & 2 \\
\hline 2: Belgium, Czech R, Hungary, Poland, & & Finland & 2 \\
\hline $\begin{array}{l}\text { Switzerland, Thailand } \\
\text { 1: Colombia, Croatia, Finland, Georgia, }\end{array}$ & & Iceland & 1 \\
\hline Greece, Lithuania, New Zealand, & German speaking (10) & Germany & 9 \\
\hline Portugal, Russia, Slovenia, Ukraine, & & Austria & 7 \\
\hline Uruguay & & Switzerland & 3 \\
\hline 34: Blank & East Asia & China & 14 \\
\hline Age of respondents: & & Japan & 6 \\
\hline 25-29: 8 & & Thailand & 4 \\
\hline 30-34: 21 & & Korea, South) & 2 \\
\hline 35-39: 20 & & Hong Kong SAR & 1 \\
\hline $\begin{array}{l}40-44: 20 \\
45-49: 15\end{array}$ & Latin America (18) & Brazil & 7 \\
\hline 50-54: 4 & & Mexico & 5 \\
\hline 55-59: 20 & & Argentina & 3 \\
\hline 60-64: 8 & & Uruguay & 1 \\
\hline $\begin{array}{l}65-69: 16 \\
70-74 \cdot 3\end{array}$ & & Colombia & 1 \\
\hline $75+: 4$ & North America \& Australia & United States & 22 \\
\hline & & Australia & 5 \\
\hline & & Canada & 4 \\
\hline & Western Asia / Middle east & Iran & 8 \\
\hline & & Turkey & 5 \\
\hline & Other (2) & Algeria & 1 \\
\hline & & Israel & 1 \\
\hline
\end{tabular}




\section{Appendix 4: Complete list of arguments and their groupings by major factors in the low fertility module of the WIC survey}

\section{Cultural and social forces in fertility ideals, norms, and desires}

1.1 Voluntary childlessness is increasingly becoming socially accepted

1.2 One-child families will become a dominant cultural norm

1.3 Society will become yet more individualistic

1.4 It is a human constant that people will always desire at least one surviving child in order to "continue living" in the future

1.5 The share of population groups with larger families will increase

1.6 The availability of grandparents for childcare and family care will decline

1.7 Religious views on family and reproduction will gain importance

1.8 High fertility will become a status symbol among the wealthy.

1.9 Globally, there will be a convergence of all populations towards a two-child family as an ideal and actual family size.

\section{Partnerships, living arrangements and gender differences}

2.1 Men are increasingly reluctant to become fathers, even when they live with a partner

2.2 Men and women will increasingly share the burden of housework and childcare

2.3 People are increasingly unable to find the right partner to form a family

2.4 Women will increasingly pursue lifestyles and activities not compatible with motherhood

2.5 Marriage will further decline and will become a minority experience

2.6 Partnership dissolution and "re-partnering" will become yet more common among women of reproductive age

2.7 Women will achieve complete equality with men with respect to their education, employment career, and income

2.8 Cross-border partnership and marriage migration will increase in importance

2.9 Adults in their 20s and even 30s will spend ever longer periods of life living with their parents

3. Role of Policies (In this case, 'Government' entails national government unless stated otherwise)

3.1 Government will raise child subsidies and tax benefits or introduce birth bonuses

3.2 Government will take an increasingly pro-natalist stance (e.g. through communication campaigns and family policies) 
3.3 Government will provide universal nursery / kindergarten access

3.4 Provision of affordable housing for families and young adults will become an important part of social policies

3.5 New policies will allow young parents to significantly reduce their working hours for several years with some compensation of income

3.6 Mothers will be increasingly expected and encouraged to return to work even when their children are small

3.7 Family-related policies, including childcare provision, will be increasingly pursued by local governments and employers

3.8 Governments will cut back on family support when economic conditions worsen.

3.9 As populations age government funds will become increasingly directed toward the elderly and away from the young

\section{Employment and economy}

4.1 Unemployment and job instability among the under-30s will further increase

4.2 Increasing average household income will lead to higher fertility

4.3 Employers will put more pressure on their employees in terms of higher working hours and more work commitments

4.4 Work practices will become more flexible in the future (e.g. telecommuting, working from home, flexi-time, part-time)

4.5 Geographical mobility, especially work-related, will further increase

4.6 Immigration from high fertility countries will increase

4.7 Continuing economic unpredictability will make individual life-course planning ever more uncertain

4.8 Informal childcare will shift from grandparents to paid domestic workers

4.9 Cities will become more child-friendly

\section{Biomedical and the timing of parenthood}

5.1 Men are becoming less fecund due to declining sperm counts or quality

5.2 Delayed childbearing will become yet more common among women

5.3 Having children under the age of 25 will be rare

5.4 The broad availability and use of efficient contraception, including post-coital methods, will make mistimed and unwanted pregnancies rare

5.5 Financial, normative and institutional barriers to Assisted ReproductiveTechnologies (ART) will keep their application limited 
5.6 Assisted reproduction and selective abortion will be increasingly used to achieve a desired sex composition as well as other characteristics of children.

5.7 The technology and availability of ART will improve sufficiently that women in their forties who want a child will routinely be able to have one.

\section{Education}

6.1 People will spend ever more years of their young adult life enrolled in education and professional training on the job

6.2 Fertility differentials by level of female education will diminish.

6.3 There will be a new trend for better educated women to have more children and simultaneously pursue a professional career. 
Appendix 5: Regional graphs of expected TFR trends up to 2050: A comparison of the global survey of experts and the $2010 \mathrm{UN}$ projection (probabilistic fertility scenarios)
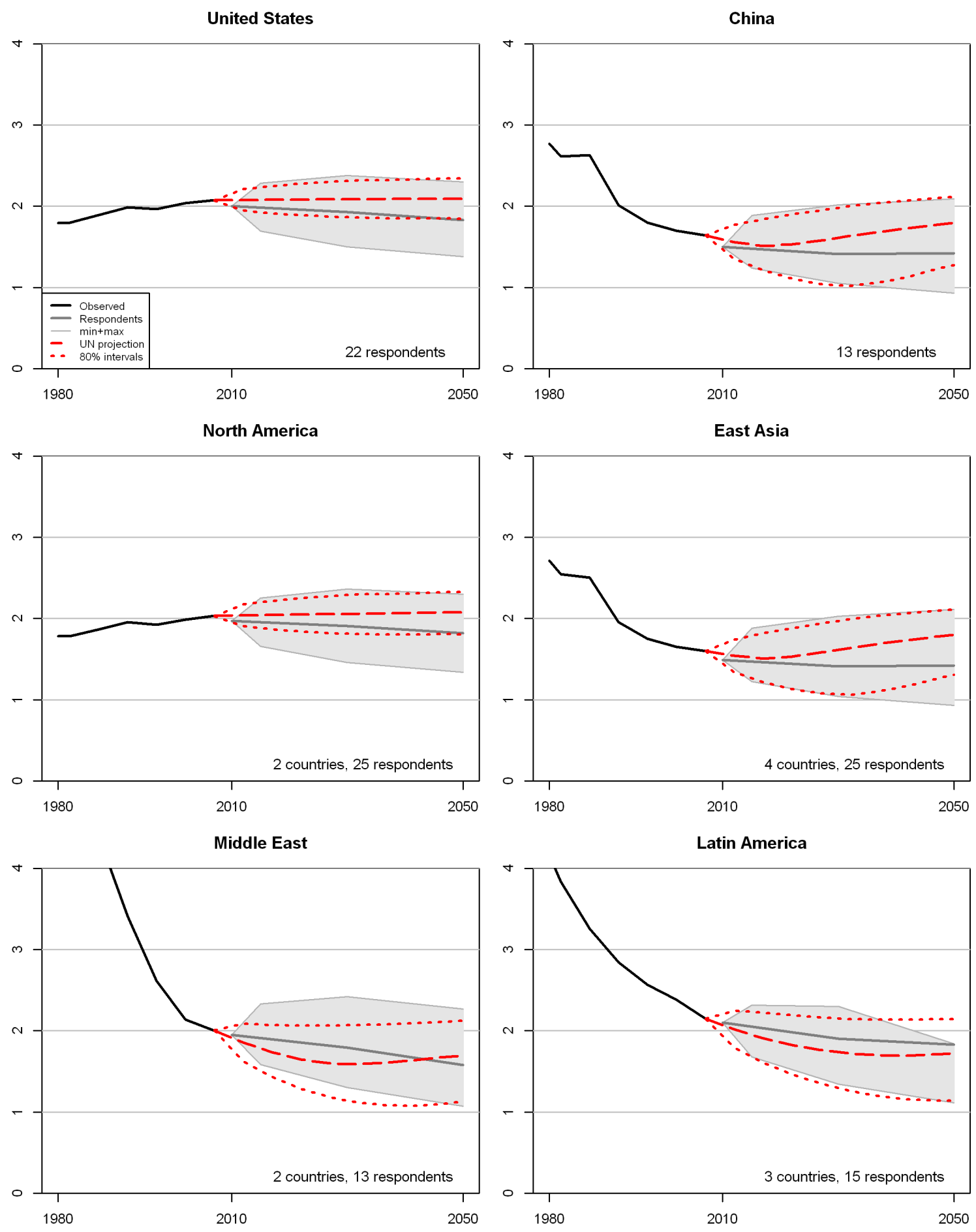

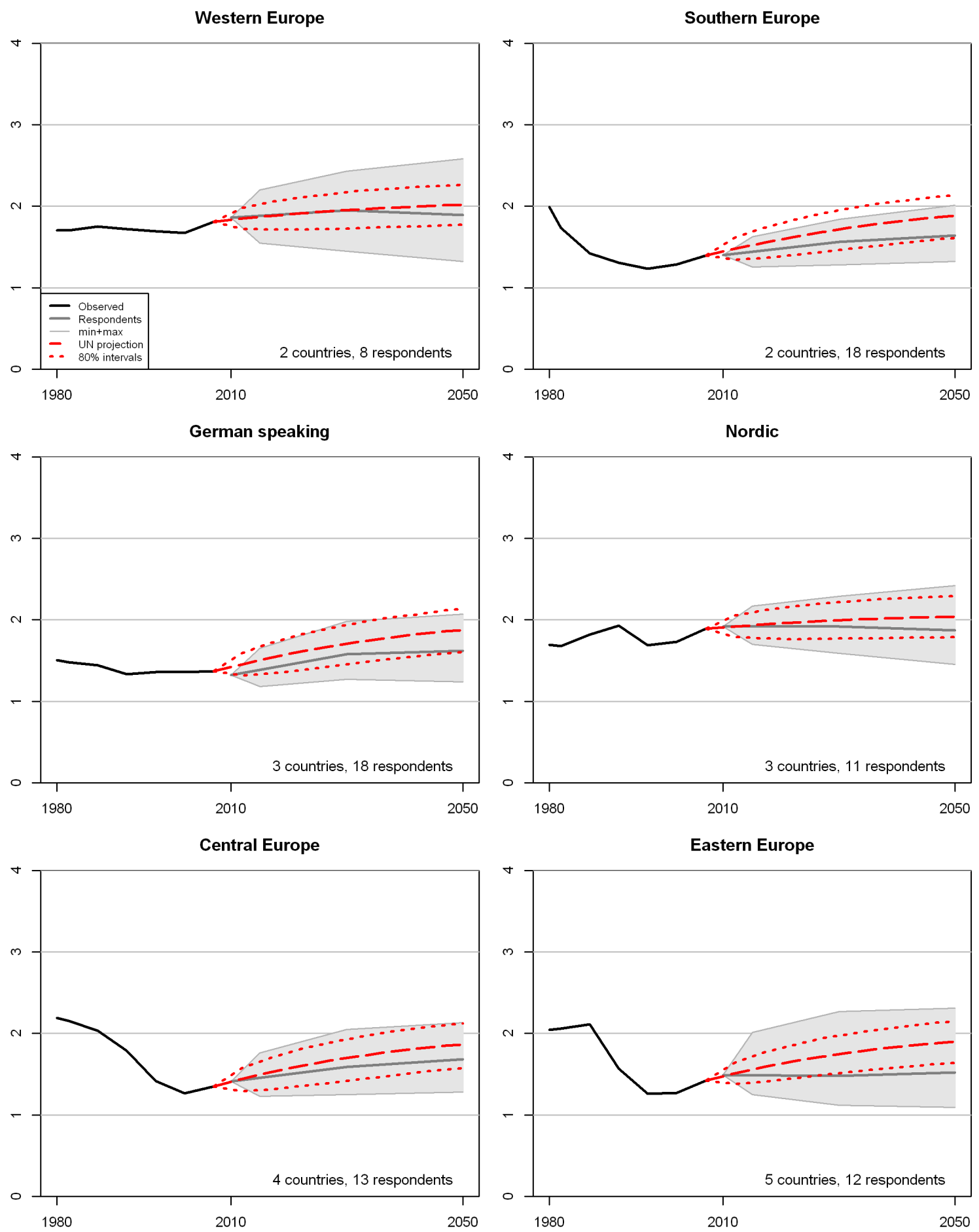


\section{Appendix 6: Specifying source data on education-fertility differentials}

Most of the data used in our analyses of education-fertility differentials in Section 5.3 are based on census results pertaining to completed or almost completed fertility among women aged 40 and over (usually, age groups 40-44 or 45-49 are used) and stratified by level of education. When cohort data were unavailable, we made use of period fertility estimates published in the literature listed below. Three broad education categories are used unless stated otherwise: "Low" (ISCED classification 0-2; when data allow this category is further subdivided into "Very low" education (ISCED 0-1) and "Lower secondary" education (ISCED 2)); "Medium" (ISCED 3 or 3-4), and "High" education (ISCED 5-6). Here we provide a list of country-specific data sources by region.

United States: Period fertility data: Hazan and Zoabi 2011, Table on p. 38, "Total fertility rate by educational groups, 2001-2009" (White US women only, data based on American Community Survey)

Australia: Tesfaghiorghis 2004, Table 1 (cohort data based on the HILDA survey conducted in 2001)

New Zealand: Census 2006

\section{South-East Asia}

South Korea: Census 2001 data

Singapore: Census 2001 data

Japan: Period fertility data for 1996-2000 computed by Retherford et al. 2004, Table 2

\section{Latin America}

Argentina: Census 2001

Colombia: Census 2005

Jamaica: Census 2001

Brazil: Census 2000

Chile: Census 2002

Costa Rica: Census 2000

Mexico: Census 2010

Trinidad and Tobago: Census 2000

\section{Middle East}

Iran: Census 2006

Israel: Census 1995

Qatar: Census 2010 


\section{Western and Northern Europe}

Austria: Population Census 2001, birth cohorts 1925-59 (trends data) and 1955-59 (recent data); data published by Statistics Austria (2005)

Belgium: Population Census 2001, birth cohorts 1930-61 (trends data) and 1957-61 (recent data); data published by Neels and De Wachter (2010), Figure 3a.

France: Period fertility data estimated for 2008; Davie and Mazuy 2010, Figure 5 (Annual census surveys 2009)

Germany: 2008 Mikrozensus survey, birth cohorts 1935-64 (trends data) and 1960-64 (recent data), data published by Statistisches Bundesamt (2009).

Netherlands: Population register data, birth cohorts 1945-64 (trends data) and 1960-64 (recent data), data published by Statistics Netherlands (2012).

Norway: Population register data, birth cohorts 1940-64 (trends data) and 1960-64 (recent data), data published by Kravdal and Rindfuss (2008: Table 2).

Switzerland: Population Census 2000, birth cohorts 1930-59 (trends data) and 1955-59 (recent data), data and computations provided by Marion Burkimsher.

Finland: Cohort data, women born 1955-59, Andersson et al. 2008.

Denmark: Computed by T. Sobotka (Register-based cohort data, women born in the early 1960s)

\section{Southern Europe}

Greece: Census 2001

Italy: Cohorts 1960-64, computations from the 2003 GGS survey (Famiglia e soggetti sociali) provided by Paola di Giulio.

\section{Central Europe}

Croatia: Census 2001

Czech Republic: Population Census 2001, birth cohorts 1920-59 (trends data) and 1955-59 (recent data); data provided by the Czech Statistical Office.

Estonia: Census 2000

Hungary: Census 2001

Poland: Census 2002

Slovakia: Census 2001

Slovenia: Census 2002

\section{Eastern Europe (and the Caucasus):}

Armenia: Census 2001 (IPUMS)

Belarus: Census 1999 
Bulgaria: Census 2001

Romania: Population Census 2002, birth cohorts 1950-54, 10\% sample, IPUMS database.

Ukraine: Census 2001 


\section{REFERENCES}

Abbasi-Shavazi, Mohammad Jalal, and Peter McDonald. 2000. "Fertility and Multiculturalism: immigrant fertility in Australia: 1977-91." International Migration Review, 34(1): 215-42.

Abbasi-Shavazi, Mohammad Jalal, and Gavin W Jones. 2005. "Socio-economic and Demographic Setting of Muslim Populations." In Islam, the State and Population, edited by Gavin W. Jones and Mehtab S. Karim, 9-39. London: Hurst and Co.

Abbasi-Shavazi, Mohammad Jalal, S. Philip Morgan, Meimanat Hossein-Chavoshi, and Peter McDonald. 2009a. "Family Change and Continuity in Iran: Birth Control Use before First Pregnancy." Journal of Marriage and the Family 71 (5): 1309-1324. doi:10.1111/j.1741-3737.2009.00670.x.

Abbasi-Shavazi, Mohammad Jalal, Peter McDonald, and Meimanat Hosseini-Chavoshi. 2009b. "The Fertility Transition in Iran: Revolution and Reproduction." Springer, Dordrecht.

Abbasi-Shavazi, Mohammad Jalal, and Fatemeh Torabi. 2012. "Women's Education and Fertility in Islamic Countries." In Population Dynamics in Muslim Countries, edited by Hans Groth and Alfonso Sousa-Poza, 43-62. Springer.

Adsera, Alicia. 2004. "Changing Fertility Rates in Developed Countries. The Impact of Labor Market Institutions." Journal of Population Economics 17 (1) (February): 17-43. doi:10.1007/s00148-003-0166-x.

. 2006. "An Economic Analysis of the Gap Between Desired and Actual Fertility: The Case of Spain." Review of Economics of the Household 4 (1): 75-95.

_. 2011a. "Where Are the Babies? Labor Market Conditions and Fertility in Europe." European Journal of Population 27 (1) (February 1): 1-32. doi:10.1007/s10680-0109222-x.

. 2011b. "The Interplay of Employment Uncertainty and Education in Explaining Second Births in Europe." Demographic Research 25: 513-544. doi:10.4054/DemRes.2011.25.16.

Adsera, Alicia, and Ana Ferrer. 2010. "The Fertility Decisions of Canadian Immigrants." In Canadian Research on Immigration, edited by A. Sweetman, T. McDonald, and E. Ruddick, 283-309. John Deutchs Institute of Economic Policy, Queen's University: McGill-Queen's Press.

Adsera, Alicia, and Alicia Menendez. 2011. "Fertility Changes in Latin America in Periods of Economic Uncertainty." Population Studies 65 (1): 37-56.

Alkema, Leontine, Adrian E. Raftery, Patrick Gerland, Samuel J. Clark, Francois Pelletier, and Thomas Buettner. 2010. "Probabilistic Projections of the Total Fertility Rate for All Countries". Working Paper 97. Center for Statistics and the Social Sciences University of Washington. http://www.csss.washington.edu/Papers/wp97.pdf.

Alkema, Leontine, Adrian E. Raftery, Patrick Gerland, Samuel J. Clark, François Pelletier, Thomas Buettner, and Gerhard K. Heilig. 2011. "Probabilistic Projections of the Total Fertility Rate for All Countries." Demography 48 (3): 815-839. 
Anderson, Thomas M., and Hans-Peter Kohler. 2012. "Education Fever and the East Asian Fertility Puzzle: A Case Study of Low Fertility in South Korea”. Working Paper 1207. Penn PSC Working Paper. http://repository.upenn.edu/psc_working_papers/38/.

Andersson, Gunnar, Marit Rønsen, Lisbeth B. Knudsen, Trude Lappegård, Gerda Neyer, Kari Skrede, Kathrin Teschner, and Andres Vikat. 2009. "Cohort Fertility Patterns in the Nordic Countries." Demographic Research 20: 313-352. doi:10.4054/DemRes.2009.20.14.

Arendell, Terry. 2000. "Conceiving and Investigating Motherhood: The Decade's Scholarship.” Journal of Marriage and Family 62 (4): 1192-1207.

Balbo, Nicoletta, Francesco C. Billari, and Melinda Mills. 2013. "Fertility in Advanced Societies: A Review of Research.” European Journal of Population 29 (1): 1-38.

Barber, Jennifer S. 2001. "Ideational Influences on the Transition to Parenthood: Attitudes Toward Childbearing and Competing Alternatives." Social Psychology Quarterly 64 (2): 101-127.

Basten, Stuart. 2013a. "Comparing Projections Assumptions of Fertility in Advanced Asian Economies; or 'thinking Beyond the Medium Variant'." Asian Population Studies forthcoming.

. 2013b. "Re-Examining the Fertility Assumptions for Pacific Asia in the UN's 2010 World Population Prospects". Barnett Papers in Social Research 2013-1. Department of Social Policy and Intervention, University of Oxford.

Basten, Stuart, and Baochang Gu. 2013. "Childbearing Preferences, Reform of Family Planning Restrictions and the Low Fertility Trap in China". Working Paper 61. Oxford Centre for Population Research Working Paper. Department of Social Policy and Intervention, University of Oxford.

Basten, Stuart, Johannes Huinink, and Sebastian Klüsener. 2011. "Spatial Variation of Subnational Fertility Trends in Austria, Germany and Switzerland." Comparative Population Studies - Zeitschrift Für Bevölkerungswissenschaft 36 (2-3). http://www.comparativepopulationstudies.de/index.php/CPoS/article/view/79.

Basten, Stuart, Wolfgang Lutz, and Sergei Scherbov. 2013. "Very Long Range Global Population Scenarios to 2300 and the Implications of Sustained Low Fertility." Demographic Research 28 (May 30): 1145-1166. doi:10.4054/DemRes.2013.28.39.

Beaujouan, Eva, and Anne Solaz. 2012. "Racing Against the Biological Clock? Childbearing and Sterility Among Men and Women in Second Unions in France." European Journal of Population: 1-29. doi:10.1007/s10680-012-9271-4.

Becker, Gary S. 1981. A Treatise on the Family. Cambridge, Massachusetts: Harvard University Press.

Beckman, Linda J. 1983. "Communication, Power, and the Influence of Social Networks in Couple Decisions on Fertility." Determinants of Fertility in Developing Countries 2: 415-443.

Beckman, Linda J, Rhonda Aizenberg, Alan B Forsythe, and Tom Day. 1983. "A Theoretical Analysis of Antecedents of Young Couples' Fertility Decisions and Outcomes." Demography 20 (4): 519-533. 
Bélanger, Alain, Jean-Dominique Morency, and Martin Spielauer. 1944. "A Microsimulation Model to Study the Interaction Between Fertility and Union Formation and Dissolution: An Application to Canada and Quebec." Canadian Studies in Population 37 (3-4) (December 31): 339 - 373.

Bericat, Eduardo. 2012. "The European Gender Equality Index: Conceptual and Analytical Issues." Social Indicators Research 108 (1) (August): 1-28.

Billari, Francesco C, and Gianpiero Dalla-Zuanna. 2012. "Is Replacement Migration Actually Taking Place in Low Fertility Countries?” Genus 67 (3): 105-123.

Billari, Francesco C, and Hans-Peter Kohler. 2004. "Patterns of Low and Lowest-low Fertility in Europe." Population Studies 58 (2) (January): 161-176. doi:10.1080/0032472042000213695.

Billari, Francesco C, and Aart C Liefbroer. 2010. "Towards a New Pattern of Transition to Adulthood?" Advances in Life Course Research 15 (2-3) (June): 59-75. doi:10.1016/j.alcr.2010.10.003.

Billari, Francesco C., Dimiter Philipov, and Maria Rita Testa. 2009. "Attitudes, Norms and Perceived Behavioural Control: Explaining Fertility Intentions in Bulgaria." European Journal of Population 25 (4) (July): 439-465. doi:10.1007/s10680-009-9187-9.

Billingsley, Sunnee. 2010. "The Post-communist Fertility Puzzle.” Population Research and Policy Review 29 (2): 193-231.

Björklund, Anders. 2006. "Does Family Policy Affect Fertility?" Journal of Population Economics 19 (1) (January): 3-24. doi:10.1007/s00148-005-0024-0.

Blossfeld, H. P., and J. Huinink. 1991. "Human Capital Investments or Norms of Role Transition? How Women's Schooling and Career Affect the Process of Family Formation." American Journal of Sociology 97 (1): 143-168. doi:10.1086/229743.

Boivin, Jacky, Laura Bunting, John A. Collins, and Karl G. Nygren. 2007. "International Estimates of Infertility Prevalence and Treatment-seeking: Potential Need and Demand for Infertility Medical Care." Human Reproduction 22 (6): 1506-1512. doi:10.1093/humrep/dem046.

Bonde, Jens Peter, Cecilia Høst Ramlau-Hansen, and Jørn Olsen. 2011. "Commentary: Trends in Sperm Counts: The Saga Continues.” Epidemiology 22 (5): 617-619.

Bongaarts, John. 1999. "The Fertility Impact of Changes in the Timing of Childbearing in the Developing World.” Population Studies 53 (3): 277-289.

. 2001. "Fertility and Reproductive Preferences in Post-transitional Societies." Population and Development Review 27 (Supplement: global fertility transition): 260281.

. 2002. "The End of the Fertility Transition in the Developed World." Population and Development Review 28 (3): 419-443.

Bongaarts, John, and R. A. Bulatao, ed. 2000. Beyond Six Billion: Forecasting the World's Population. Panel on Population Projections, Committee on Population, Commission on Behavioral and Social Sciences and Education. Washington, D.C.: National Academy Press.

Bongaarts, John, and Griffith Feeney. 1998. "On the Quantum and Tempo of Fertility." Population and Development Review 24 (2) (June 1): 271-291. doi:10.2307/2807974. 
2006. "The Quantum and Tempo of Life-cycle Events." Vienna Yearbook of Population Research 2006: 115-151. doi:10.1553/populationyearbook2006s115.

Bongaarts, John, and Tomáš Sobotka. 2012. "A Demographic Explanation for the Recent Rise in European Fertility." Population and Development Review 38 (1): 83-120. doi:10.1111/j.1728-4457.2012.00473.x.

Bradshaw, Jonathan, and Emese Mayhew. 2006. "Family Benefit Packages." In Social Policy, Employment and Family Change in Comparative Perspective, edited by J. Bradshaw and A. Hatland, 97-117.

Brewster, Karin L., and Ronald R. Rindfuss. 2000. "Fertility and Women's Employment in Industrialized Nations.” Annual Review of Sociology 26: 271-296.

Broekmans, Frank J, Erik AH Knauff, Egbert R. te Velde, Nick S Macklon, and Bart C Fauser. 2007. "Female Reproductive Ageing: Current Knowledge and Future Trends." Trends in Endocrinology \& Metabolism 18 (2): 58-65.

Bumpass, Larry L., and Minja Kim Choe. 2004. "Attitudes Relating to Marriage and Family Life." In Marriage, Work, and Family Life in Comparative Perspective: Japan, South Korea, and the United States, edited by Noriko O. Tsuya and Larry L. Bumpass, 1938. Honolulu: University of Hawai'i Press.

Bumpass, Larry L., Ronald R. Rindfuss, Minja Kim Choe, and Noriko O. Tsuya. 2009. "The Institutional Context of Low Fertility: The Case of Japan." Asian Population Studies 5 (3): 215-235. doi:10.1080/17441730903351479.

Butz, William P, and Michael P Ward. 1979. "Will US Fertility Remain Low? A New Economic Interpretation." Population and Development Review 5 (4): 663-688.

Bystrov, Evgenia. 2012. "The Second Demographic Transition in Israel: One for All?" Demographic Research 27 (August 21): 261-298. doi:10.4054/DemRes.2012.27.10.

Cai, Yong. 2008. "An Assessment of China's Fertility Level Using the Variable-r Method." Demography 45 (2): 271-281.

2010. "China's Below-replacement Fertility: Government Policy or Socioeconomic Development?" Population and Development Review 36 (3): 419-440.

2011. "United Nations Population Projection still overestimated China's fertility level." First Caijing Daily, 23 May 2011, May 23. http://big5.xinhuanet.com/ gate/big5/www.cnstock.com/index/gdbb/201105/1317694.htm.

Caldwell, John C. 1976. "Toward a Restatement of Demographic Transition Theory." Population and Development Review 2 (3/4): 321-366.

. 2001. "The Globalization of Fertility Behavior." Population and Development Review 27: 93-115.

Caldwell, John C., and Thomas Schindlmayr. 2003. "Explanations of the Fertility Crisis in Modern Societies: a Search for Commonalities." Population Studies 57 (3) (November): 241-63. doi:10.1080/0032472032000137790.

Carlsen, Elisabeth, Aleksander Giwercman, Niels Keiding, and Niels E. Skakkebæk. 1992. "Evidence for Decreasing Quality of Semen During Past 50 Years." British Medical Journal 305 (6854) (September 12): 609-613. doi:10.2307/29716905. 
Cassens, Insa, Marc Luy, and Rembrandt D. Scholz. 2009. Die Bevölkerung in Ost-und Westdeutschland: Demografische, Gesellschaftliche Und Wirtschaftliche Entwicklungen seit der Wende. Springer.

Casterline, John B, and Jennifer Adams Mendoza. 2009. "Unwanted Fertility in Latin America: Historical Trends, Recent Patterns." In Demographic Transformations and Inequalities in Latin America, 193-218. Rio de Janeiro: ALAP.

Castles, Francis G. 2003. "The World Turned Upside down: Below Replacement Fertility, Changing Preferences and Family-friendly Public Policy in 21 OECD Countries." Journal of European Social Policy 13 (3): 209-227.

Castro Martin, T. 1995. "Women's Education and Fertility: Results from 26 Demographic and Health Surveys." Studies in Family Planning 26 (4): 187-202.

CBS. 2011. "Statistical Abstract of Israel 2011. Chapter 3: Vital Statistics". 62. Jerusalem: The Central Bureau of Statistics.

CDC. 2011. "Assisted Reproductive Technology Success Rates 2009. National Summary and Fertility Clinic Reports". Atlanta: Center for Disease Control and Prevention, American Society for Reproductive Medicine, Society for Assisted Reproductive Technology. http://www.cdc.gov/art/ART2009/PDF/ART_2009_Full.pdf.

. 2012. "Key Statistics from the National Survey of Family Growth". Atlanta: Center for Disease Control and Prevention, American Society for Reproductive Medicine, Society for Assisted Reproductive Technology. http://www.cdc.gov/nchs/nsfg/abc_list_i.htm\#impaired.

CELADE. 2012. "Sistema de Indicadores Sociodemográficos de Poblaciones y Pueblos Indígenas (SISPPI)". Electronic database. Latin American Demography Center CELADE. http://celade.cepal.org/redatam/PRYESP/SISPPI.

Chamie, Joseph. 1981. Religion and Fertility: Arab Christian-Muslim Differentials. Cambridge; New York: Cambridge University Press.

Chatters, Linda M., and Robert J. Taylor. 2005. "Religion and Families." In Sourcebook of Family Theory and Research, edited by Vern L. Bengtson, Alan A. Acock, Katherine R. Allen, Peggye Dilworth-Anderson, and David M. Klein, 517-541. London: Sage.

Chen, Y.H. 2012. "Trends in Low Fertility and Policy Responses in Taiwan." The Japanese Journal of Population 10 (1): 78-88.

Choe, Minja Kim. 2006. "Modernization, Gender Roles and Marriage Behavior in South Korea." In Transformations in Twentieth Century Korea, edited by Yun-Shik Chang and Hugh Lee, Steven, 291-309. London: Routledge.

Choe, Minja Kim, and Kyung-Ae Park. 2006. "Fertility Decline in South Korea: Forty Years of Policy-behavior Dialogue." Korea Journal of Population Studies 29 (2): 1-26.

Choe, Minja Kim, and Robert D Retherford. 2009. "The Contribution of Education to South Korea's Fertility Decline to 'lowest-low' Level." Asian Population Studies 5 (3): 267288.

Choi, Jae-Seuk. 1970. "Comparative Study on the Traditional Families in Korea, Japan and China." In Families in East and West, edited by R. Hill and R. Koenig, 202-210. Paris: Mouton. 
Chung, Woojin, and Monica Das Gupta. 2007. "The Decline of Son Preference in South Korea: The Roles of Development and Public Policy." Population and Development Review 33 (4): 757-783.

Cobo, Ana, José Remohí, Ching-Chien Chang, and Zsolt Peter Nagy. 2011. "Oocyte Cryopreservation for Donor Egg Banking." Reproductive BioMedicine Online 23 (3): 341-346.

Cohen, Joel E, Øystein Kravdal, and Nico Keilman. 2011. "Childbearing Impeded Education More Than Education Impeded Childbearing Among Norwegian Women." Proceedings of the National Academy of Sciences of the United States of America 108 (29) (July): 11830-11835. doi:10.1073/pnas.1107993108.

Coleman, D. A. 1998. "Reproduction and Survival in an Unknown World: What Drives Today's Industrial Populations, and to What Future?" NIDI Hofstee Lecture Series 5. The Hague: Netherlands Interdisciplinary Demographic Institute (NIDI). http://economics.ouls.ox.ac.uk/13108/.

Coleman, David. 2009. "Migration and Its Consequences in 21st Century Europe." Vienna Yearbook of Population Research 7: 1-18.

Conrad, Christoph, Michael Lechner, and Welf Werner. 1996. "East German Fertility after Unification: Crisis or Adaptation?" Population and Development Review 22 (2): 331358.

Cooke, Lynn Prince. 2004. "The Gendered Division of Labor and Family Outcomes in Germany." Journal of Marriage and Family 66 (5): 1246-1259.

Courbage, Youssef. 1999. "Economic and Political Issues of Fertility Transition in the Arab world-Answers and Open Questions." Population \& Environment 20 (4): 353-379.

D'Addio, Anna Christina, and Marco Mira d' Ercole. 2005. "Trends and Determinants of Fertility Rates: The Role of Policies". 27. OECD Social, Employment and Migration Working Papers. OECD Publishing. http://www.oecdilibrary.org/docserver/download/5lg14dh07kf8.pdf?expires=1373961132\&id=id\&accn ame $=$ guest\&checksum=8F6AA36C44FC0004A6116380F9D9A13D.

Das Gupta, Monica, Woojin Chung, and Li Shuzhuo. 2009. "Evidence for an Incipient Decline in Numbers of Missing Girls in China and India." Population and Development Review 35 (2): 401-416.

David, Henry Philip. 1999. From Abortion to Contraception: A Resource to Public Policies and Reproductive Behavior in Central and Eastern Europe from 1917 to the Present. Greenwood Publishing Group.

Davie, Emma, and Magali Mazuy. 2011. "Women's Fertility and Educational Level in France: Evidence from the Annual Census Surveys." Population (English Edition) 65 (3): 415-449.

De Cooman, Eric, John Ermisch, and Heather Joshi. 1987. "The Next Birth and the Labour Market: A Dynamic Model of Births in England and Wales." Population Studies 41 (2): 237-268.

De la Rochebrochard, Elise, and Patrick Thonneau. 2003. "Paternal Age $\geq 40$ Years: An Important Risk Factor for Infertility." American Journal of Obstetrics and Gynecology 189 (4) (October): 901-905. doi:10.1067/S0002-9378(03)00753-1. 
Del Bono, Emilia, Andrea Weber, and Rudolf Winter-Ebmer. 2012. "Clash of Career and Family: Fertility Decisions after Job Displacement." Journal of the European Economic Association 10 (4): 659-683.

Delgado, Margarita, Gerardo Meil, and Francisco Zamora López. 2008. "Spain: Short on Children and Short on Family Policies." Demographic Research 19 (27): 1059-1104. doi:10.4054/DemRes.2008.19.27.

DellaPergola, Sergio. 2007. "Actual, Intended, and Appropriate Family Size in Israel: Trends, Attitudes and Policy Implications: A Preliminary Report". Avraham Harman Institute of Contemporary Jewry. Israel. http://www.bjpa.org/Publications/details.cfm?PublicationID=2022.

Demeny, Paul. 2004. "Population Futures for the Next Three Hundred Years: Soft Landing or Surprises to Come?" Population and Development Review 30 (3): 507-517.

Derosas, Renzo, and Frans W. A. van Poppel. 2006. Religion and the Decline of Fertility in the Western World. Springer.

Dorbritz, Jürgen. 2008. "Germany: Family Diversity with Low Actual and Desired Fertility." Demographic Research 19 (17): 557-598.

Dorius, Shawn F. 2008. "Global Demographic Convergence? A Reconsideration of Changing Intercountry Inequality in Fertility." Population and Development Review 34 (3): 519537. doi:10.1111/j.1728-4457.2008.00235.x.

Dunson, David B, Donna D Baird, and Bernardo Colombo. 2004. "Increased Infertility with Age in Men and Women." Obstetrics \& Gynecology 103 (1): 51-56.

Dunson, David B, Bernardo Colombo, and Donna D Baird. 2002. "Changes with Age in the Level and Duration of Fertility in the Menstrual Cycle." Human Reproduction 17 (5): 1399-1403.

Duthé, Géraldine, France Meslé, Jacques Vallin, Irina Badurashvili, and Karine Kuyumjyan. 2012. "High Sex Ratios at Birth in the Caucasus: Modern Technology to Satisfy Old Desires." Population and Development Review 38 (3): 487-501.

Duvander, Ann-Zofie, Trude Lappegård, and Gunnar Andersson. 2010. "Family Policy and Fertility: Fathers' and Mothers' Use of Parental Leave and Continued Childbearing in Norway and Sweden." Journal of European Social Policy 20 (1): 45-57. doi:10.1177/0958928709352541.

Dyer, Paul D. 2008. "Demography in the Middle East: Implications and Risks." In Transnational Trends: Middle Eastern and Asian Views, edited by Ellen Laipson and Amit Pandya, 62-90. Washington, DC: The Henry L. Stimson Center. http://www.stimson.org/books-reports/transnational-trends-middle-eastern-and-asianviews/.

Dyson, Tim. 2012. "Causes and Consequences of Skewed Sex Ratios." Annual Review of Sociology 38: 443-461.

Easterlin, Richard A. 1976. "The Conflict Between Aspirations and Resources." Population and Development Review 2 (3/4) (September 1): 417-425. doi:10.2307/1971619. . 1980. Birth and Fortune: The Impact of Numbers on Personal Welfare. New York: Basic Books. 
Eberstadt, N. 2011. "The Global War Against Baby Girls." The New Atlantis Fall 2011. http://www.aei.org/files/2012/01/12/-the-global-war-against-babygirls_094915483477.pdf.

Eberstadt, Nicholas, and Apoorva Shah. 2012. "Fertility Decline in the Muslim World, c. 1975-c. 2005: a Veritable Sea-change, Still Curiously Unnoticed." In Population Dynamics in Muslim Countries: Assembling the Jigsaw, edited by Hans Groth and Alfonso Sousa-Poza, 11-27. Springer.

Edmonston, Barry, Sharon M. Lee, and Zheng Wu. 2010. "Fertility Intentions in Canada: Change or No Change?" Canadian Studies in Population 37 (3-4) : 297 - 337.

Ekert-Jaffé, Olivia, Heather Joshi, Kevin Lynch, Rémi Mougin, Michael S Rendall, and David Shapiro. 2002. "Fertility, Timing of Births and Socio-economic Status in France and Britain: Social Policies and Occupational Polarisation." Population (English Edition) 57 (3): 475-507.

Engelhardt, Henriette, and Alexia Prskawetz. 2004. "On the Changing Correlation Between Fertility and Female Employment over Space and Time." European Journal of Population 20 (1): 35-62.

ESF. 2010. "Male Reproductive Health. Its Impacts in Relation to General Wellbeing and Low European Fertility Rates". Science Policy Briefings 40. European Science Foundation. http://www.esf.org/publications/science-policy-briefings.html.

ESHRE. 2010. "Europe the Continent with the Lowest Fertility." Human Reproduction Update 16 (6): 590-602. doi:10.1093/humupd/dmq023.

Esping-Andersen, Gosta. 2009. The Incomplete Revolution: Adapting Welfare States to Women's New Roles. Cambridge: Polity Press.

Eurostat. 2012. "Data on Period Total Fertility Rate". Eurostat Statistics Database. Eurostat. http://epp.eurostat.ec.europa.eu.

. 2013. "Population by Country of Birth". Eurostat Statistics Database. Eurostat. http://epp.eurostat.ec.europa.eu/portal/page/portal/product_details/dataset?p_product_ code $=$ TPS00178.

Fargues, Philippe. 2000. "Protracted National Conflict and Fertility Change: Palestinians and Israelis in the Twentieth Century." Population and Development Review 26 (3): 441482.

Ferraretti, A. P., V. Goossens, J. de Mouzon, S. Bhattacharya, J. A. Castilla, V. Korsak, M. Kupka, et al. 2012. "Assisted Reproductive Technology in Europe, 2008: Results Generated from European Registers by ESHRE.” Human Reproduction 27 (9): 25712584. doi:10.1093/humrep/des255.

Festy, Patrick. 1979. "La Fécondité Des Pays Occidentaux (1870-1970).” Population 34 (1): 163-173.

Finer, Lawrence B, and Stanley K Henshaw. 2006. "Disparities in Rates of Unintended Pregnancy in the United States, 1994 and 2001." Perspectives on Sexual and Reproductive Health 38 (2): 90-96.

Finer, Lawrence B, and Mia R Zolna. 2011. "Unintended Pregnancy in the United States: Incidence and Disparities, 2006." Contraception 84 (5) (November): 478-85. doi:10.1016/j.contraception.2011.07.013. 
Fisch, Harry. 2008. "Declining Worldwide Sperm Counts: Disproving a Myth." Urologic Clinics of North America 35 (2): 137-146.

Fisch, Harry, and Stephen R Braun. 2013. "Trends in Global Semen Parameter Values." Asian Journal of Andrology 15 (2): 169-173.

Fokkema, Tineke, Helga de Valk, Joop de Beer, and Coen Van Duin. 2008. "The Netherlands: Childbearing Within the Context of a 'Poldermodel' Society." Demographic Research 19 (July 1): 743-794. doi:10.4054/DemRes.2008.19.21.

Foster, C. 2000. "The Limits to Low Fertility: A Biosocial Approach." Population and Development Review 26 (2): 209-234. doi:10.1111/j.1728-4457.2000.00209.x.

Frank, Reanne, and Patrick Heuveline. 2005. "A Crossover in Mexican and MexicanAmerican Fertility Rates: Evidence and Explanations for an Emerging Paradox." Demographic Research 12 (4): 77-104.

Frattarelli, John L, Kathleen A Miller, Bradley T Miller, Karen Elkind-Hirsch, and Richard T Scott Jr. 2008. "Male Age Negatively Impacts Embryo Development and Reproductive Outcome in Donor Oocyte Assisted Reproductive Technology Cycles." Fertility and Sterility 90 (1): 97-103.

Frejka, Tomas. 2004. “The 'Curiously High' Fertility of the USA: Discussion of Paper 'Explanations of the Fertility Crisis in Modern Societies: a Search for Commonalities', Population Studies 57(3): 241-263, by John Caldwell and Thomas Schindlmayr." Population Studies 58 (1): 77-94.

. 2011. "The Role of Contemporary Childbearing Postponement and Recuperation in Shaping Period Fertility Trends." Comparative Population Studies - Zeitschrift Für Bevölkerungswissenschaft 36 (4): 927-958.

Frejka, Tomas, Gavin W Jones, and Jean-Paul Sardon. 2010. "East Asian Childbearing Patterns and Policy Developments." Population and Development Review 36 (3): 579606.

Frejka, Tomas, and Tomáš Sobotka. 2008. "Fertility in Europe: Diverse, Delayed and Below Replacement." Demographic Research, Special Collection 719 (Childbearing trends and policies in Europe) (July 1): 15-46. doi:10.4054/DemRes.2008.19.3.

Frejka, Tomas, and Charles F Westoff. 2008. "Religion, Religiousness and Fertility in the US and in Europe." European Journal of Population/Revue Européenne de Démographie 24 (1): 5-31.

Furuoka, Fumitaka. 2009. "Looking for a J-shaped Development-fertility Relationship: Do Advances in Development Really Reverse Fertility Declines?" Economics Bulletin 29 (4): 3067-3074.

Garssen, Joop, and Han Nicolaas. 2008. "Fertility of Turkish and Moroccan Women in the Netherlands: Adjustment to Native Level Within One Generation." Demographic Research 19 (33): 1249-1280.

Gauthier, Anne H. 2002. "Family Policies in Industrialized Countries: Is There Convergence?" Population (English Edition) 57 (3): 447-474.

2007. "The Impact of Family Policies on Fertility in Industrialized Countries: a Review of the Literature." Population Research and Policy Review 26 (3) (June): 323346. doi:10.1007/s11113-007-9033-x. 
Goldin, Claudia. 2006. “The Quiet Revolution That Transformed Women's Employment, Education, and Family." American Economic Review 96 (2) (May): 1-21.

Goldin, Claudia, and Lawrence F. Katz. 2002. "The Power of the Pill: Oral Contraceptives and Women's Career and Marriage Decisions." Journal of Political Economy 110 (4): 730-770. doi:10.1086/340778.

Goldscheider, Calvin, and Peter R. Uhlenberg. 1969. "Minority Group Status and Fertility." American Journal of Sociology 74 (4): 361-372. doi:10.2307/2776057.

Goldscheider, Frances, Livia Sz. Oláh, and Allan Puur. 2010. "Reconciling Studies of Men's Gender Attitudes and Fertility." Demographic Research 22 (8): 189-198. doi:10.4054/DemRes.2010.22.8.

Goldstein, Joshua R. 2006. "How Late Can First Births Be Postponed? Some Illustrative Population-level Calculations." Vienna Yearbook of Population Research 4: 153-165.

Goldstein, Joshua R, and Michaela Kreyenfeld. 2011. "Has East Germany Overtaken West Germany? Recent Trends in Order-specific Fertility." Population and Development Review 37 (3): 453-472.

Goldstein, Joshua R., M. Kreyenfeld, Aiva Jasilioniene, and D.D.K. Örsal. 2013. "Fertility Reactions to the 'Great Recession' in Europe." Demographic Research 29 (4): 85104.

Goldstein, Joshua R., Wolfgang Lutz, and Maria Rita Testa. 2003. "The Emergence of Subreplacement Family Size Ideals in Europe." Population Research and Policy Review 22 (5-6): 479-496. doi:10.1023/B:POPU.0000020962.80895.4a.

Goldstein, Joshua R., Tomáš Sobotka, and Aiva Jasilioniene. 2009. "The End of 'lowest-low' Fertility?" Population and Development Review 35 (4): 663-699. doi:10.1111/j.17284457.2009.00304.x.

Gornick, Janet C., Marcia K. Meyers, and Katherin E. Ross. 1997. "Supporting the Employment of Mothers: Policy Variation Across Fourteen Welfare States.” Journal of European Social Policy 7 (1) (February 1): 45-70. doi:10.1177/095892879700700103.

Griffith, Janet D, Helen P Koo, and Chirayath M Suchindran. 1985. "Childbearing and Family in Remarriage." Demography 22 (1): 73-88.

Grossman, Lisa C, Daniel H Kort, and Mark V Sauer. 2012. "Managing Assisted Reproduction in Women over the Age of 50 Years: a Clinical Update." Expert Review of Obstetrics \& Gynecology 7 (6) (November 1): 525-533. doi:10.1586/eog.12.62.

Gu, Baochang, Feng Wang, Guo Zhigang, and Zhang Erli. 2007. "China's Local and National Fertility Policies at the End of the Twentieth Century." Population and Development Review 33 (1): 129-148.

Guo, Z. 2008. "China's low fertility and their determinants.” Population Research 32 (4): 112.

. 2009. "The reasons for recent marked fertility 'resurgence'." Chinese Journal of Population Science 2: 2-15.

Gustafsson, Siv. 2005. "Having Kids Later. Economic Analyses for Industrialized Countries." Review of Economics of the Household 3 (1): 5-16. doi:10.1007/s11150-004-0977-x. 
Gustafsson, Siv, and A. Kalwij, ed. 2006. Education and Postponement of Maternity. Economic Analyses for Industrialized Countries. Dordrecht, The Netherlands: Kluwer Academic Publishers and Springer.

Habbema, J Dik F, John Collins, Henri Leridon, Johannes LH Evers, and Bruno Lunenfeld. 2004. "Towards Less Confusing Terminology in Reproductive Medicine: a Proposal." Human Reproduction 19 (7): 1497-1501.

Habbema, J. Dik F., Marinus J.C. Eijkemans, Geeta Nargund, Gijs Beets, Henri Leridon, and Egbert R. te Velde. 2009. "The Effect of in Vitro Fertilization on Birth Rates in Western Countries." Human Reproduction 24 (6): 1414-1419. doi:10.1093/humrep/dep004.

Hackett, Conrad. 2008. "Religion and Fertility in the United States: The Influence of Affiliation, Region and Congregation". Unpublished PhD-thesis.

Hagewen, Kellie J, and S. Philip Morgan. 2005. "Intended and Ideal Family Size in the United States, 1970-2002." Population and Development Review 31 (3): 507-527. doi:10.1111/j.1728-4457.2005.00081.x.

Hayford, Sarah R, and Philip S Morgan. 2008. "Religiosity and Fertility in the United States: The Role of Fertility Intentions." Social Forces 86 (3): 1163-1188. doi:10.1353/sof.0.0000.

Hazan, Moshe, and Hosny Zoabi. 2011. "Do Highly Educated Women Choose Smaller Families?" CEPR Discussion Papers. http://econpapers.repec.org/RePEc:cpr:ceprdp:8590.

He, J., and W. Ju. 2008. "Influence of Cigarette Smoking on Semen Quality in Males." Chinese Journal of Andrology 22 (8): 31-37.

Heaton, Tim B. 2011. "Does Religion Influence Fertility in Developing Countries." Population Research and Policy Review 30 (3): 449-465. doi:10.1007/s11113-0109196-8.

Heino, Eveliina. 2012. "Concern over the Future of the Nation-a Discourse Analytical Study on Changes in Russian Demographic Policy in the Years 2000-2010." Finnish Yearbook of Population Research 47: 65-89.

Henshaw, Stanley K. 1998. "Unintended Pregnancy in the United States." Family Planning Perspectives 30 (1): 24-46.

Héran, François. 2004. "Five Immigration Myths.” Population and Societies (397).

Heuveline, Patrick, Jeffrey M Timberlake, and Frank F Furstenberg Jr. 2003. "Shifting Childrearing to Single Mothers: Results from 17 Western Countries." Population and Development Review 29 (1): 47-71.

Hewlett, S.A. 2002. Creating a Life. Professional Woman and the Quest for Children. New York: Talk Mirimax Books.

Heyns, Barbara. 2005. "Emerging Inequalities in Central and Eastern Europe." Annual Review of Sociology 163: 163-197.

Hilgeman, Christin, and Carter T. Butts. 2009. "Women's Employment and Fertility: A Welfare Regime Paradox.” Social Science Research 38 (1): 103-117. 
Hoem, Britta. 2000. "Entry into Motherhood in Sweden: The Influence of Economic Factors on the Rise and Fall in Fertility, 1986-1997." Demographic Research 2 (4): 28.

Hoem, Jan M, Gerda Neyer, and Gunnar Andersson. 2006. "Educational Attainment and Ultimate Fertility Among Swedish Women Born in 1955-59." Demographic Research 14 (16): 381-404. doi:10.4054/DemRes.2006.14.16.

Hoorens, Stijn, Jack Clift, Laura Staetsky, B. Janta, S. Diepeveen, M. Morgan Jones, and J. Grant. 2011. Low Fertility in Europe: Is There Still Reason to Worry? RAND Europe. http://www.jstor.org/stable/10.7249/mg1080re.

Hosseini-Chavoshi, Meimanat, Peter McDonald, Mohammad Jalal Abbasi-Shavazi, and Arash Rashidian. 2013, Tempo and quantum of fertility in Iran: An Application of the Synthetic Parity Progression Ratio Method. Paper presented at the XXVII IUSSP International Population Conference, 26- 31 August, Busan, Republic of Korea.

Hou, Ya-fei, Xiao-hong Ma, and Kuang-shi Huang. 2008. "Research on the Fertility Desire and Behavior of Beijing Urban Women from Only-child Families." Population and Development 1.

Hout, Michael, Andrew Greeley, and Melissa J Wilde. 2001. "The Demographic Imperative in Religious Change in the United States." American Journal of Sociology 107 (2): $468-500$.

Iacovou, Maria, and Lara Patrício Tavares. 2011. "Yearning, Learning, and Conceding: Reasons Men and Women Change Their Childbearing Intentions." Population and Development Review 37 (1): 89-123. doi:10.1111/j.1728-4457.2011.00391.x.

IBGE. 2010. "Síntese de Indicadores Sociais. Uma Análise Das Condições de Vida Da População Brasileira 2010. Estudos e Pesquisas". 27. Informação Demográfi ca e Socioeconômica. Rio de Janeiro: Instituto Brasileiro de Geografi a e Estatística.

Ishii-Kuntz, Masako, Katsuko Makino, Kuniko Kato, and Michiko Tsuchiya. 2004. "Japanese Fathers of Preschoolers and Their Involvement in Child Care." Journal of Marriage and Family 66 (3): 779-791. doi:10.1111/j.0022-2445.2004.00052.x.

Iwamoto, Teruaki, Shiari Nozawa, and Miki Yoshiike. 2007. "Semen Quality of Asian Men." Reproductive Medicine and Biology 6 (4): 185-193.

Jansen, M, and Aart C Liefbroer. 2006. "Couples' Attitudes, Childbirth, and the Division of Labor." Journal of Family Issues 27 (11): 1487-1511. doi:10.1177/0192513x06291038.

Jefferies, Julie. 2008. "Fertility Assumptions for the 2006-based National Population Projections." Population Trends 131: 19.

Jensen, Tina Kold, Niels Jørgensen, Margus Punab, Trine B. Haugen, Jyrki Suominen, Birute Zilaitiene, Antero Horte, et al. 2004. "Association of in Utero Exposure to Maternal Smoking with Reduced Semen Quality and Testis Size in Adulthood: a Crosssectional Study of 1,770 Young Men from the General Population in Five European Countries." American Journal of Epidemiology 159 (1): 49-58. doi:10.1093/aje/kwh002.

Joffe, Michael. 2000. "Time Trends in Biological Fertility in Britain.” Lancet 355 (9219): 1961-1965. doi:10.1016/s0140-6736(00)02328-x. 
Jones, Gavin W. 2007. "Delayed Marriage and Very Low Fertility in Pacific Asia." Population and Development Review 33 (3): 453-478. doi:10.1111/j.17284457.2007.00180.x.

2012. "Where Are All the Jobs? Capturing the Demographic Dividend in Islamic Countries." In Population Dynamics in Muslim Countries, edited by Hans Groth and Alfonso Sousa-Poza, 31-42. Springer.

Jones, Gavin W., and Mehtab S Karim. 2005. Islam, the State and Population. C. Hurst \& Co. Publishers.

Jones, Gavin W., and Dorothy Nortman. 1968. "Roman Catholic Fertility and Family Planning: a Comparative Review of the Research Literature." Studies in Family Planning 1 (34): 1-27.

Jørgensen, Niels, Elisabeth Carlsen, Ingrid Nermoen, Margus Punab, Jyrki Suominen, AnneGrethe Andersen, Anna-Maria Andersson, et al. 2002. "East-West Gradient in Semen Quality in the Nordic-Baltic Area: a Study of Men from the General Population in Denmark, Norway, Estonia and Finland." Human Reproduction 17 (8): 2199-2208.

Joshi, Heather. 2002. "Production, Reproduction, and Education: Women, Children, and Work in a British Perspective." Population and Development Review 28 (3): 445-474. doi:10.1111/j.1728-4457.2002.00445.x.

Karim, Mehtab S. 1997. Reproductive Behavior in Muslim Countries. Macro International Inc.

Kaufman, Gayle. 2000. "Do Gender Role Attitudes Matter? Family Formation and Dissolution Among Traditional and Egalitarian Men and Women." Journal of Family Issues 21 (1): 128-144.

Kaufmann, Eric. 2010. Shall the Religious Inherit the Earth? Demography and Politics in the Twenty-First Century. London: Profile Books.

KC, Samir, and Michaela Potančoková. 2013. "Differential Fertility by Level of Education in DHS Countries." Presented at the 2013 Annual Meeting of the Population Association of America, New Orleans, 11-13 April 2013.. http://paa2013.princeton.edu/papers/132306.

Kim, Doo-Sub. 2007. Cross-Border Marriage: Process and Dynamics. Seoul: Hanyang University.

Kirk, D. 1946. Europe's Population in the Interwar Years. Princeton, New Jersey: League of Nations and Princeton University Press.

. 1966. "Factors Affecting Moslem Natality." In Family Planning and Population Programs: A Review of World Developments, edited by Bernard Berelson. University of Chicago Press.

Kohler, Hans-Peter, Francesco C. Billari, and José Antonio Ortega. 2002. "The Emergence of Lowest-Low Fertility in Europe During the 1990s." Population and Development Review 28 (4): 641-680. doi:10.1111/j.1728-4457.2002.00641.x.

Kohler, Hans-Peter, and José Antonio Ortega. 2002. "Tempo-adjusted Period Parity Progression Measures, Fertility Postponement and Completed Cohort Fertility." Demographic Research 6 (6): 91-144. doi:10.4054/DemRes.2002.6.6. 
Kravdal, Øystein. 2002. "The Impact of Individual and Aggregate Unemployment on Fertility in Norway." Demographic Research 6 (April 5): 263-294. doi:10.4054/DemRes.2002.6.10. . 2004. "An Illustration of the Problems Caused by Incomplete Education Histories in Fertility Analyses." Demographic Research Special edition 3: 135-154. doi:10.4054/DemRes.2004.S3.6.

Kravdal, Øystein, and Ronald R. Rindfuss. 2008. "Changing Relationships Between Education and Fertility: A Study of Women and Men Born 1940 to 1964." American Sociological Review 73 (5): 854-873.

Kreyenfeld, Michaela. 2010. "Uncertainties in Female Employment Careers and the Postponement of Parenthood in Germany." European Sociological Review 26 (3): 351-366. doi:10.1093/esr/jcp026.

Krzywinski, Martin, Jacqueline Schein, İnanç Birol, Joseph Connors, Randy Gascoyne, Doug Horsman, Steven J. Jones, and Marco A. Marra. 2009. "Circos: An Information Aesthetic for Comparative Genomics." Genome Research 19 (9): 1639-1645. doi:10.1101/gr.092759.109.

Kühnert, Bianca, and Eberhard Nieschlag. 2004. "Reproductive Functions of the Ageing Male." Human Reproduction Update 10 (4): 327-339.

Landgren Möller, Elisabeth. 2002. Mammor Och Pappor-Om Kvinnors Och Mäns Föräldraskap 2001. Demografiska rapporter 2002:7.

Lanzieri, Giampaolo. 2013. “Towards a 'baby Recession' in Europe? Differential Fertility Trends During the Economic Crisis". Statistics in Focus 13. Statistics in Focus. Luxembourg: Eurostat. http://epp.eurostat.ec.europa.eu/cache/ITY_OFFPUB/KS-SF13-013/EN/KS-SF-13-013-EN.PDF.

Lappegård, Trude, and Marit Rønsen. 2005. "The Multifaceted Impact of Education on Entry into Motherhood." European Journal of Population 21 (1): 31-49. doi:10.1007/s 10680-004-6756-9.

Lappegård, Trude, Marit Rønsen, and Kari Skrede. 2011. "Fatherhood and Fertility." Fathering: A Journal of Theory, Research, and Practice About Men as Fathers 9 (1): 103-120.

Lavely, William, and Ronald Freedman. 1990. "The Origins of the Chinese Fertility Decline." Demography 27 (3): 357-367.

Lee, Ronald. 1990. "The Demographic Response to Economic Crisis in Historical and Contemporary Populations." Population Bulletin of the United Nations 29: 1-15.

Lehrer, Evelyn L. 1996. "Religion as a Determinant of Marital Fertility." Journal of Population Economics 9 (2): 173-196.

- 2004. "Religion as a Determinant of Economic and Demographic Behavior in the United States." Population and Development Review 30 (4): 707-726.

Lerchl, Alexander. 1995. "Evidence for Decreasing Quality of Sperm. Presentation of Data on Sperm Concentration Was Flawed.” British Medical Journal 311 (7004): 569.

Leridon, Henri. 2004. "Can Assisted Reproduction Technology Compensate for the Natural Decline in Fertility with Age? A Model Assessment." Human Reproduction 19 (7) : 1548-53. doi:10.1093/humrep/deh304. 
- 2006. "Demographic Effects of the Introduction of Steroid Contraception in Developed Countries." Human Reproduction Update 12 (5): 603-616. doi:10.1093/humupd/dml025.

2007. "Studies of Fertility and Fecundity: Comparative Approaches from Demography and Epidemiology." Comptes Rendus Biologies 330 (4): 339-46. doi:10.1016/j.crvi.2007.02.013.

2008. "A New Estimate of Permanent Sterility by Age: Sterility Defined as the Inability to Conceive." Population Studies 62 (1): 15-24. doi:10.2307/27643443.

Leridon, Henri, and Rémy Slama. 2008. "The Impact of a Decline in Fecundity and of Pregnancy Postponement on Final Number of Children and Demand for Assisted Reproduction Technology." Human Reproduction 23 (6): 1312-1319.

Lesthaeghe, Ron J. 1995. "Second Demographic Transition in Western Countries: An Interpretation." In Gender and Family Change in Industrialized Countries, edited by Karen Oppenhiem Mason and An-Magritt Jensen, 17-62. Oxford: Clarendon Press. . 2010. "The Unfolding Story of the Second Demographic Transition." Population and Development Review 36 (2): 211-251.

Liefbroer, A.C., and E.-M. Merz. 2010. "Report on Analysis of ESS Data on Cross-national Differences in Perceived Norms Concerning Fertility-related Behaviour". REPRO project. http://www.oeaw.ac.at/vid/repro/norms.html.

Liefbroer, Aart C. 2009. "Changes in Family Size Intentions Across Young Adulthood: A Life-course Perspective." European Journal of Population 25 (4): 363-386. doi:10.1007/s 10680-008-9173-7.

Liu, Jianghua, Anna Rotkirch, and Virpi Lummaa. 2012. "Maternal Risk of Breeding Failure Remained Low Throughout the Demographic Transitions in Fertility and Age at First Reproduction in Finland." PLoS ONE $7 \quad$ (4): e34898. doi:10.1371/journal.pone.0034898.

Livingston, Gretchen. 2011. "In a Down Economy, Fewer Births." Pew Research Center Social and Demographic Trends (October 12). http://www.pewsocialtrends.org/2011/10/12/in-a-down-economy-fewer-births/.

Livingston, Gretchen, and D'V. Cohn. 2012. “U.S. Birth Rate Falls to a Record Low; Decline Is Greatest Among Immigrants." Pew Research Center Social and Demographic Trends $\quad$ (November http://www.pewsocialtrends.org/files/2012/11/Birth_Rate_Final.pdf.

29).

Luci, Angela, and Olivier Thévenon. 2011. "Does Economic Development Explain the Fertility Rebound in OECD Countries?” INED Working Paper 481.

- 2012. "The Impact of Family Policy Packages on Fertility Trends of OECD Countries." INED Working Paper 174.

Lutz, Wolfgang. 2006. “Fertility Rates and Future Population Trends: Will Europe's Birth Rate Recover or Continue to Decline?" International Journal of Andrology 29 (1): 2533. doi:10.1111/j.1365-2605.2005.00639.x.

Lutz, Wolfgang, William P. Butz, and Samir KC. forthcoming. World Population and Human Capital in the 21st Century. Oxford University Press. 
Lutz, Wolfgang, Anne Goujon, and Gabriele Doblhammer-Reiter. 1998. "Demographic Dimensions in Forecasting: Adding Education to Age and Sex." Population and Development Review 24 : 42-58. doi:10.2307/2808050.

Lutz, Wolfgang, and Samir KC. 2011. "Global Human Capital: Integrating Education and Population.” Science 333 (6042): 587-592. doi:10.1126/science.1206964.

Lutz, Wolfgang, Warren Sanderson, and Sergei Scherbov. 1999. "Expert-based Probabilistic Population Projections." Population and Development Review 24 (Supplementary Issue: Frontiers of Population Forecasting): 139-155.

Lutz, Wolfgang, Vegard Skirbekk, and Maria Rita Testa. 2006. "The Low-fertility Trap Hypothesis: Forces That May Lead to Further Postponement and Fewer Births in Europe." Vienna Yearbook of Population Research 4: 167-192.

Luy, Marc. 2011. "Tempo Effects and Their Relevance in Demographic Analysis." Comparative Population Studies - Zeitschrift Für Bevölkerungswissenschaft 35 (3) (September 15): 415-446.

Ma, J. 2011. "Ma Jian-Tang explains China's sixth national population census." News 163, May. http:// news.163.com/11/0503/11/734K2LBJ00014JB5.html.

Macaluso, Maurizio, Tracie J Wright-Schnapp, Anjani Chandra, Robert Johnson, Catherine L Satterwhite, Amy Pulver, Stuart M Berman, Richard Y Wang, Sherry L Farr, and Lori A Pollack. 2010. "A Public Health Focus on Infertility Prevention, Detection, and Management." Fertility and Sterility 93 (1) (January): 16.e1-10. doi:10.1016/j.fertnstert.2008.09.046.

Macunovich, Diane J. 1996. "Relative Income and Price of Time: Exploring Their Effects on US Fertility and Female Labor Force Participation." Population and Development Review 22: 223-257.

Maheshwari, Abha, Maureen Porter, Ashalata Shetty, and Siladitya Bhattacharya. 2008. "Women's Awareness and Perceptions of Delay in Childbearing." Fertility and Sterility 90 (4) (October): 1036-1042. doi:10.1016/j.fertnstert.2007.07.1338.

Maheshwari, Abha, Graham Scotland, Jacqueline Bell, Alison McTavish, Mark Hamilton, and Siladitya Bhattacharya. 2010. "Direct Health Services Costs of Providing Assisted Reproduction Services in Older Women." Fertility and Sterility 93 (2) (January 15): 527-536. doi:10.1016/j.fertnstert.2009.01.115.

Martin, Philip, and Elizabeth Midgley. 2010. "Population Bulletin Update: Immigration in America 2010". Population Reference Bureau. http://prb.org/Publications/PopulationBulletins/2010/immigrationupdate1.aspx? $p=1$.

Martin, Teresa Castro. 1995. "Women's Education and Fertility: Results from 26 Demographic and Health Surveys." Studies in Family Planning 26 (4): 187-202.

Martín-García, Teresa, and Pau Baizán. 2006. "The Impact of the Type of Education and of Educational Enrolment on First Births.” European Sociological Review 22 (3): 259275.

Mascarenhas, Maya N, Hoiwan Cheung, Colin D Mathers, and Gretchen A Stevens. 2012. "Measuring Infertility in Populations: Constructing a Standard Definition for Use with Demographic and Reproductive Health Surveys." Population Health Metrics 10 (1): 17. 
Mascarenhas, Maya N, Seth R Flaxman, Ties Boerma, Sheryl Vanderpoel, and Gretchen A Stevens. 2012. "National, Regional, and Global Trends in Infertility Prevalence Since 1990: a Systematic Analysis of 277 Health Surveys." PLoS Medicine 9 (12): e1001356.

Mason, Andrew, Noriko O. Tsuya, and Minja Kim Choe. 1998. "Changing Family in Comparative Perspective $\square$ : Asia and the United States". Honolulu: East-West Center.

Mason, Karen Oppenheim. 1997. "Explaining Fertility Transitions." Demography 34 (4): 443-454. doi:10.2307/3038299.

Matysiak, Anna, and Daniele Vignoli. 2008. "Fertility and Women's Employment: A Metaanalysis." European Journal of Population 24 (4): 363-384.

Mazuy, Magali, France Prioux, and Magali Barbieri. 2011. "Recent Demographic Developments in France." Population (English Edition) 66 (3): 422-472.

McDonald, Peter. 2000a. "Gender Equity in Theories of Fertility Transition." Population and Development Review 26 (3): 427-439. . 2000b. "Gender Equity, Social Institutions and the Future of Fertility." Journal of Population Research 17 (1): 1-16.

. 2009. "Explanations of Low Fertility in East Asia." In Ultra-low Fertility in Pacific Asia: Trends, Causes and Policy Issues, edited by PT Straughan, A Chan, and G Jones, 23-39. Oxon: Routledge.

. 2013. "Societal Foundations for Explaining Fertility: Gender Equity." Demographic Research 28 (May 15): 981-994. doi:10.4054/DemRes.2013.28.34.

McDonald, Peter, and Helen Moyle. 2010. "Why Do English-speaking Countries Have Relatively High Fertility?” Journal of Population Research 27 (4): 247-273.

McQuillan, Kevin. 2004. “When Does Religion Influence Fertility?" Population and Development Review 30 (1): 25-56. doi:10.1111/j.1728-4457.2004.00002.x.

Mencarini, Letizia, and Maria Letizia Tanturri. 2004. "Time Use, Family Role-set and Childbearing Among Italian Working Women.” Genus 60 (1): 111-137.

Menken, Jane. 1985. “Age and Fertility: How Late Can You Wait?” Demography 22 (4): 469-483. doi:10.2307/2061583.

Merz, E. M., and Aart C. Liefbroer. 2012. "The Attitude Toward Voluntary Childlessness in Europe: Cultural and Institutional Explanations." Journal of Marriage and Family 74 (3): 587-600. doi:10.1111/j.1741-3737.2012.00972.x.

Merzenich, Hiltrud, Hajo Zeeb, and Maria Blettner. 2010. "Decreasing Sperm Quality: a Global Problem?" BMC Public Health 10 (1): 24.

Miettinen, A. 2010. "Voluntary or Involuntary Childlessness? Socio-demographic Factors and Childless Intentions Among Childless Finnish Men and Women Aged 25-44." Finish Yearbook of Population Research: 5-24.

Miettinen, Anneli, Stuart Basten, and Anna Rotkirch. 2011. "Gender Equality and Fertility Intentions Revisited." Demographic Research 24: 469-496. doi:10.4054/DemRes.2011.24.20. 
Miller, Warren B. 2011. "The Relationship Between Childbearing Motivations and Attitude Toward Abortion Among Married Men and Women." Family Planning Perspectives 26 (4): 165-168.

Miller, Warren B., Lawrence J. Severy, and David J. Pasta. 2004. "A Framework for Modelling Fertility Motivation in Couples." Population Studies 58 (2): 193-205. doi: $10.2307 / 4148229$.

Mills, M., and H.-P. Blossfeld. 2005. "Globalization, Uncertainty and Youth in Society." In Globalization, Uncertainty and Youth in Society, edited by H.-P. Blossfeld, E. Klijzing, M. Mills, and K. Kurz, 1-24. Advances in Sociology. London/New York: Routledge.

Mills, Melinda. 2010. "Gender Roles, Gender (in)equality and Fertility: An Empirical Test of Five Gender Equity Indices." Canadian Studies in Population 37 (3-4): 445-474.

Mills, Melinda, Letizia Mencarini, Maria Letizia Tanturri, and Katia Begall. 2008. "Gender Equity and Fertility Intentions in Italy and the Netherlands." Demographic Research 18 (1): 1-26. doi:10.4054/DemRes.2008.18.1.

Mills, Melinda, Ronald R. Rindfuss, Peter McDonald, Egbert R. te Velde, and ESHRE Task Force. 2011. "Why Do People Postpone Parenthood? Reasons and Social Policy Incentives." Human Reproduction Update $17 \quad$ (6): 848-860. doi:10.1093/humupd/dmr026.

Ministry of Labour. 2010. "National Demographic Security Programme of the Republic of Belarus, 2011 - 2015". Ministry of Labour and Social Protection, Republic of Belarus. http://www.mintrud.gov.by/en/national-demographic-security-programme-of-therepublic-of-belarus-2011---2015.

Morgan, S. Philip. 2001. "Should Fertility Intentions Inform Fertility Forecasts?" In The Direction of Fertility in the United States, edited by G. K. Spencer, 153-170. Proceedings of US Census Bureau Conference, Session III. Washington, D. C.: US Census Bureau. http://www.copafs.org/UserFiles/file/reports/The\%20Direction\%20of\%20Fertility\%20 in $\% 20$ the $\% 20$ United $\% 20$ States.pdf\#page $=165$.

2003. "Is Low Fertility a Twenty-first-century Demographic Crisis?" Demography 40 (4): 589-603.

Morgan, S. Philip, and Christine A. Bachrach. 2011. "Is the Theory of Planned Behaviour an Appropriate Model for Human Fertility?" Vienna Yearbook of Population Research 9: $11-18$.

Morgan, S. Philip, and Heather Rackin. 2010. "The Correspondence Between Fertility Intentions and Behavior in the United States." Population and Development Review 36 (1): 91-118.

Morgan, S. Philip, Sharon Stash, Herbert L. Smith, and Karen Oppenheim Mason. 2002. "Muslim and non-Muslim Differences in Female Autonomy and Fertility: Evidence from Four Asian Countries." Population and Development Review 28 (3): 515-537.

Morgan, S. Philip, Guo Zhigang, and Sarah R. Hayford. 2009. "China's Below-replacement Fertility: Recent Trends and Future Prospects." Population and Development Review 35 (3): 605-629. doi:10.1111/j.1728-4457.2009.00298.x. 
Mosher, W.D., and W.F. Pratt. 1985. "Fecundity and Infertility in the United States, 196582." Advance Data from Vital and Health Statistics. Hyattsville: National Center for Health Statistics. http://198.246.124.29/nchs/data/ad/ad104acc.pdf.

Mosher, William D, and Jo Jones. 2010. "Use of Contraception in the United States: 19822008." Vital and Health Statistics No. 29. Series 23, Data from the National Survey of Family Growth.

Murphy, Mike. 1992. "Economic Models of Fertility in Post-war Britain-a Conceptual and Statistical Re-interpretation.” Population Studies 46 (2): 235-258.

Musick, Kelly, Paula England, Sarah Edgington, and Nicole Kangas. 2009. "Education Differences in Intended and Unintended Fertility." Social Forces 88 (2): 543-572.

Myrskylä, Mikko, Joshua R. Goldstein, and Yen-hsin Alice Cheng. 2012. "New Cohort Fertility Forecasts for the Developed World". MPIDR Working Paper 2012-014.

. 2013. "New Cohort Fertility Forecasts for the Developed World: Rises, Falls, and Reversals." Population and Development Review 39 (1): 31-56. doi:10.1111/j.17284457.2013.00572.x.

Myrskylä, Mikko, Hans-Peter Kohler, and Francesco C. Billari. 2009. "Advances in Development Reverse Fertility Declines.” Nature 460 (7256): 741-743. doi:10.1038/nature08230.

. 2011. "High Development and Fertility: Fertility at Older Reproductive Ages and Gender Equality Explain the Positive Link". PSC Working Papers Series 10-3-2011. University of Pennsylvania: Population Studies Center.

Myrskylä, Mikko, and Rachel Margolis. 2012. "Happiness: Before and after the Kids". MPIDR Working Paper 013. Max Planck Institute for Demographic Research, Rostock, Germany.

National Strategy on Population Development Research Group. 2007. The General Report on China's National Strategy on Population Development. Beijing: China Population Publishing House (in Chinese).

Neels, Karel, and David De Wachter. 2010. "Postponement and Recuperation of Belgian Fertility: How Are They Related to Rising Female Educational Attainment?" Vienna Yearbook of Population Research 8: 77-106. doi:10.1553/populationyearbook2010s77.

Neels, Karel, Zita Theunynck, and Jonas Wood. 2013. "Economic Recession and First Births in Europe: Recession-induced Postponement and Recuperation of Fertility in 14 European Countries Between 1970 and 2005.” International Journal of Public Health 58 (1): 43-55. doi:10.1007/s00038-012-0390-9.

Nettle, Daniel. 2011. "Flexibility in Reproductive Timing in Human Females: Integrating Ultimate and Proximate Explanations." Philosophical Transactions of the Royal Society B: Biological Sciences 366 (1563): 357-365. doi:10.1098/rstb.2010.0073.

New Zealand Government. 2010. "The Social Report." http://www.socialreport.msd.govt.nz/people/fertility.html.

Ní Bhrolcháin, Máire. 2011. “Tempo and the TFR.” Demography 48 (3): 841-861. doi:10.1007/s13524-011-0033-4. 
Ní Bhrolcháin, Máire, and Éva Beaujouan. 2012. "Fertility Postponement Is Largely Due to Rising Educational Enrolment." Population Studies 66 (3): 311-327. doi:10.1080/00324728.2012.697569.

Notestein, Frank W. 1945. "Population: The Long View." Food for the World 36: 57.

Noyes, N, E Porcu, and A Borini. 2009. "Over 900 Oocyte Cryopreservation Babies Born with No Apparent Increase in Congenital Anomalies." Reproductive BioMedicine Online 18 (6): 769-776. doi:10.1016/S1472-6483(10)60025-9.

Oakley, L., P. Doyle, and N. Maconochie. 2008. "Lifetime Prevalence of Infertility and Infertility Treatment in the UK: Results from a Population-based Survey of Reproduction." Human Reproduction 23 (2): 447-450. doi:10.1093/humrep/dem369.

OECD. 2011. Doing Better for Families. OECD Publishing.

. 2012. "OECD Population Pyramids in 2000 and 2050". OECD Publishing. http://www.oecd.org/dataoecd/52/31/38123085.xls.

Oláh, Livia Sz. 2003. "Gendering Fertility: Second Births in Sweden and Hungary." Population Research and Policy Review 22 (2): 171-200.

ONE. 2012. "Anuario Demográfico de Cuba 2011. Capitulo II. Nacimientos". Havana: Oficina Nacional de Estadísticas.

Paasch, Uwe, Andrea Salzbrunn, Hans Juergen Glander, Kai Plambeck, Harald Salzbrunn, Sonja Grunewald, Julia Stucke, Niels E Skakkebæk, and Niels Jørgensen. 2008. "Semen Quality in Sub-fertile Range for a Significant Proportion of Young Men from the General German Population: a Co-ordinated, Controlled Study of 791 Men from Hamburg and Leipzig." International Journal of Andrology 31 (2): 93-102.

Park, Chai Bin, and Nam-Hoon Cho. 1995. "Consequences of Son Preference in a LowFertility Society: Imbalance of the Sex Ratio at Birth in Korea." Population and Development Review 21 (1): 59-84. doi:10.2307/2137413.

Parrado, Emilio. 2010. "How High Is Hispanic/Mexican Fertility in the U.S.? Immigration and Tempo Considerations." PSC Working Paper Series. http://repository.upenn.edu/psc_working_papers/18.

Parrado, Emilio A., and S. Philip Morgan. 2008. "Intergenerational Fertility Among Hispanic Women: New Evidence of Immigrant Assimilation.” Demography 45 (3): 651-671.

PDR. 2006. "Vladimir Putin on Raising Russia's Birth Rate." Population and Development Review 32 (2): 385-389.

Perelli-Harris, Brienna, Michaela Kreyenfeld, Wendy Sigle-Rushton, Renske Keizer, Trude Lappegård, Aiva Jasilioniene, Caroline Berghammer, and Paola Di Giulio. 2012. "Changes in Union Status During the Transition to Parenthood in Eleven European Countries, 1970s to Early 2000s." Population Studies 66 (2): 167-182. doi:10.1080/00324728.2012.673004.

Pew Research Center. 2011. The Future of the Global Muslim Population. Projections for 2010-2030. Washington, DC: Pew Research Center.

Philipov, Dimiter. 2003. "Fertility in Times of Discontinuous Societal Change." In Population of Central and Eastern Europe: Challenges and Opportunities, edited by Irena Kotowska and Janina Józwiak, 665-689. Warsaw: Statistical Publishing Establishment. http://dmo.econ.msu.ru/aa/PDF_files/texte\%205\%20AVDEEV.pdf. 
Philipov, Dimiter, and Caroline Berghammer. 2007. "Religion and Fertility Ideals, Intentions and Behaviour: a Comparative Study of European Countries." Vienna Yearbook of Population Research 5: 271-305.

Philipov, Dimiter, and Jürgen Dorbritz. 2003. Demographic Consequences of Economic Transition in Countries of Central and Eastern Europe. Population Studies 39. Strasbourg: Council of Europe.

Philipov, Dimiter, Zsolt Spéder, and Francesco C Billari. 2006. "Soon, Later, or Ever? The Impact of Anomie and Social Capital on Fertility Intentions in Bulgaria (2002) and Hungary (2001)." Population Studies 60 (3) (November): 289-308. doi:10.1080/00324720600896080.

Pinborg, A., C.O. Hougaard, A. Nyboe Andersen, D. Molbo, and L. Schmidt. 2009. "Prospective Longitudinal Cohort Study on Cumulative 5-year Delivery and Adoption Rates Among 1338 Couples Initiating Infertility Treatment." Human Reproduction 24 (4): 991-999. doi:10.1093/humrep/den463.

Pla, Anne, and Catherine Beaumel. 2012. "Bilan Démographique 2011: La Fécondité Reste Élevé”. Insee première 1385.

Potter, Joseph E., Carl P. Schmertmann, Renato M. Assunção, and Suzana M. Cavenaghi. 2010. "Mapping the Timing, Pace, and Scale of the Fertility Transition in Brazil." Population and Development Review 36 (2): 283-307. doi:10.1111/j.17284457.2010.00330.x.

PRB. 2010. “2010 World Population Data Sheet”. Washington, D.C.: Population Reference Bureau. http://www.prb.org/pdf10/10wpds_eng.pdf —. 2012. "2012 World Population Data Sheet". Washington, D.C.: Population Reference Bureau. http://www.prb.org/Publications/Datasheets/2012/world-population-data-sheet.aspx.

Preston, Samuel H. 1986. "Changing Values and Falling Birth Rates." Population and Development Review 12 (Supplement): 176-195.

Prioux, France. 2005. "Late Fertility in Europe: Some Comparative and Historical Data." Revue D'épidémiologie et de Santé Publique 53 (Supplement 2): 3-11.

Prioux, France, Magali Mazuy, and Magali Barbieri. 2010. "Recent Demographic Developments in France: Fewer Adults Live with a Partner." Population (English Edition) 65 (3): 363-413. doi:10.3917/pope.1003.0363.

Prskawetz, Alexia, David Elliot Bloom, and Wolfgang Lutz. 2008. Population Aging, Human Capital Accumulation, and Productivity Growth. Supplement to Volume 34, 2008, Population and Development Review. New York: Population Council.

Puur, Allan, Livia Sz. Oláh, Mariam Irene Tazi-Preve, and Jürgen Dorbritz. 2008. "Men's Childbearing Desires and Views of the Male Role in Europe at the Dawn of the 21st Century." Demographic Research 19 (56) : 1883-1912. doi:10.4054/DemRes.2008.19.56.

Quesnel-Vallée, Amélie, and S. Philip Morgan. 2003. "Missing the Target? Correspondence of Fertility Intentions and Behavior in the US." Population Research and Policy Review 22 (5/6): 497-525. doi:10.1023/B:POPU.0000021074.33415.c1. 
Raftery, Adrian E., Nan Li, Hana Ševčíková, Patrick Gerland, and Gerhard K. Heilig. 2012. "Bayesian Probabilistic Population Projections for All Countries." Proceedings of the National Academy of Sciences 109 (35) (August 28): 13915-13921. doi:10.1073/pnas.1211452109.

RAND Corporation. 2012. "Europe's Demography: Are Babies Back? The Recent Recovery in EU Period Fertility Due to Older Childbearing". Research brief RB-9566-RE. http://www.rand.org/pubs/research_briefs/RB9566.html.

Rashad, Hoda. 2000. "Demographic Transition in Arab Countries: a New Perspective." Journal of Population Research 17 (1): 83-101.

Rashad, Hoda, Magued Osman, and Farzaneh Roudi-Fahimi. 2005. Marriage in the Arab World. Population Reference Bureau.

Rendall, Michael S, Olivia Ekert-Jaffé, Heather Joshi, Kevin Lynch, and Rémi Mougin. 2009. "Universal Versus Economically Polarized Change in Age at First Birth: a FrenchBritish Comparison." Population and Development Review 35 (1): 89-115.

Retherford, Robert D, and Naohiro Ogawa. 2006. "Japan's Baby Bust: Causes, Implications, and Policy Responses." The Baby Bust: Who Will Do the Work: 5-47.

Retherford, Robert D., Minja K Choe, Jiajian Chen, Xiru Li, and Hongyan Cui. 2005. "Fertility in China: How Much Has It Really Declined." Population and Development Review 19 (1): 57-84.

Retherford, Robert D., Naohiro Ogawa, Rikiya Matsukura, and Hajime Ihara. 2004. Trends in Fertility by Education in Japan, 1966-2000. University Population Research Institute, Tokyo; East-West Center, Honolulu; Statistics Bureau, etc., Tokyo, June 2004.

Rindfuss, Ronald R. 2004. "The Family in Comparative Perspective." In Marriage, Work, and Family Life in Comparative Perspective: Japan, South Korea, and the United States, edited by Noriko O Tsuya and Larry L Bumpass, XIV-177. Honolulu: University of Hawai'i Press.

Rindfuss, Ronald R., David K. Guilkey, S. Philip Morgan, and Øystein Kravdal. 2010. "Child-care Availability and Fertility in Norway." Population and Development Review 36 (4): 725-748.

Rindfuss, Ronald R., S. Philip Morgan, and Gray Swicegood. 1988. First Births in America. London: University of California Press.

Rocca, Corinne H, Alan E Hubbard, Jennifer Johnson-Hanks, Nancy S Padian, and Alexandra M Minnis. 2010. "Predictive Ability and Stability of Adolescents' Pregnancy Intentions in a Predominantly Latino Community." Studies in Family Planning 41 (3) (September): 179-192.

Rodríguez, Jorge. 2011. "High Adolescent Fertility in the Context of Declining Fertility in Latin America." In New York: Population Division, Department of Economic and Social Affairs, United Nations Secretariat. http://www.un.org/esa/population/meetings/egm-adolescents/p01_rodriguez.pdf. 
Rodríguez Wong, Laura L. Rodríguez. 2009. "Evidences of Further Decline of Fertility in Latin America-Reproductive Behavior and Some Thoughts on the Consequences on the Age Structure." In Demographic Transformations and Inequalities in Latin America, edited by S. Cavenaghi, 99-136. Rio de Janeiro: ALAP. http://www.alapop.org/docs/publicaciones/investigaciones/demogtransformations.pdf\# page $=99$.

Roig Vila, Marta, and Teresa Castro-Martín. 2008. "Childbearing Patterns of Foreign Women in a New Immigration Country." Population (English Edition) 62 (3) (February 25): 351-379. doi:10.3917/pope.703.0351.

Rolland, M., J. Le Moal, V. Wagner, D. Royère, and J. De Mouzon. 2013. "Decline in Semen Concentration and Morphology in a Sample of 26609 Men Close to General Population Between 1989 and 2005 in France." Human Reproduction 28 (2): 462-470. doi:10.1093/humrep/des415.

Romaniuk, Anatole. 2010. "Fertility in the Age of Demographic Maturity: An Essay." Canadian Studies in Population 37 (3-4): 283-295.

Rønsen, Marit, and Kari Skrede. 2010. "Can Public Policies Sustain Fertility in the Nordic Countries? Lessons from the Past and Questions for the Future." Demographic Research 22 (13): 321-346.

Rosero-Bixby, Luis, Teresa Castro-Martín, and Teresa Martín-García. 2009. "Is Latin America Starting to Retreat from Early and Universal Childbearing?" Demographic Research 20 (9): 169-194.

Rotkirch, Anna, Stuart Basten, H. Väisänen, and Markus Jokela. 2012. "Baby Longing and Men's Reproductive Motivation.” Vienna Yearbook of Population Research 9: 283306. doi:10.1553/populationyearbook2011s283.

Roudi, Farzaneh. 2012. "Iran Is Reversing Its Population Policy". Viewpoints 7. Wilson Center.

Rovi, Susan LD. 1994. “Taking 'No' for an Answer: Using Negative Reproductive Intentions to Study the Childless/childfree." Population Research and Policy Review 13 (4): 343-365.

Saraceno, Chiara, Jane Lewis, and Arnlaug Leira. 2012. Families and Family Policies. Cheltenham: Edward Elgar Publishing.

Sartorius, Gideon A, and Eberhard Nieschlag. 2010. "Paternal Age and Reproduction." Human Reproduction Update 16 (1): 65-79. doi:10.1093/humupd/dmp027.

SCB. 2010. “Tabeller Över Sveriges Befolkning 2009". Stockholm: Statistics Sweden. http://www.scb.se/Pages/PublishingCalendarViewInfo 259923.aspx?PublObjId=1 1400 .

Scharping, T. 2005. "Chinese Fertility Trends 1979-2000: A Comparative Analysis of Birth Numbers and School Data." Population Research 29 (4): 1-12.

Scheike, Thomas H., Lars Rylander, Lisbeth Carstensen, Niels Keiding, Tina Kold Jensen, Ulf Stromberg, Michael Joffe, and Olof Akre. 2008. "Time Trends in Human Fecundability in Sweden.” Epidemiology 19 (2): 191-196. 
Schmidt, L., T. Sobotka, J. G. Bentzen, and A Nyboe Andersen. 2012. "Demographic and Medical Consequences of the Postponement of Parenthood." Human Reproduction Update 18 (1) (January): 29-43. doi:10.1093/humupd/dmr040.

Schmidt, Lone, Kirstine Münster, and Peter Helm. 1995. "Infertility and the Seeking of Infertility Treatment in a Representative Population." BJOG: An International Journal of Obstetrics \& Gynaecology 102 (12): 978-984.

Schoen, Robert. 2004. "Timing Effects and the Interpretation of Period Fertility." Demography 41 (4): 801-819. doi:10.1353/dem.2004.0036.

Schoen, Robert, Nan Marie Astone, Young J Kim, Constance A Nathanson, J M Fields, and M Fields. 1999. "Do Fertility Intentions Affect Fertility Behavior?" Journal of Marriage and the Family 61 (3): 790-799. doi:10.2307/353578.

Sedgh, Gilda, Susheela Singh, Iqbal H Shah, Elisabeth Åhman, Stanley K Henshaw, and Akinrinola Bankole. 2012. "Induced Abortion: Incidence and Trends Worldwide from 1995 to 2008." Obstetrical \& Gynecological Survey 67 (6): 341-342.

Setti, P. E. L., M. Desgro, A. Vaiarelli, and P. Patrizio. 2012. "Oocyte Cryopreservation: Who, How and What to Expect." Journal of Fertilization: In Vitro 2 (5): e118.

Sharpe, Richard M, and Niels E Skakkebaek. 1993. "Are Oestrogens Involved in Falling Sperm Counts and Disorders of the Male Reproductive Tract?" The Lancet 341 (8857): 1392-1396.

Shkolnikov, Vladimir M., Evgueni M. Andreev, René Houle, and James W. Vaupel. 2007. "The Concentration of Reproduction in Cohorts of Women in Europe and the United States." Population and Development Review 33 (1): 67-100. doi:10.1111/j.17284457.2007.00159.x.

Sigle-Rushton, Wendy. 2008. "England and Wales: Stable Fertility and Pronounced Social Status Differences." Demographic Research $19 \quad$ (15): 455-502. doi:10.4054/DemRes.2008.19.15. . 2009. "Fertility in England and Wales: a Policy Puzzle?" Demografie 51 (4): 258265.

Singerman, Diane. 2007. "The Economic Imperatives of Marriage: Emerging Practices and Identities Among Youth in the Middle East". Middle East Youth Initiative Working Paper 6.

Singh, Susheela, Gilda Sedgh, and Rubina Hussain. 2010. "Unintended Pregnancy: Worldwide Levels, Trends, and Outcomes." Studies in Family Planning 41 (4): 241250 .

Skirbekk, Vegard. 2008. "Fertility Trends by Social Status." Demographic Research 18 (5) (March 28): 145-180. doi:10.4054/DemRes.2008.18.5.

Skirbekk, Vegard, Eric Kaufmann, and Anne Goujon. 2010. "Secularism, Fundamentalism, or Catholicism? The Religious Composition of the United States to 2043." Journal for the Scientific Study of Religion 49 (2): 293-310. doi:10.1111/j.14685906.2010.01510.x.

Skouby, S. O. 2004. "Contraceptive Use and Behavior in the 21st Century: a Comprehensive Study Across Five European Countries." European Journal of Contraception and Reproductive Healthcare 9 (2): 57-68. 
Sleebos, Joelle. 2003. "Low Fertility Rates in OECD Countries: Facts and Policy Responses".OECD Social, Employment and Migrations Working Paper 15. OECD Publishing. http://ideas.repec.org/p/oec/elsaaa/15-en.html.

Sobotka, Tomáš. 2003. "Tempo-quantum and Period-cohort Interplay in Fertility Changes in Europe. Evidence from the Czech Republic, Italy, the Netherlands and Sweden." Demographic Research 8: 151-214.

. 2004a. "Is Lowest-low Fertility in Europe Explained by the Postponement of Childbearing?" Population and Development Review 30 (2): 195-220. doi:10.1111/j.1728-4457.2004.010_1.x.

. 2004b. "Postponement of Childbearing and Low Fertility in Europe". PhD Thesis, Amsterdam: Amsterdam University Press.

. 2008a. "Does Persistent Low Fertility Threaten the Future of European Populations?" In Demographic Challenges for the 21st Century. A State of Art in Demography, edited by J. Surkyn, P. Deboosere, and J. van Bavel, 27-89. Brussels: VUBPRESS.

2008b. "The Rising Importance of Migrants for Childbearing in Europe." Demographic Research 19 (9): 225-248.

. 2009. "Sub-Replacement Fertility Intentions in Austria." European Journal of Population 25 (4) (May 8): 387-412. doi:10.1007/s10680-009-9183-0.

. 2011. "Fertility in Central and Eastern Europe after 1989: Collapse and Gradual Recovery." Historical Social Research/Historische Sozialforschung 36 (2): 246-296.

. 2012. "Fertility in Austria, Germany and Switzerland: Is There a Common Pattern?" Comparative Population Studies 36 (2-3). doi:10.4232/10.CPoS-2011-12en. http://160.45.170.111/index.php/CPoS/article/view/81.

. 2013. "Oocyte Cryopreservation as an Insurance Strategy: A Socio-demographic View." In Proceedings of the 1st International Symposium on Social Egg Freezing, 428. Barcelona. http://www.socialfreezing.org/wpcontent/uploads/2013/02/symposium_2013.pdf.

Sobotka, Tomáš, Stuart Basten, and Kryštof Zeman. 2013. "Future Fertility in Low Fertility Countries: Results from a Global Survey of Experts.” Manuscript Under Review.

Sobotka, Tomáš, Martin A. Hansen, Tina Kold Jensen, Anette Tønnes Pedersen, Wolfgang Lutz, and Niels Erik Skakkebæk. 2008. "The Contribution of Assisted Reproduction to Completed Fertility: An Analysis of Danish Data." Population and Development Review 34: 79-101.

Sobotka, Tomáš, Kohler, H.-P., and Billari, F.C. 2007. "The Increase in Late Childbearing in Europe, Japan and the United States." Presented at the Annual Meeting of the Population Association of America, 29-31 March 2007, New York, .

Sobotka, Tomáš, and Wolfgang Lutz. 2011. "Misleading Policy Messages Derived from the Period TFR: Should We Stop Using It?" Comparative Population Studies - Zeitschrift Für Bevölkerungswissenschaft 35 (3): 637-664. doi:10.4232/10.CPoS-2010-15en.

Sobotka, Tomáš, Vegard Skirbekk, and Dimiter Philipov. 2011. "Economic Recession and Fertility in the Developed World." Population and Development Review 37 (2): 267 306. doi:10.1111/j.1728-4457.2011.00411.x. 
Sobotka, Tomáš, and Laurent Toulemon. 2008. "Changing Family and Partnership Behaviour: Common Trends and Persistent Diversity across Europe." Demographic Research 19 (6): 85-138.

Souza, P.H.F. 2012. "Políticas Sociales y Reducción de La Desigualdad En Brasil: Logros y Retos". 135. International Policy Centre for Inclusive Growth One Pager.

Spéder, Zsolt, and Balázs Kapitány. 2009. "How Are Time-Dependent Childbearing Intentions Realized? Realization, Postponement, Abandonment, Bringing Forward." European Journal of Population 25 (4): 503-523. doi:10.1007/s10680-009-9189-7.

Spoorenberg, Thomas, and Daniel Schwekendiek. 2012. "Demographic Changes in North Korea: 1993-2008." Population and Development Review 38 (1): 133-158.

Statistics Austria. 2005. Volkszählung 2001. Haushalte Und Familien. Vienna: Statistics Austria.

Statistics Netherlands. 2012. Vruchtbaarheid van Mannen En Vrouwen Met Verschillend Opleidingsniveau. Statistics Netherlands.

Statistisches Bundesamt. 2009. Mikrozensus 2008 - Neue Daten Zur Kinderlosigkeit in Deutschland. Wie: Statistisches Bundesamt.

Stephen, Elizabeth Hervey, and Anjani Chandra. 2006. "Declining Estimates of Infertility in the United States: 1982-2002.” Fertility and Sterility 86 (3) (September): 516-523. doi:10.1016/j.fertnstert.2006.02.129.

Surkyn, Johan, and Ron J. Lesthaeghe. 2004. "Value Orientations and the Second Demographic Transition (SDT) in Northern, Western and Southern Europe: An Update." Demographic Research 3 (3): 45-86.

Swan, Shanna H, Eric P Elkin, and Laura Fenster. 2000. "The Question of Declining Sperm Density Revisited: An Analysis of 101 Studies Published 1934-1996." Environmental Health Perspectives 108 (10): 961.

Szreter S. 1993. "The Idea of Demographic Transition and the Study of Fertility Change: a Critical Intellectual History." Population and Development Review 19 (4): 659-701.

Tarín, Juan J, Juan Brines, and Antonio Cano. 1998. "Long-term Effects of Delayed Parenthood." Human Reproduction 13 (9): 2371-2376.

Te Velde, Egbert, Dik Habbema, Henri Leridon, and Marinus Eijkemans. 2012. "The Effect of Postponement of First Motherhood on Permanent Involuntary Childlessness and Total Fertility Rate in Six European Countries Since the 1970s." Human Reproduction 27 (4): 1179-83. doi:10.1093/humrep/der455.

Tesching, Karin. 2012. "Education and Fertility: Dynamic Interrelations Between Women's Educational Level, Educational Field and Fertility in Sweden". Stockholm University Demography Unit - Dissertation series 6. $\mathrm{http} / / \mathrm{su}$.divaportal.org/smash/record.jsf?pid=diva2:458413.

Tesfaghiorghis, Habtemariam. 2004. "Education, Work and Fertility: A HILDA Survey Based Analysis." Australian Social Policy 2004: 51-73.

Testa, Maria Rita. 2006. "Childbearing Preferences and Family Issues in Europe". Special Eurobarometer 253/Wave 65.1 - TNS Opinion \& Social. European Commission. http://ec.europa.eu/public_opinion/archives/ebs/ebs_253_en.pdf. 
. 2012a. "Family Sizes in Europe: Evidence from the 2011 Eurobarometer Survey". European Demographic Research Papers 2. Vienna: Vienna Institute of Demography. http://www.oeaw.ac.at/vid/download/edrp_2_2012.pdf.

2012b. "Couple Disagreement About Short-term Fertility Desires in Austria: Effects on Intentions and Contraceptive Behaviour." Demographic Research 26: 63-98. doi:10.4054/DemRes.2012.26.3.

Testa, Maria Rita, Laura Cavalli, and Alessandro Rosina. 2011. "Couples' Childbearing Behaviour in Italy: Which of the Partners Is Leading It?" Vienna Yearbook of Population Research 9: 157-178.

Thévenon, Olivier. 2011. "Family Policies in OECD Countries: A Comparative Analysis." Population and Development Review 37 (1): 57-87. doi:10.1111/j.17284457.2011.00390.x.

Thévenon, Olivier, and Anne H Gauthier. 2011. "Family Policies in Developed Countries: A 'fertility-booster' with side-effects." Community, Work \& Family 14 (2): 197-216.

Thomson, Elizabeth. 1997. "Couple Childbearing Desires, Intentions, and Births." Demography 34 (3): 343-54.

Thomson, Elizabeth, and Jan M Hoem. 1998. "Couple Childbearing Plans and Births in Sweden.” Demography 35 (3): 315-322.

Thomson, Elizabeth, Maria Winkler-Dworak, Martin Spielauer, and Alexia Prskawetz. 2012. "Union Instability as an Engine of Fertility? A Microsimulation Model for France." Demography 49 (1): 175-195. doi:10.1007/s13524-011-0085-5.

Thonneau, Patrick, Sophie Marchand, Anne Tallec, Marie-Laure Ferial, Béatrice Ducot, Jacques Lansac, Patrice Lopes, Jean-Marie Tabaste, and Alfred Spira. 1991. "Incidence and Main Causes of Infertility in a Resident Population (1 850 000) of Three French Regions (1988-1989)." Human Reproduction 6 (6): 811-816.

Toner, James P, David A Grainger, and Linda M Frazier. 2002. "Clinical Outcomes Among Recipients of Donated Eggs: An Analysis of the U.S. National Experience, 19961998." Fertility and Sterility 78 (5) (November): 1038-1045. doi:10.1016/S00150282(02)03371-X.

Torabi, Fatemeh, Angela Baschieri, Lynda Clarke, and Mohammad Jalal Abbasi-Shavazi. 2012. "Marriage Postponement in Iran: Accounting for Socio-economic and Cultural Change in Time and Space." Population, Space and Place 19 (3): 258-274. doi:10.1002/psp.

Toulemon, Laurent and Magali Mazuy. 2001. "Les naissances sont retardées mais la fécondité est stable". Population 56 (4): 611-644.

Toulemon, Laurent, Ariane Pailhé, and Clémentine Rossier. 2008. "France: High and Stable Fertility." Demographic Research 19 (6): 553-556.

Tromans, Nicola, Eva Natamba, and Julie Jefferies. 2009. "Have Women Born Outside the UK Driven the Rise in UK Births Since 2001?" Population Trends Summer 2009 (136): $28-42$.

Tsimbos, Cleon. 2008. "Immigrant and Native Fertility in Greece: New Estimates and Population Prospects (2005-2025)." Population Review 47 (2): 67-84. 
Tsuya, Noriko O., Larry L. Bumpass, Minja Kim Choe, and Ronald R. Rindfuss. 2005. "Is the Gender Division of Labour Changing in Japan?” Asian Population Studies 1 (1): 47 67.

Tsuya, Noriko O., Minja Kim Choe, and Nihon Daigaku. 1991. Changes in Intrafamilial Relationships and the Roles of Women in Japan and Korea. Nihon University, Population Research Institute.

Tsuya, Noriko O., Minja Kim Choe, and Feng Wang. 2009. "Below-replacement Fertility in East Asia: Patterns, Factors, and Policy Implications." Paper presented at the IUSSP International Population Conference, Marrakech, 27 September - 2 October 2009, .Tuiran, Rodolfo, Virgilio Partida, Octavio Mojarro, and Elena Zúñiga. 2002. "Fertility in Mexico: Trends and Forecast." Report of the United Nations Population Division.

UN. 2009. "World Population Prospects: The 2008 Revision”. New York, NY: Department of Economic and Social Affairs, Population Division. http://www.un.org/esa/population/publications/wpp2008/wpp2008_highlights.pdf.

. 2011. "World Population Prospects: The 2010 Revision. Volume 1: Comprehensive Tables". New York, NY: United Nations, Department of Economic and Social Affairs, Population Division. http://esa.un.org/wpp/Excel-Data/fertility.htm.

. 2012. "Probabilistic Population Projections Based on the 2010 Revision of the World Population Prospects". Data, documentation and supplementary materials. New York, NY: United Nations, Department of Economic and Social Affairs, Population Division. http://esa.un.org/unpd/ppp/.

. 2013. "World Population Prospects: The 2012 Revision, Key Findings and Advance Tables". New York, NY.: United Nations, Department of Economic and Social Affairs, Population Division.

Van Agtmaal-Wobma, Elma, and Mila van Huis. 2008. "De Relatie Tussen Vruchtbaarheid En Opleidingsniveau van de Vrouw [The Relationship Between Fertility and Educational Level of Women]." Bevolkingtrends 56 (2): 32-41.

Van Bavel, Jan. 2010a. "Subreplacement Fertility in the West before the Baby Boom: Past and Current Perspectives." Population Studies 64 (1): 1-18. doi:10.1080/00324720903362806.

. 2010b. "Choice of Study Discipline and the Postponement of Motherhood in Europe: The Impact of Expected Earnings, Gender Composition, and Family Attitudes." Demography 47 (2): 439-458. doi:10.1353/dem.0.0108.

- 2012. "The Reversal of Gender Inequality in Education, Union Formation and Fertility in Europe." Vienna Yearbook of Population Research 10: 127-154. doi:10.1553/populationyearbook2012s127.

Van Bavel, Jan, and Joanna Różańska-Putek. 2010. "Second Birth Rates Across Europe: Interactions Between Women's Level of Education and Child Care Enrolment." Vienna Yearbook of Population Research 8: 107-138. doi:10.1553/populationyearbook2010s107.

Van de Kaa, Dirk J. 1987. “Europe's Second Demographic Transition.” Population Bulletin 42 (1): $1-59$. 
1994. "The Second Demographic Transition Revisited: Theories and Expectations." In Population and Family in the Low Countries 1993: Late Fertility and Other Current Issues, edited by Gijs Beets, 81-126. 30. NIDI/CBGS Publication.

Van Imhoff, Evert. 2001. "On the Impossibility of Inferring Cohort Fertility Measures from Period Fertility Measures." Demographic Research 5: 23-64. doi:10.4054/DemRes.2001.5.2.

Van Loendersloot, L. L., L. M. Moolenaar, B. W. J. Mol, S. Repping, F. van der Veen, and M. Goddijn. 2011. "Expanding Reproductive Lifespan: a Cost-effectiveness Study on Oocyte Freezing." Human Reproduction $26 \quad$ (11): 3054-3060. doi:10.1093/humrep/der284.

Van Poppel, Frans W. A. 1985. "Late Fertility Decline in the Netherlands: The Influence of Religious Denomination, Socioeconomic Group and Region." European Journal of Population 1 (4): 347-373.

VID. 2012. "European Demographic Data Sheet 2012”. Vienna Institute of Demography: Vienna Institute of Demography. http://www.oeaw.ac.at/vid/datasheet/index.html.

Vikat, Andres. 2004. "Women's Labor Force Attachment and Childbearing in Finland." Demographic Research 3 (8): 175-212.

Wang, Feng, Yong Cai, and Baochang Gu. 2013. "Population, Policy, and Politics: How Will History Judge China's One-child Policy?" Population and Development Review 38, Supplement s 1 (edited by G. McNicoll et al.): 115-129. doi:10.1111/j.17284457.2013.00555.x.

Wang, Qingbin, and Qin Zhou. 2010. "China's Divorce and Remarriage Rates: Trends and Regional Disparities.” Journal of Divorce \& Remarriage 51 (4): 257-267.

Westoff, Charles F., and Tomas Frejka. 2007. "Religiousness and Fertility Among European Muslims." Population and Development Review 33 (4): 785-809.

Westoff, Charles F., and Jenny Higgins. 2009. "Relationships Between Men's Gender Attitudes and Fertility." Demographic Research 21 (3): 65-74. doi:10.4054/DemRes.2009.21.3.

Westoff, Charles F., and Elise F. Jones. 1979. “The End of 'Catholic' Fertility.” Demography $16(2): 209-217$.

Wilson, Chris. 2001. "On the Scale of Global Demographic Convergence 1950-2000." Population and Development Review 27 (1) (March 1): 155-171. doi:10.2307/2695158.

2011. "Understanding Global Demographic Convergence Since 1950." Population and Development Review 37 (2): 375-388. doi:10.1111/j.1728-4457.2011.00415.x.

. 2013. "Thinking About Post-transitional Demographic Regimes." Demographic Research 28: 1373-1388. doi:10.4054/DemRes.2013.28.46.

Wilson, Chris, and Gilles Pison. 2004. "More Than Half of the Global Population Lives Where Fertility Is Below Replacement Level.” Population et Societes 405: 1-4.

Woldemicael, Gebremariam, and Roderic Beaujot. 2012. "Fertility Behavior of Immigrants in Canada: Converging Trends." Journal of International Migration and Integration 13 (3): 325-341. 
Wyndham, Nichole, Paula Gabriela Marin Figueira, and Pasquale Patrizio. 2012. “A Persistent Misperception: Assisted Reproductive Technology Can Reverse the 'aged Biological Clock'." Fertility and Sterility 97 (5): 1044-1047. doi:10.1016/j.fertnstert.2012.02.015.

Yao, Xinwu. 1995. "Fertility Data of China." Beijing, China: Data User Service, China Population Information and Research Center.

Yap, Mui Teng. 2009. "Ultra-low Fertility in Singapore: Some Observations." In Ultra-low Fertility in Pacific Asia: Trends, Causes and Policy Dilemmas, edited by Gavin Jones, Paulin Tay-Straughan, and Angelique Chan, 160-180. Routledge.

Yerkes, Mara. 2009. "Part-time Work in the Dutch Welfare State: The Ideal Combination of Work and Care?" Policy \& Politics 37 (4): 535-552.

Yoo, S.H. 2013. "Was Fertility Decline in Korea Driven by Educational Expansion? A Cohort Analysis." Presented at the Annual Meeting of the Population Association of America, April 11-13 2013, New Orleans. . http://paa2013.princeton.edu/papers/131177.

Zegers-Hochschild, Fernando, G David Adamson, Jacques de Mouzon, Osamu Ishihara, Ragaa Mansour, Karl Nygren, Elisabeth Sullivan, and Sheryl Van der Poel. 2009. "The International Committee for Monitoring Assisted Reproductive Technology (ICMART) and the World Health Organization (WHO) Revised Glossary on ART Terminology, 2009." Human Reproduction 24 (11): 2683-2687.

Zeman, Kryštof, Tomáš Sobotka, Richard Gisser, Maria Winkler-Dworak, and Wolfgang Lutz. 2011. "Geburtenbarometer Vienna: Analysing Fertility Convergence Between Vienna and Austria." VID Working Papers 7.

Zeng, Yi. 1996. "Is Fertility in China in 1991-1992 Far Below Replacement Level?" Political Studies 50 (1): 27-34.

Zhang, G. 2004. "Does the Family Planning Program Affect Fertility Preferences? The Case of China." Presented at the Australian Population Association 12th Biennial Conference, Canberra.

Zhang, Li. 2008. "Religious Affiliation, Religiosity and Male and Female Fertility." Demographic Research 18 (8): 233-262.

Zhao, Zhongwei, and Wei Chen. 2011. "China's Far Below Replacement Fertility and Its Longterm Impact: Comments on the Preliminary Results of the 2010 Census." Demographic Research 25 (26): 819-36.

Zhao, Zhongwei, and Zhigang Guo. 2010. "China's Below Replacement Fertility: A Further Exploration." Canadian Studies in Population 37 (3-4): 525-562.

Zhao, Zhongwei, and Xiaomu Zhang. 2010. "China's Recent Fertility Decline: Evidence from Reconstructed Fertility Statistics." Population (English Edition) 65 (3): 451-478. doi:10.3917/pope.1003.0451.

Zheng, Zhenzhen, Yong Cai, Feng Wang, and Baochang Gu. 2009. "Below-replacement Fertility and Childbearing Intention in Jiangsu Province, China." Asian Population Studies 5 (3) (November): 329-347. doi:10.1080/17441730903351701.

Zorn, Branko, Jacques Auger, V Velikonja, M Kolbezen, and Helena Meden-Vrtovec. 2008. "Psychological Factors in Male Partners of Infertile Couples: Relationship with Semen Quality and Early Miscarriage.” International Journal of Andrology 31 (6): 557-564. 


\section{VIENNA INSTITUTE OF DEMOGRAPHY}

\section{Working Papers}

Sharygin, Ethan, The Carbon Cost of an Educated Future: A Consumer Lifestyle Approach, VID Working Paper 04/2013.

Winkler-Dworak, Maria and Heiner Kaden, The Longevity of Academicians: Evidence from the Saxonian Academy of Sciences and Humanities in Leipzig, VID Working Paper 03/2013.

Feichtinger, Gustav, Alexia Prskawetz, Andrea Seidl, Christa Simon and Stefan Wrzaczek, Do Egalitarian Societies Boost Fertility?, VID Working Paper 02/2013.

Muttarak, Raya, Is it (dis)Advantageous to Have Mixed Parentage? Exploring Education \& Work Characteristics of Children of Interethnic Unions in Britain?, VID Working Paper 01/2013.

Testa, Maria Rita and Stuart Basten, Have Lifetime Fertility Intentions Declined During the "Great Recession"?, VID Working Paper 09/2012.

Buber, Isabella, Ralina Panova, and Jürgen Dorbritz, Fertility Intentions of Highly Educated Men and Women and the Rush Hour of Life, VID Working Paper 08/2012.

Testa, Maria Rita, Laura Cavalli, and Alessandro Rosina, The Decision of Whether to Have a Child: Does Couple Disagreement Matter?, VID Working Paper 07/2012.

Kuhn, Michael and Klaus Prettner, Growth and Welfare Effects of Health Care in Knowledge Based Economies, VID Working Paper 06/2012.

Sander, Nikola and Martin Bell, Age, Period and Cohort Effects on Migration of the Baby Boomers in Australia, VID Working Paper 05/2012.

Grafeneder-Weissteiner, Theresa, Ingrid Kubin, Klaus Prettner, Alexia Prskawetz, and Stefan Wrzaczek, Coping with Inefficiencies in a New Economic Geography Model, VID Working Paper 04/2012.

Goujon, Anne, Éric Caron Malenfant, and Vegard Skirbekk, Towards a Catholic North America? Projections of Religion in Canada and the US beyond the Mid-21st Century, VID Working Paper 03/2012.

Di Giulio, Paola, Christoph Bühler, Andreas Ette, Romina Fraboni, and Kerstin Ruckdeschel, Social Capital and Fertility Intentions: The Case of Italy, Bulgaria, and West Germany, VID Working Paper 02/2012.

The Vienna Institute of Demography Working Paper Series receives only limited review. Views or opinions expressed herein are entirely those of the authors. 